\title{
WHAT ARE YOUNG PACIFIC PEOPLES UNDERSTANDINGS OF LEADERSHIP IN AOTEAROA NEW ZEALAND?
}

\author{
BY \\ GRACE MILE FALETUTULU
}

A thesis

Submitted to the Victoria University of Wellington in fulfilment of the requirements for the degree of Masters of Arts

Victoria University of Wellington

2017 



\section{DEDICATIONS}

This thesis is dedicated to my five siblings, Victor, Joshua, Faith, Daniel and Lyvia.

Without all five of you I would have not made it this far in life or completed my Master's degree. You are all part of my driving force and I thank God every day I have you all in my life.

With all my love, Grace

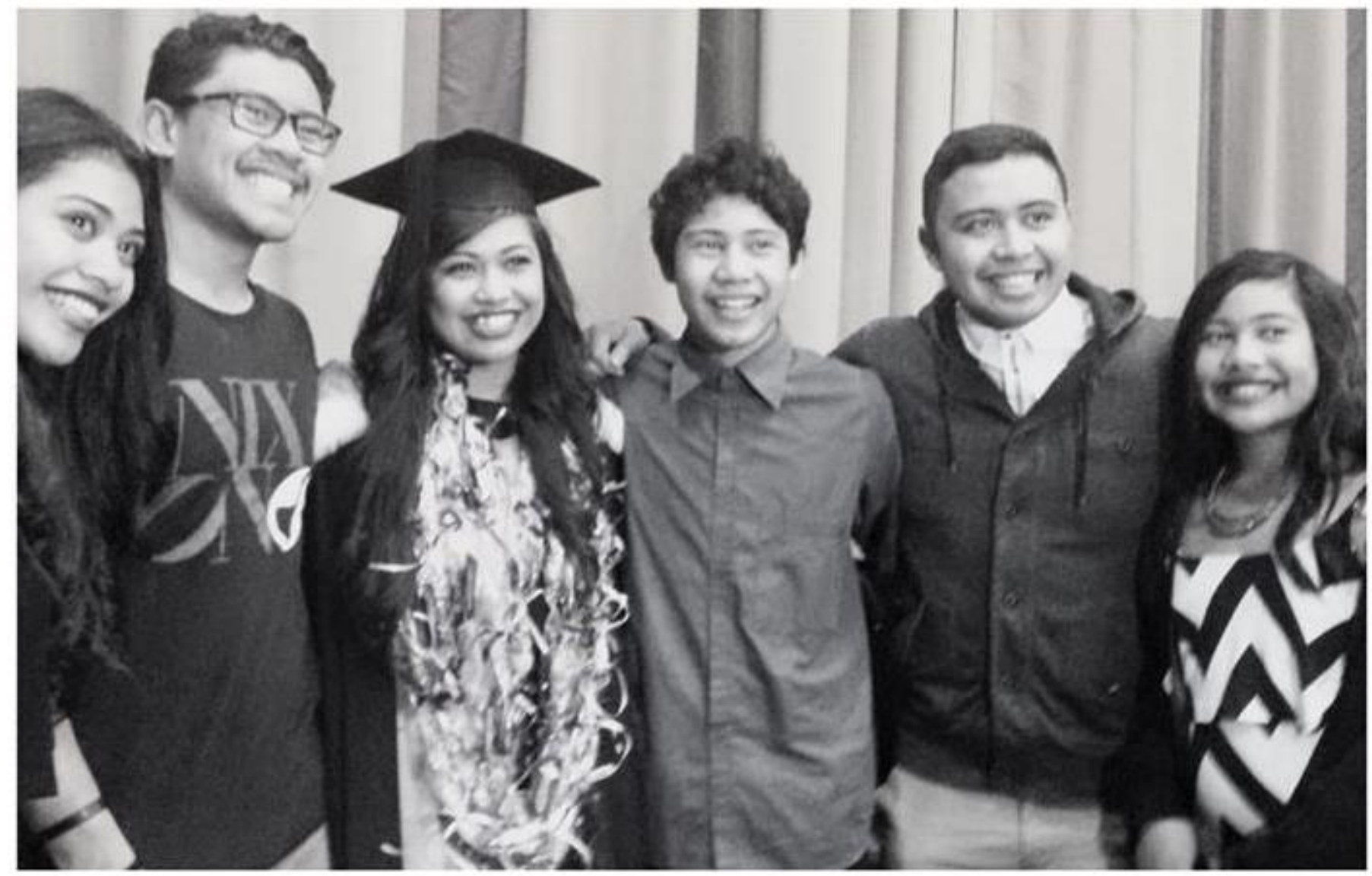




\begin{abstract}
This thesis is an exploration of the way leadership is understood by young Pacific peoples. It looks at the possible relationship between leadership and education outcomes for young Pacific peoples. It is located in an interpretative paradigm, and uses qualitative methods and seeks phenomenological date. This is because individuals interpret experiences differently, therefore understanding how these young Pacific people interpret ideas can help answer the thesis question. As Pacific research it foregrounds Pacific concepts such as vā and Pacific methods such as talanoa. These features seek to alignment with the community participating in the study. The findings suggest that young Pacific peoples understand leadership as a negotiation between Pacific and Western ideas. This negotiation is performed contextually. However, young Pacific peoples are also redefining leadership for themselves and a way they are doing this is by combining their Pacific and Western understandings of leadership. From the research there were three implications found for young Pacific peoples. Firstly, too much focus on culture can become a problem. Secondly, the different contexts that young Pacific peoples are being raised in influences their leadership beliefs, especially compared to the older generation. Lastly, young Pacific peoples need to receive recognition for their ability to negotiate ideas between the Pacific and Western worlds. Therefore, recommendations for future research come under two main categories environment. This is focused on rethinking leadership, firstly for young Pacific peoples in New Zealand-Pacific context, then rethinking for young Pacific peoples in a Western context. The second recommendation discusses ways to improve leadership development programs for young Pacific peoples in New Zealand.
\end{abstract}




\title{
ACKNOWLEDGMENTS
}

\author{
"Acknowledge him in all your ways and He will make your path straight" \\ Proverbs 3:6
}

Firstly, I want to give thanks to the giver of all good things, my Lord and Saviour Jesus Christ. I am very grateful and blessed to be given the life and opportunities I have. Although life has not always been easy, with many valleys, the view on the hilltops has always made it worth the journey.

Secondly, my supervisors Dr Cherie Chu and Dr Fuapepe Rimoni. I cannot thank each of you enough for the help and life lessons you both have taught me through my Master's journey. Cherie, thank you for your fearless leadership. Your courage and hope to help better the lives of Pacific people inspires me every day. I strive to live up to the fullness that my life has been called to because of your example. Fuapepe, thank you for always reminding me that everything does not have to be so serious, and to stop and enjoy the journey. Thank you for bringing humour and laughter into our supervision sessions. Listening to you and Cherie share about your dog's always reminded me that life is holistic, made up of many different factors. I know my Master's journey has had many twists and turns, however, I am thankful for both of you, for your patience and love. It will never be forgotten.

I must thank my unofficial third supervisor and palagi uncle, Dr Martyn Reynolds. Thank you, Martyn, for guiding me step by step through my Master's. I can honestly say that this piece would not have come together the way it has without you. Thank you for being an example of great leadership, and mentoring me through this journey. Your passion and commitment for Pacific peoples has not gone unnoticed. I hope that this thesis and research that will come out of it will make you proud.

What would a journey be without great company? I want to thank my friends for their support. I know that my friendships do not get enough acknowledgement so this is where I would like to say thank you to all of you. Thank you for listening to me rant about how much reading, writing, and editing I had to do. Thank you for understanding that sometimes I just could not make that lunch or dinner because I needed to work on my thesis. Thank you for reminding me that at the end of this Master's I would have achieved something I could only dream of 
completing. This includes the staff at Victoria who have been amazing especially those at Te Putahi Atawhai. Thank you all for the food, coffee and endless hours of laughter that filled my soul and helped me to get back to work. Special thanks to these groups of people: Level 9, Matt or Cat, The Bermuda Triangle, The Spice Girls, The Pacific Students Council (2016), and The Revolution.

To end my acknowledgements, I want to thank the people who mean the world to me, my family. Thank you all for your belief in me. Thank you for encouraging me and supporting me to achieve whatever my heart desires.

To my grandparents who have all passed on before I could finish, Sale and Mile Faletutulu, Talosia Vanilau and Laumata Seiuli. Thank you all for your love. Although our time was limited your legacies live on through my parents, my siblings and me. I promise to live the life you dreamt of for your children, grandchildren, and future generations.

Lastly, but most importantly, I want to thank my parents Lepisi Max Faletutulu and Sharon Sarona Faletutulu. I do not know how to put into words how grateful I am; however, I will try my best. Dad, thank you for always telling me that I can achieve all my hopes and dreams. Thank you for raising me with values and beliefs that have helped me to stay the path. One thing that I will never forget and pass onto my kids are these two sayings "there's no such word as can't" and "be your own boss". These two sayings helped me break down barriers in my mind whenever I felt I was not good enough to reach my goals. For this reason, Dad, thank you. To my Mum, the hardest working person I know. If there was one person who encompassed determination, dedication, and perseverance, it is you. I am in awe looking at your life journey. From working fulltime at the age of sixteen to help your mother as the eldest child to now having a degree and multiple qualifications, it gives me no excuse but to strive for greatness. Thank you both Dad and Mum for your endless support throughout my university years and always being there for me when I needed reassurance. I hope I am making you both proud. Love you both endlessly, Grace. 


\section{GLOSSARY}

Fa'aaloalo: To be respectful or show respect (Samoan)

Fa'aSamoa: The Samoan way (Samoan)

Teu le vā: To care for the vā (Samoan)

Tupulaga fou: Next or new generation

Va, Vā: Sacred relational space, relationality, relationship Samoan language) 


\section{Table of Contents}

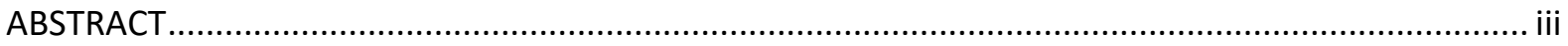

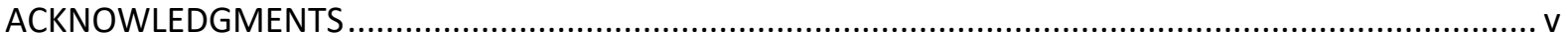

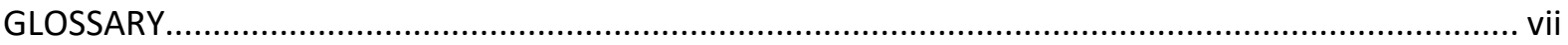

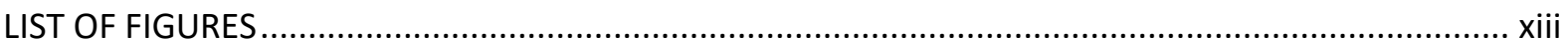

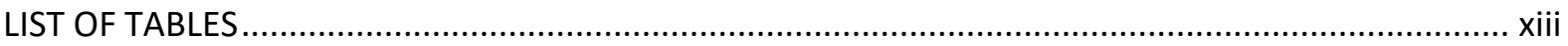

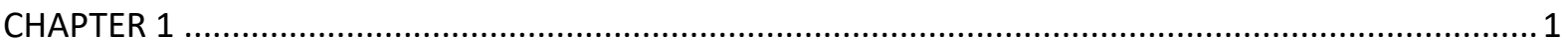

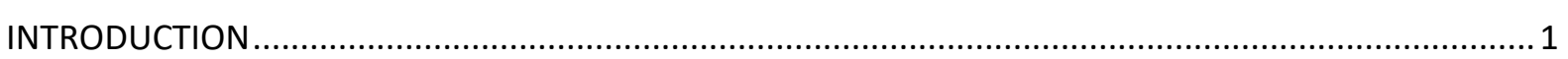

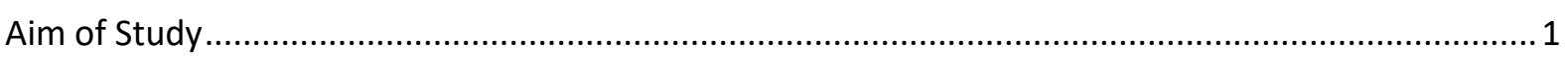

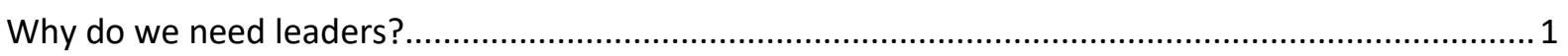

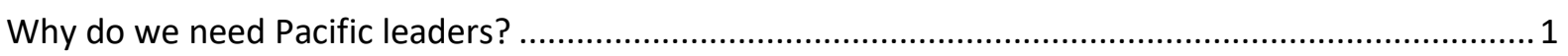

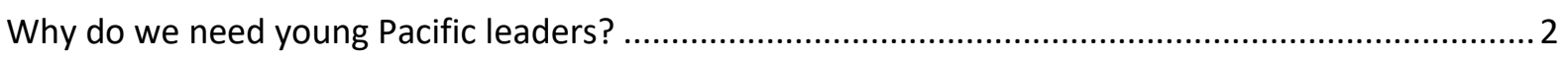

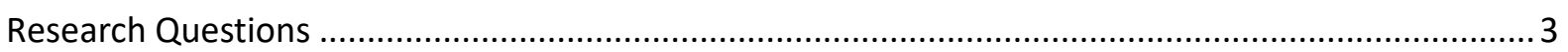

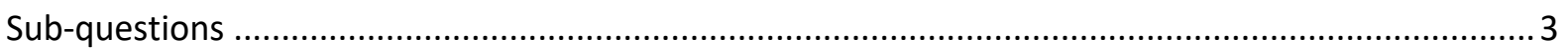

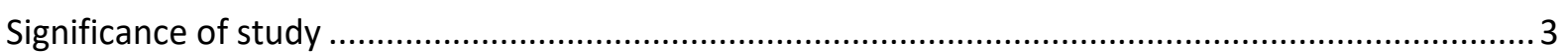

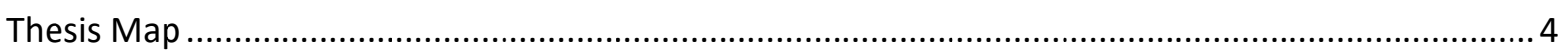

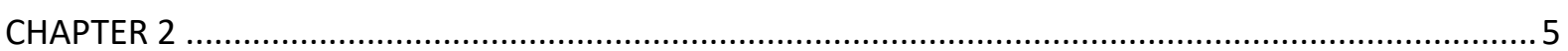

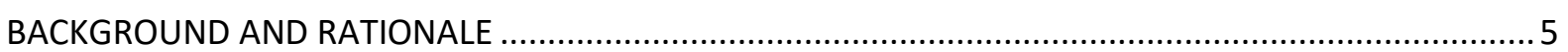

My story

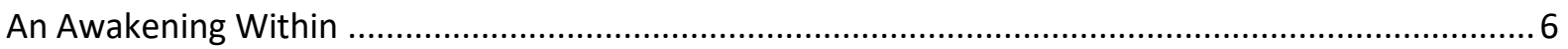

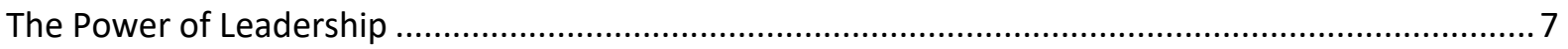

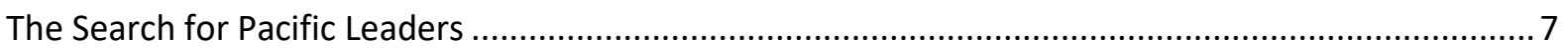

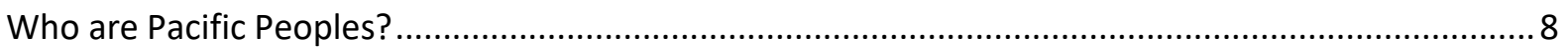

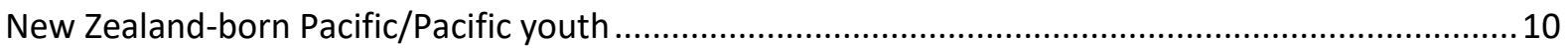

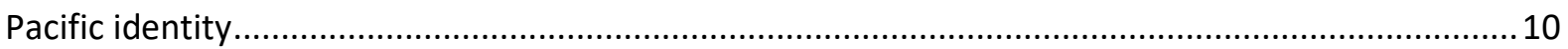

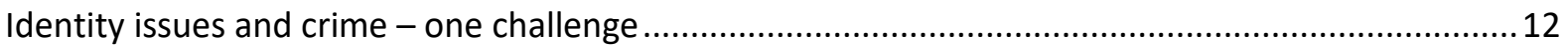

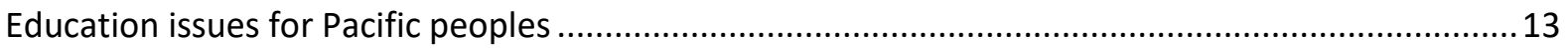

The need for Pacific leadership by Young Pacific Peoples ................................................................ 16

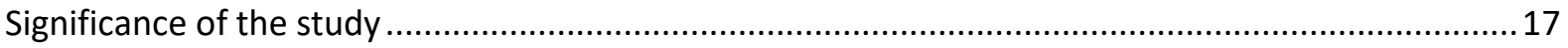

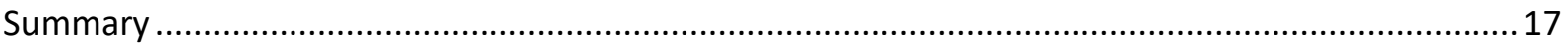

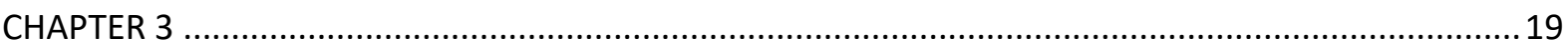

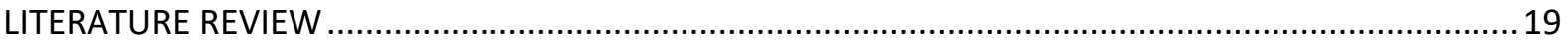

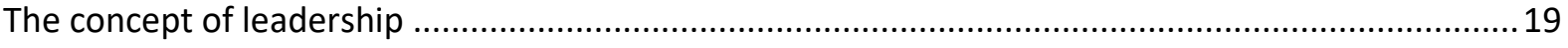

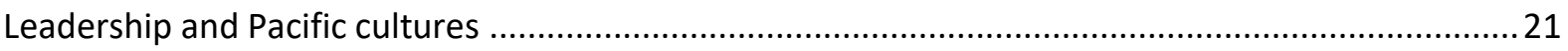




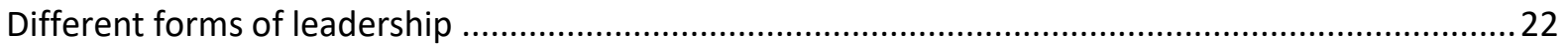

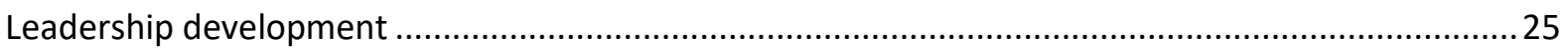

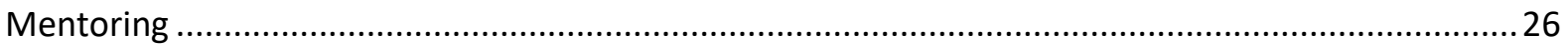

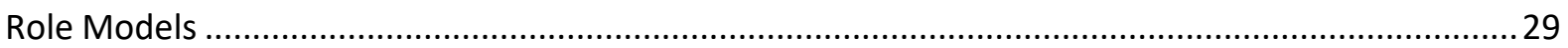

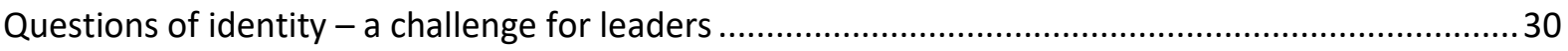

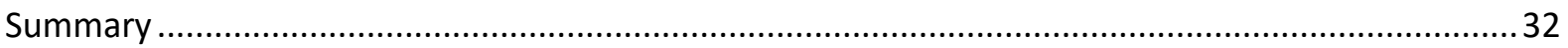

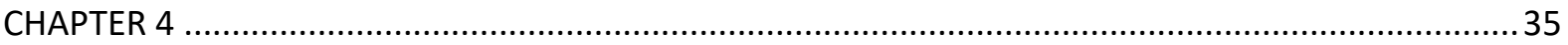

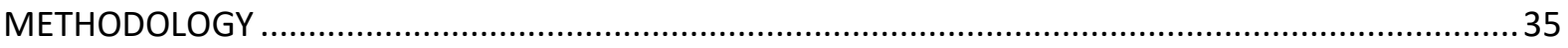

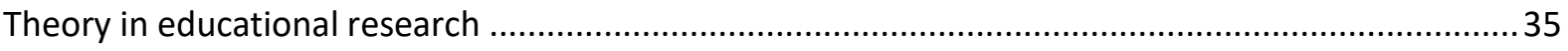

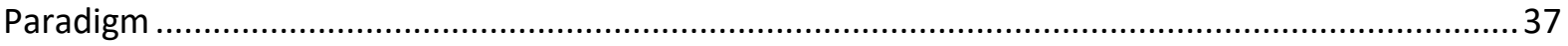

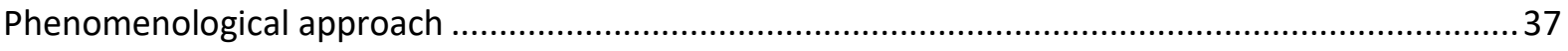

Methodology

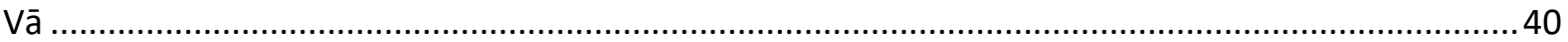

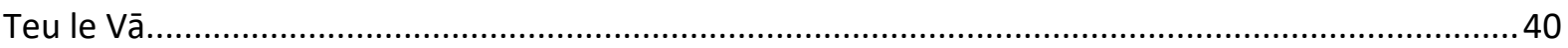

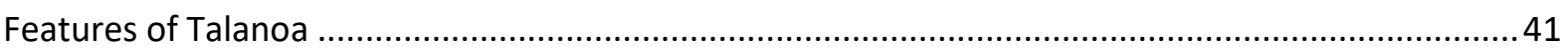

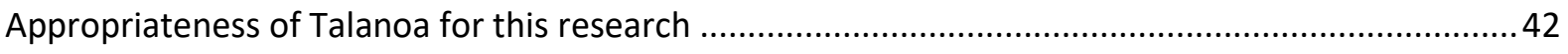

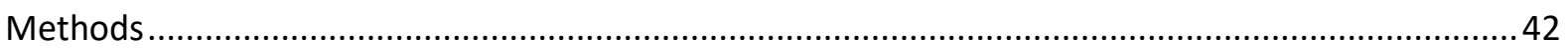

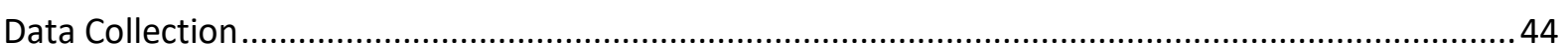

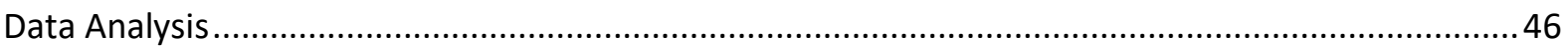

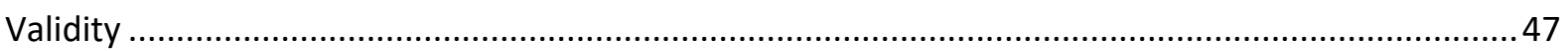

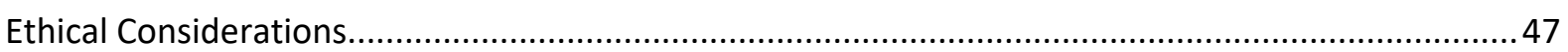

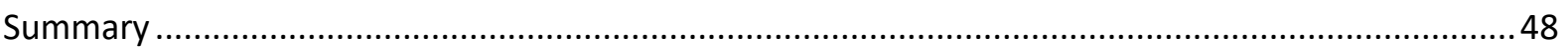

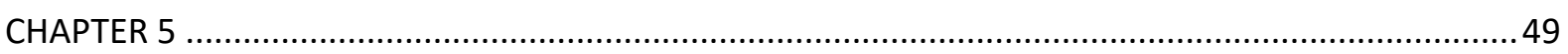

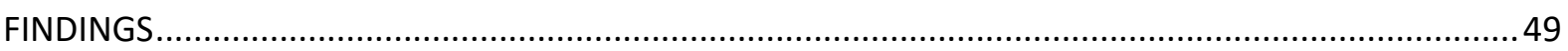

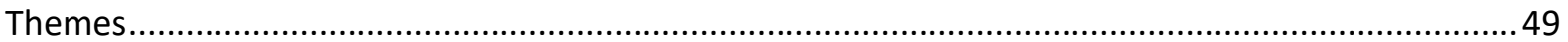

Theme 1: Where do young Pacific people's ideas of leadership come from and what forms do they take?

Theme 2: What challenges are experienced by young Pacific leaders? ............................................53

Theme 3: What forms of leadership are valued by young Pacific leaders? ........................................... 59

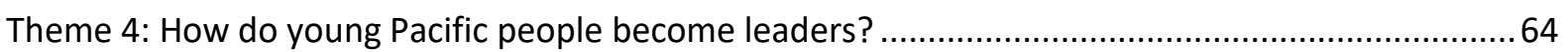

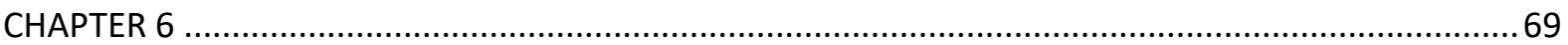

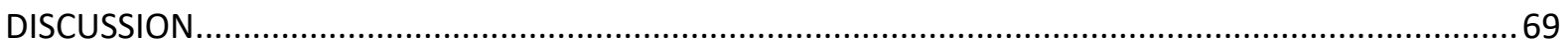

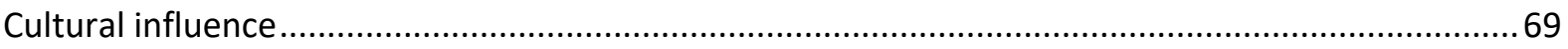

Environmental contexts where young Pacific peoples' ideas about leadership develop ....................71

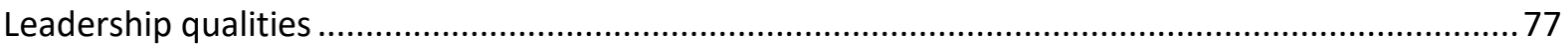

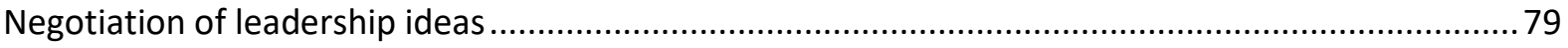




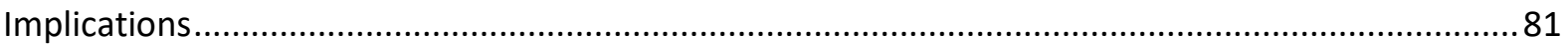

Recommendations for young Pacific peoples' leadership development ............................................. 82

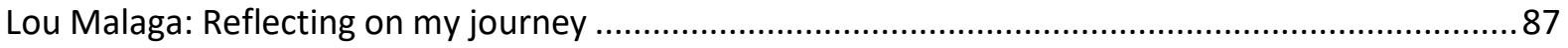

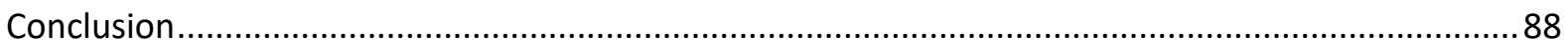

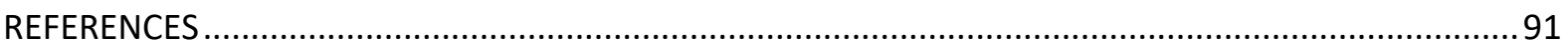

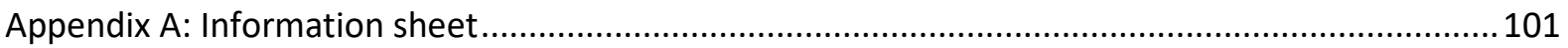

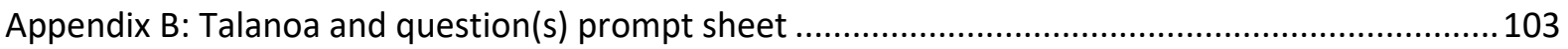

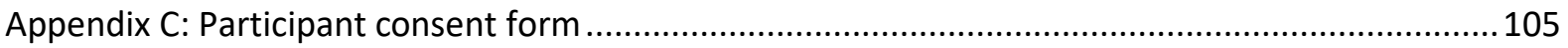

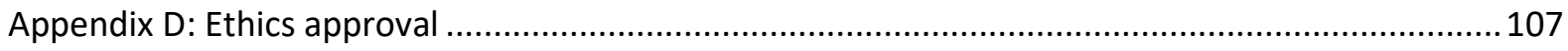




\section{LIST OF FIGURES}

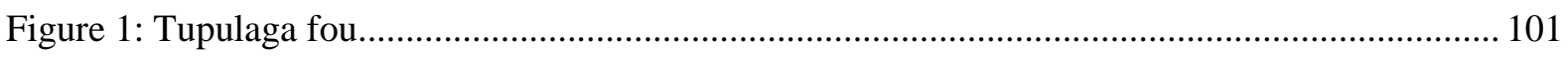

\section{LIST OF TABLES}

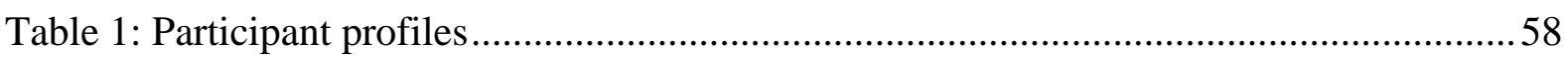

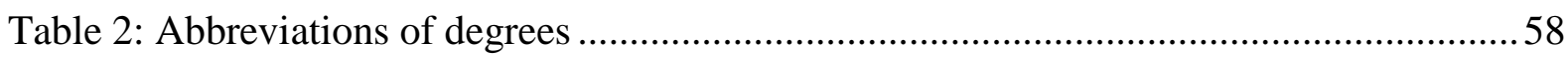




\section{CHAPTER 1 \\ INTRODUCTION}

\section{Aim of Study}

The aim of this study is to explore young Pacific people's understandings of leadership. In this study, young Pacific people are understood as individuals of Pacific descent aged between twenty to thirty-five living in Aotearoa New Zealand. Leadership is important because it is forward looking and contributes to the welfare of the individual of the group. This study sees leadership as a trait everyone possess, but for it to be lived out it must be cultivated in the right environment to grow and succeed.

Young Pacific peoples get their ideas about leadership from many different sources associated with the environments that they are exposed to. In this study the main environments are home life, school, and church. All three of these environments contribute to young Pacific peoples' understandings of leadership as they move from childhood to adulthood. Ideas of leadership vary because of different cultural values and beliefs such as between Pacific and Western world, a variation which will be discussed below.

\section{Why do we need leaders?}

Leaders are important because they guide the way for others. Leaders show that something can be achieved that may appear impossible to others. When leaders are from specific communities, other community members can look to them for inspiration and motivation believing that whatever the situation is, success is attainable. This shows that leaders are important because they can help make unfamiliar spaces familiar to their group. Situations or spaces that may have felt like they excluded the group may no longer have that stigma at the same strength through the act of a leader.

\section{Why do we need Pacific leaders?}

Pacific leaders as leaders for Pacific peoples are important for three main reasons: they can understand the challenges of the Pacific diaspora; they can represent the community in 
negotiation with leaders of other communities; they can provide mentorship for young Pacific people. These three reasons deserve elaboration.

Pacific leaders are needed because of new contexts Pacific peoples are living in, no long in the Pacific nations, but in the Western context of Aotearoa New Zealand. Pacific leaders are understanding the diaspora experientially. They have knowledge about the difference of time and space experienced by the old generation and younger generations. Pacific leaders understand that the passage of time is a fundamental influence on young Pacific peoples' values and beliefs: culture and always evolving and change. This means that what Pacific young people's parents are used to and understand as culture can differ from their children's understanding. Leaders may help to bridge the gap. Secondly, space is important for Pacific leaders to understand, in relation to young Pacific peoples'. This thesis focuses on young Pacific peoples in Aotearoa New Zealand, and their understandings of leadership as a Pacific person being raised away from their Pacific homeland. Their values and beliefs can informed from the Pacific through their home life but conflict with ideas from the West experienced through school. Pacific leaders are needed who understand the space-based challenges children of the diaspora face.

Building on the potential of understanding young Pacific peoples raised away from the Pacific homeland, Pacific leaders are needed to negotiate with leaders from other communities. For example, their Pacific leaders can build bridges with other cultural and community groups, either Pacific or otherwise. These relationships can help make the experience of leaving and adopting new ways of living easier in new home countries. These leaders can also teach these skills to younger Pacific peoples who can carry on mission.

Pacific leaders are important as mentors for young Pacific peoples. The importance of their mentorship in Pacific communities its relational core. Pacific leaders who act as mentors may understand the challenges that young Pacific peoples will encounter, and ways to overcome these challenges. Fundamentally this is because they will understand the values and beliefs which Pacific young people encounter.

\section{Why do we need young Pacific leaders?}

Young Pacific leaders are needed because they understand the changing nature of the Pacific community. Young Pacific leaders understand one another and the challenges that they face which can be different for each generation. This is because if the fluid diasporic context that 
the young Pacific peoples are in. For example, having a peer who can speak of the same experiences relate to them can make a crucial difference in young Pacific peoples feeling they themselves can speak out. In time, young Pacific leaders will of community leadership and become the adults who will take up the mantle and learn to transform their future and the future of the community. Therefore, Pacific leaders are important, but more so young Pacific leaders with the skills discussed to pave the way for others to follow.

\section{Research Questions}

In order to investigate this area, the main research question posed in this study is 'How do young Pacific peoples' understand leadership?'

This question is important to ask because at the present time social and educational outcomes for Pacific young people are not satisfactory. That is, leadership is required to support change. For instance, in education there are low achievement rates for Pacific students for many complex reasons. Understanding the ideas of leadership which Pacific young people can bring to education offers a way of supporting change. By answering this question, this research aims to understand young Pacific peoples' understandings of leadership will bring about some solutions in areas such as education.

To guide the investigation, sub-questions were formed.

\section{Sub-questions}

- What are the cultural strengths and challenges for young Pacific peoples in leadership in the community?

- In what ways are leadership positions created or inhibited?

These sub-questions offer a purchase on the strengths of Pacific young people, the barriers they face, and the interaction between Pacific young people and the people who otherwise define leadership through various kinds of position.

\section{Significance of study}

There is a scarcity of research and literature on the topic of Pacific people's and leadership. This study will contribute to the leadership literature, and provide researchers ideas when 
thinking about the definition, influences, and characteristics of Pacific leadership in diasporic communities.

A particular strength of this research is the fact that it will explore and frame an understanding of the nature of leadership in a context beyond the family environment in the Pacific diaspora. Since leadership is present in almost all areas of one's lives, whether we are the leader or another is, looking at how leadership is understood particularly in the context of young Pacific peoples and education can expose areas for research which are occurring through the negotiation of Pacific young people with a Western context which is significant in their lives. In order to make discoveries, this study intend to help young Pacific peoples' voices to be expressed and understood.

\section{Thesis Map}

This thesis is divided into six chapters. The first chapter has stated the aims of the research and the research question, as well the significance of the research. The second chapter provides the background and rationale of the researcher's desire to pursue this topic and provide knowledge of and for the groups of people being studied. Chapter Three delves into the theories and literature relevant to the study, exploring some sources from where young Pacific peoples get their ideas about leadership. Chapter Four describes the methodology used in this research while Chapter Five presents an analysis of the findings. Lastly, Chapter Six offers a detailed discussion around the findings, presents a model developed from the research, the applications of the study and overall conclusion. 


\section{CHAPTER 2}

\section{BACKGROUND AND RATIONALE}

This chapter explains the group of people this research is about, Pacific peoples in Aotearoa New Zealand. It provides background information about Pacific peoples' migration to Aotearoa New Zealand, and the challenges they faced and continue to face. This chapter first gives part of my own story before turning to the broad question: Who are Pacific peoples? It is important to know their migration stories which include their reasons for moving to Aotearoa New Zealand. Secondly, this chapter focuses on the issue of New Zealand-born Pacific people and their identity. This will be followed by a discussion where I address challenges and issues within the education space in relation to young Pacific peoples and leadership. The need for Pacific leaders and leadership development will then be explained. This includes the power of leadership. Ultimately, this chapter presents a consideration of areas which underpin an inquiry into the understandings of leadership held by Pacific people in Aotearoa New Zealand.

\section{My story}

My position as a Pacific tertiary student has greatly influenced my decision to explore young Pacific peoples' understandings of leadership. The aim of rethinking leadership for young Pacific peoples in Aotearoa New Zealand originated from my own personal struggle. This struggle involved identity as a New Zealand-born Samoan, my place in education as a young Pacific person, and what it means to be a leader. These personal challenges are prevalent for young Pacific peoples in New Zealand as I discovered through discussion with my peers.

As a New Zealand-born Samoan, my family migration story is as follows. The first kin of my bloodline that migrated to New Zealand was my great-grandmother along with my grandmother and other members of the extended family in the early 1940's. My mother was the first-born child and also the first New Zealand-born. Although they lived in New Zealand, life was difficult. My grandmother, was the primary income earner with three children of her own, four adopted children, my great grandmother and three uncles all living in one house. My mother left high school at the young age of sixteen to work and help her mother to help make ends meet. Years later my mother met my father who came to New Zealand as a scholarship student from Samoa. They married and had six children, including myself. These stories remind 
me that the life I live and future generations will live is only possible because of the sacrifices that were made with us in mind. This was my earliest memory of leadership.

\section{An Awakening Within}

Being a New Zealand-born Samoan strongly influences my position as the researcher, but my different point-of-view was not as obvious as others may think. During my years at high school there were few, if any Pacific leaders or role models where I attended. At high school, I realised that I was different, not by outwards appearance, but by cultural values and beliefs. Thinking back, I was very naïve in how I viewed the world. My parents have always taught me to treat everyone fairly and equally, and always stand up for what is right. One memory is of my year 10 English class. At that time, less than ten percent of the school identified as Maori or Pacific of fifteen hundred students.

One day my English class was informed that some items from another class had gone missing and if we had any knowledge about the whereabouts of these items to let the office know. One boy from the class openly said something like, “Aw, c'mon Ms. We already know it was one of the brown boys!" I responded immediately from the other side of the room, "Ew, racist!" The teacher was obviously surprised by both of our comments, but her facial expression seemed to be more surprised towards mine than the boy's. The teacher quickly gave him a 'light' telling off. This moment is significant to me because I realised that my view of Pacific peoples as a Pacific person was different from my peers. Although this may seem obvious to others, it was an eye-opening moment for me. I am often shocked when I think back to my quick response at such a young age. It is a response that made me proud, reminded me that I must do what is right, especially for my people, and become a positive influence.

Young New Zealand-born Pacific leaders are important because they are the ones who can provide Pacific youth with advice about how to handle conflicting identities (Singh \& White, 2000). Pacific leaders can help Pacific youth with their identity by creating positive associations with them. Well-being can result (McMahon, 2002). Positive Pacific leaders are needed now. They can avoid deficit discourse such as that in my English classroom, and instead highlight positives. This includes Pacific individuals and groups who have been successful. The act of giving attention to these stories which provide inspiration is a form of leadership. With the development of leadership in areas such as education and health, life can improve for the wider Pacific community. 
Pacific leaders are needed to help to maintain a direction in the group identity. These individuals continue cultural practices and ensure the maintenance cultural values and beliefs are upheld.

\section{The Power of Leadership}

Within the university setting, senior students (second year of university onwards) paved the way for me through encouragement and support. They showed that doing the journey alongside one another is best. We can reach higher and go further than one alone would have. I observed students helping and giving service to those around them without being asked or requiring a position of status. This is what I identified as leadership in my first year of university. I hope to be considered a leader to younger students in the future. My peers and I are aware that there are no incentives. What is required is the willingness to give is the most valuable commodity, time. These senior students demonstrated that leadership is about helping others and providing a service.

The idea of taking the academic journey together has made university more exciting and fun, where leadership roles are involved. Leadership is not selfish nor "a lone journey" (Rimoni 2012, p.55). By having a community of students who have experienced what I have been through and may encounter in the future, some peace is provided. I know that there is support for me.

\section{The Search for Pacific Leaders}

Prior to attending university pursing higher education was a foreign concept to me. This was because I did not know of many young Pacific peoples who had completed university. It intrigued me that I could not find Pacific leaders to aspire to follow before I attended university. Although, there were many Pacific leaders within the community I came from, none that I knew of at the time had attended and completed education at such a level.

Prior to university studies, I never wanted to do anything within tertiary studies or higher education. However, I am forever grateful for the Pacific leaders, lecturers, and mentors from the School of Education who have positively influenced and changed my perspective about leadership and education. Their leadership inspires myself and many others to make positive change in the world. Their passion, patience and unselfish transfer of knowledge have truly 
transformed my thinking as an academic and citizen of the world. These leaders have helped me understand the true meaning of 'education'. I have learned that I must also be unselfish with the knowledge that has been bestowed onto me and which has given me the passion to help Pacific students excel in education.

\section{Who are Pacific Peoples?}

Turning to more general matters, the first thing to consider when asking about questions of development of leadership amongst Pacific peoples is to discuss who Pacific people are. This can be answered in several ways. Researchers have attended to accounts of geographical movement or migration, and to subsequent discussions of ethnicity.

Following World War Two, migrants came to New Zealand as groups of Pacific peoples from Samoa, Tonga, Tokelau, Cook Islands, and Niue (Statistics New Zealand, 2013). The reason for Pacific peoples' migration was that they had hopes for a better life in New Zealand. It was evident that New Zealand provided employment opportunities in agricultural and industrial sectors for migrants and their families (Teaiwa \& Mallon, 2005). Those who remained in their homeland were continually encouraged by the New Zealand government to migrate to New Zealand for work, and during this time previous migration restrictions were relaxed (Tanielu \& Johnson, 2013). Thus, one of the main reasons that Pacific people migrated to New Zealand was to fulfil their desire for a prosperous life through the opportunities New Zealand offered. In return, Pacific migrants helped to build the New Zealand economy as relatively cheap labour (Tanielu \& Johnson, 2013).

In 2013, seven major Pacific groups were identified by Statistics New Zealand (Population Projections, 2013): Samoan 144,138; Cook Islands Maori 61,839; Rorotongan 792; Tongan 60, 336; Niuean 23,883; Tokelauan 7,176; and Fijian 14,445. Pacific peoples are the fastest growing population in New Zealand; the significant growth of New Zealand-born Pacific peoples have shown to be the main cause for this (Tukuitonga, 2013) rather than new migration. Tanielu and Johnson (2013) estimate that the New Zealand Pacific population had increased by 10,000 people every five to six years from 2006 to 2012. Using this estimation, it becomes evident that the resident Pacific population will continue to grow and contribute to the New Zealand economy.

The Pacific population will continue to increase in New Zealand as each generation goes on to have children (Ministry of Pacific Peoples, 2013). The largest portion of Pacific peoples 
comprises of children and young people (0-25 years). This age group of Pacific peoples is larger in comparison to other ethnic groups such as European, Maori and Asian (Ministry of Pacific Peoples, 2013). As this population continues to grow, the need for positive Pacific leaders becomes more important. This trend also adds to my motivation to pay attention to leadership development as specific to the New Zealand born Pacific diaspora as opposed to new migrants.

\section{Is there a difference between the terms Pacific, Pasefika, and Pasifika?}

Identity is something that has often been debated and discussed for Pacific peoples in New Zealand. I have heard and read several terms that are used to refer to people from the Pacific region. These are various, but derive from or include the word 'Pacific'. Terms such as 'Pacific Islanders', 'Pasefika' and/or 'Pasifika' are often used to cover over the diverse range of nations, languages, histories of the Pacific Islands. Umbrella terms such as Pacific and Pasifika have been used to conveniently group people from Pacific nations together (Petelo, 2003; MilaSchaaf, 2010). This has led to a glossing over any differences and has created a space for broad generalisations about all Pacific peoples. Pacific peoples may reluctantly refer to themselves as Pacific Islanders or PI's because of such common negative generalisation (Petelo, 2003; Mila-Schaaf, 2010). Pacific peoples may also identify as Pacific Islanders or PI's to avoid explaining how their homeland is different to other Pacific nations, especially to an audience who may not value the explanation. It is evident to me that terms such as Pacific and Pasifika are European and Western constructs that cluster groups of peoples together for policy and statistics (Tanielu \& Johnson, 2013). These terms are often used for Samoa, Tonga, Niue, Fiji, Cook Islands and Tokelau, but bypass Tuvalu, Solomon Islands and other people from Polynesia, Melanesia and Micronesia (Tanielu \& Johnson, 2013). Anae et al., (2001) take a stern position and state explain that there is no generic Pacific community, but rather:

Pacific people who align themselves variously, and at the different times, along ethnic, geographic, church, family, school, age/gender based, youth elders, island born/NZ born, occupational lines or a mix of these (Anae et al., 2001, p. 7).

From this discussion it becomes clear that the Pacific community includes various groups of people, but and that general terms cannot differentiate the unique cultural values and customs of these groups. However, acknowledging the difficulties of the simplicity of the term, and with the hopes of being more inclusive, I have preferred to use the term 'Pacific peoples' to include peoples from Polynesian, Melanesian and Micronesian nations. 


\section{New Zealand-born Pacific/Pacific youth}

The age of the Pacific population is important to this study. The Ministry of Pacific Peoples (2013) report that in 2013, young Pacific peoples under 20 years old made up to $46.1 \%$ of the total Pacific populations, and 54.9\% were younger than 25 years old. This generation are (at the time of this research) are either in the workforce or are about to enter the workforce.

But who constitutes a New Zealand born Pacific person? This label refers to Pacific peoples born and raised in New Zealand (Anae, 2001). For instance, young Pacific peoples are being raised in a country that is not the homeland of their parents or grandparents. New Zealand-born Pacific people have a different view of Pacific cultural values and beliefs than Island-born people because of the New Zealand culture influence (Anae, 2001). Their values and beliefs are strongly influenced by New Zealand culture, in comparison to those being raised in the homeland (Teaiwa \& Mallon, 2005). In 2013 62.3\% (181, 791) of the New Zealand Pacific population reported that their place of birth was New Zealand (Ministry of Pacific Peoples, 2013).

Because of age and context, I see that there is a need for Pacific leaders who can help young Pacific peoples by positively influencing their lives and assist in creating deliberately purposeful future that addresses the needs and concerns of identity challenges. Traditional Pacific leadership structures may not be effective in the culture of New Zealand. The traditional forms or training places such as the village, where young Pacific people may have been taught leadership are not readily available. Therefore, people do not have the traditional leadership development opportunities they would receive in the Pacific islands. As the numbers of young Pacific peoples continues to increase in New Zealand, it is important to ensure that leadership suits the needs of the younger generation who experience both Pacific and Western leadership styles. Because New Zealand culture influences Pacific youth born and raised here, and because their experience as a Pacific person will be different to an individual born and raised in a Pacific nation, Pacific young people may cause question their identity as a Pacific person (Teaiwa \& Mallon, 2005). In this context, responsive leadership is valuable.

\section{Pacific identity}

Identity and leadership are interconnected because one must first understand who they are before they can lead others well. I have noticed identity challenges in my Pacific community 
and see that leadership has not attended to such needs. Sidler and Ebrary (2010) explain there are two parts to defining identity; personal identity (the relationship with self), and the social identity (the relationship with others). This implies that individuals construct their identity by their own definition and by how others define them. The definition includes: personality; appearance; and exploration of self, all in attempts to answer the question 'who am I?' (Crawford \& Rossiter, 2006). This suggests the way that external influences such as peers play an important part in who people are. Identity for New Zealand-born Pacific peoples is in focus in various studies (Seidler \& Ebrary, 2010; Ioane, Lambie, \& Percival, 2013; Manuela \& Sibley, 2014). Generally, these studies emphasise that identity is a challenge for Pacific peoples because they may struggle to place themselves in a Western context as a Pacific person. I see this as an ongoing challenge.

Where the external influences of New Zealand and Pacific cultures come together, young Pacific people face the challenge of trying to navigate through different cultural values and beliefs and applying them in the right context (Mila-Schaaf, 2011). It is important to understand how young Pacific peoples view themselves and understand that their values and beliefs are manifested through their thoughts, words and actions (Eckerman, 1994). Tupuola's ground breaking (2004) research focuses on Pasifika edgewalkers and explores the identity issues of the Pacific diaspora. She emphasises that New Zealand-born Pacific peoples have struggled with their place to call home, whether that is their parents' home country or their country of birth (Tupuola, 2004).

Young Pacific people's understanding of the world is likely to be different from Pacific peoples raised in the homeland in terms of culture and because of environment (Teaiwa \& Mallon, 2005). One example is the practice of cultural customs such as service and respect. Many elders and parents wish for their children to show these Island-origin traits. However, such things can be being questioned by the younger generation of Pacific peoples, who may ask why certain customs must still be upheld (Anae, 1997). In their context, young people reflect on how to retain some culture but also adopt popular culture (such as Americanisation). These values and the views associated with them can be distinctively different and come into conflict (Crawford \& Rossiter, 2006). Young Pacific people may view themselves in one of two ways; caught or blessed. As an edge-walker they may face challenges navigating the space they are walking in, for example knowing what skills to use in the different contexts. Without the blessing of the ability to do this with fluidity, the complications may feel like being 'caught between' 
The dilemma of could viewing oneself as caught between two worlds of culture (Tiatia, 1998) suggests that Pacific peoples' identities have changed and are changing as a consequence of their surroundings. Influences such as social media and school may come to the fore, and their parents' origins from the Pacific may not be as important to them (Anae, 1998; Macpherson, 1996). A way to help them navigate this path is by look at others, leaders who have been successful in their field as a New Zealand-born Pacific person.

Celebrities who identify as New Zealand-born Pacific people have spoken about how they dealt with the challenge of identity in order to live a holistic life. In their stories, a secure identity can be part of their success. An example of a well-known New Zealand-born Pacific person is Tana Umaga who faced this challenge as a New Zealand-born Samoan. Umaga explains his position as 'a New Zealander with Samoan parents', proud of his culture and his parents' background but 'a New Zealander first and foremost' (Rutherford, 2005, C4 as cited in Teawai $\&$ Mellon, 2005, p. 218). The sense of identity that Umaga has found may be more common with other Pacific people raised away from their Pacific homeland, but what the literature has also shown is that new found or adapted identity is the case for all New Zealand-born people. The complexities of identity for Pacific young people also includes mixed origin, both interIsland and Pacific-Palagi. This suggest that as the Pacific populations continues to expand an 'ambivalent kinship' will also continue to develop where the boundaries of relationship shift by context.

Identity issues and crime - one challenge

Identity development has shown itself to be a global issue for children of migrants (Ioane, Lambie, \& Percival, 2013). The results of identity search can impact negatively on young people and researchers have shown links between minority groups, identity, and crime (Seidler \& Ebrary, 2010; Ioane, Lambie, \& Percival, 2013; Manuela \& Sibley, 2014. A possible explanation as to why people from minority groups are involved with crime and violence could be that a drift towards crime is a result of the challenge and search for identity (Mullins, 2006). For example, when offenders feel that their identity is being questioned, they can retaliate negatively (Seidler \& Ebrary, 2010). This suggests the value identity has to a person. Often young peoples' peers have a significant input on their actions and behaviours. Nakhid, et al, (2009) found that Pacific youth identify with their close friends in ways which are of equal importance as identification with family. When peers' influences are negative this can project 
and promote damaging behaviour on the self, community and society (Ioane, Lambie, \& Percival, 2013). This possibility again emphasizing the need for Pacific leaders to intervene in Pacific young peoples' lives and assist them in navigating their way through society and education through developing a strong, stable and positive identity.

\section{Education issues for Pacific peoples}

It is important to consider New Zealand-born Pacific peoples identity contextually because in different spaces this has been questioned and debated. One of those spaces is education which has the power to affirm an individual's identity or devalue it. Unfortunately, the picture painted for Pacific education is not ideal. Pacific education often elicits ideas of low-achievers, low socio-economic status, and poor health, mental and physical (Mila-Schaaf, 2011). Such issues have been identified as key influencers to Pacific student's educational achievement.

One main measure of achievement in New Zealand is the National Certificate of Educational Achievement (NCEA). As a qualification, NCEA is offered to students in their last three years of high school. Each subject offers credits contingent on assessment. In the final year of NCEA there is additional award, University Entrance (UE). Students must also attain certain levels of credit in a limited range of subjects to enter university in New Zealand. Unfortunately, Pacific students have the lowest achievement rates for NCEA and UE (New Zealand Qualifications Authority, 2014).

Pacific peoples' achievement result in education has slowly improved in the past ten years, but there is still room for improvements in comparison to other ethnic groups such as New ZealandEuropean. NCEA statistics show that the number of Pacific peoples gaining NCEA qualifications and tertiary degrees have grown and continues to grow, but they are still behind their New Zealand-European and Asian peers (New Zealand Qualifications Authority, 2014). As mentioned above there are many contributing factors these types of results.

Achievement rates for Pacific peoples in tertiary education follow trends for those of Pacific secondary students (Ministry of Education, 2005). The reasons for educational challenges at the tertiary level have been investigated by research. This indicates that students who come from schools with a high Pacific population could experience culture shock, feel they do not belong and are marginalised by unfamiliarity (Nakhid, 2011). A qualitative study conducted by Davison - Toumu'a and Dunbar (2009) found that there are many limitations for Pacific tertiary students. Responsibilities affects these students most: supporting their family by 
helping to earn money; the time they must divide amongst work, university, friends, family and other priorities; and sharing physical space needed for their studies. Space and money, for instance, that can be taken for granted by many other peers. Most students do not share the same responsibilities.

A particular barrier some Pacific students face is their family's financial circumstances. Pacific students are expected to assist their family financially, which takes time away from their university studies. What is unique about the Pacific students is that they are closely connected to their family community and their family role requires specific tasks and expectations to be completed to the best of their ability. Therefore, this balancing act reveals a strength of these students as home requirements need to successfully incorporated into university studies (Davison - Toumu'a and Dunbar, 2009).

However, schooling achievement is not the only portrayal of Pacific people's knowledge. In research, Pacific peoples have expressed that responsibilities outside of education take higher priority, such as working to support the family. A very early study by Anae (2002) supports this idea. In the words of one participant, "My brother's room is in the lounge, and the TV's on, and my family came over in the evening, and so I have nowhere to go" (Anae, 2002, p. 67). Space and time for study does not always fit well into family life.

As indicated by literature, the responsibilities and challenges that Pacific are extensive. Education is usually important to students and their families but if their time is pulled in different directions it might appear to others that Pacific people do not value education. Davidson-Toumu'a and Dunbar (2009) discuss factors which constitute as barriers in achieving academic success. They found that the concept of time and time management can differ between the Pacific students and those from other ethnic groups, especially important where lecturers express “...concern for students' apparent lack of regard for the conventions associated with time keeping" (Davidson-Toumu'a \& Dunbar, 2009, p. 75). This reveals differences in paradigm regarding time. An outsider perspective such as this shows a different story from students' ideas. A 'lack' of time can be associated with leaving things 'until the last minute'. One student explained that there was "never enough time" (Davidson- Toumu'a \& Dunbar, 2009, p. 76), and that the roles in which the students have in their family take first priority.

Differences such as the way time is understood reveal the need for cultural awareness. Hynds and MacDonald's (2009) study of New Zealand educators ranging from primary to tertiary 
education used interviews and questionnaires to find that the most effective educators are those who promote learning for all students taking into consideration the ethnic differences, background and beliefs, excluding no one. In tertiary education, this practice is less common than in high school because of the masses of students and the 'one way' everyone is taught by the lecturer. Mass education and historical practices do not suit everyone. Cultural awareness in relation to time is important, for instance, in understanding questions which have been set. Where something can be interpreted and understood in different ways, time may be required by some to gain appreciation of what is being asked.

Academic staff at universities who are not of Pacific Island ethnicity may not understand the challenges Pacific students face on a day to day basis (Nakhid, 2011). Accordingly, they may form negative assumptions about Pacific peoples based on their understanding of their experiences. To improve this, educators should be understanding that their students have a life outside of their institution. Pacific students, however, must make others aware of their challenges (Davidson-Toumu'a \& Dunbar, 2009).

Factors such as conflicts between values systems over concepts such as time contribute to the student's perception of self, both inside and outside of university and to how this defines them as a person through the formation of identity. Many students struggle with identity within tertiary education and this has been identified as a barrier which many Pacific students encounter. Nakhid's (2011) study of Pacific students in tertiary education found that they often felt marginalised and out of place. This issue has been examined elsewhere:

I poked my head into the classroom and when I see that I'm the only brown face there I turn around and walk out. And it's that sense of, it's daunting enough being in a huge institution like this and being a Pacific student, and then going into a classroom in which you have to go in day in day out for the rest of your course, and finding that you are the only person in there. (Davidson-Toumu'a \& Dunbar, 2009, p. 68)

Such comments reveals the unease produced by a new learning environment and unfamiliar faces. Additionally, students have expressed a lack of engagement with lecturers and also issues understanding academic work. Although the students are attending lecturers and tutorials they described themselves as "being a foreigner or alien" (Davidson-Toumu'a \& Dunbar, 2009, p. 68). Nakhid (2011) says that for success, tertiary institutions must support Pacific students and their identity, displaying appreciation and importance. One way is to acknowledge students' 
unique heritages and identities which will further encourage positive attitudes towards attendance and tertiary education as whole.

Within the education spaces, particularly in secondary and tertiary sectors, Pacific peoples' identities are being questioned most by others, such by friends. This makes students feel insecure and uncertain about themselves, particularly when they are trying to succeed in a culture that has different values and beliefs to their home life. Equity is an often-used word, but Nakhid (2011) found a lack of awareness among tertiary staff regarding what equity is, and what it might means to marginalise groups, including Pacific peoples. The understanding of equity many staff used involved people having the same opportunity as everyone else. This is equality rather than equity, and erases factors of access such as those discussed above. Nakhid (2011) further states that in the dominant western culture in which students are studying, the separation between fair and equal has become blurred. This can be overcome when student's identities and differences are acknowledged in the classroom, and everyone is respected. Leadership is important to bring to fruition changes such as this, especially to communicate the issues involved to those who can action them.

Leaders and role models in education for young Pacific peoples are needed now to support students to navigate the spaces of family, education, work, and play. Young Pacific leaders are the individuals most likely to help young Pacific peoples because they have similar lived experiences. They are also those who can represent their community to others.

\section{The need for Pacific leadership by Young Pacific Peoples}

The issues and concerns raised in this chapter indicate that there is a need for young Pacific peoples to take the reins of Pacific leadership. This is evident through the challenges in the lives of Pacific people in New Zealand discussed above, such as levels of educational achievement, the ceasing population, the increasing percentages of New Zealand-born and the way these issues affect identity. Where Pacific people have a secure identity, their actions are likely to be more confident and positive. The reverse is true. Research has taken two views of identity formation. Young Pacific peoples have the talent and skills to be of influence on others within their own contexts.

As discussed, Tupuola's (2004) research takes a potentially positive view of the way Pacific people can hold their identity. She shows the ways that Pacific people born in New Zealand 
can navigate themselves through two cultures and how Pacific youth identify themselves as Pacific but also as global people. However, negative statistics question the actualisation of this potential. These indicate that at-risk Pacific/non-Pacific groups may increase dramatically in future generations (upwards of 3.3\% of the population by 2026). Programmes which might contribute to Pacific identity and therefore leadership exist. If these programs support identity by challenging the validity of negative stereotypes expressed toward Pacific peoples by others in New Zealand society (Manuela and Sibley, 2014), benefit may arise.

\section{Significance of the study}

All in all, I can see my former self in the research, because I can identify with the challenges discussed above as a New Zealand-born Samoan. Before I had learned to accept myself, my differences, and similarities with other, I struggled with who I was, where I belonged and what I was going to do. I have many Pacific friends who identify with the challenges I faced. It is from this base that I explore modern day understanding of Pacific leadership from the perspective of young Pacific peoples in New Zealand.

\section{Summary}

This chapter has provided a background from which research can proceed. It has touched on the issues of identity and the need for young leaders within the Pacific communities. The following chapter turns to a review of the literature to refine the research focus. 


\section{CHAPTER 3}

\section{LITERATURE REVIEW}

This thesis addresses the issue of the understanding of leadership held by young Pacific peoples in educational settings. The literature relevant to this field reiterates identity as significant for peoples understanding of leadership. Identity is made especially relevant to this study as it focuses on people of a diaspora. The review begins with identifying different concepts of leadership, viewing European concepts and Pacific concepts. Secondly, how leadership has been applied in different contexts will be reviewed, followed by a discussion of leadership development. Literature regarding mentoring as a form of leadership will also be reviewed as a tool to develop leaders.

The concept of leadership

Important to note is that there is no shared definition of leadership, and it appears different in various settings. (Batmanglich, 2015). In order to truly understand a concept, returning to the root is important. In leadership this involves leadership experiences, gender roles, and status positions. To grasp an understanding historical understandings of leadership in the West, early European-based accounts of leadership and leaders will be traced back to the Greek philosophy. This is relevant for Pacific leadership because Pacific people live in New Zealand in a European culture with connections to the ancient Greek.

\section{Plato}

Raybum (2010) says that early definitions of leadership tend to focus on positions of power and status as a right to lead. One of the most influential Greek philosophers on leadership was Plato. Plato's ideas of leadership encompassed an ideal society that consisted of individuals fitting into one of three distinct components: the appetitive, the spirited, and the rational (Cawthon, 2002). For Plato's ideal society to run efficiently it should contain these three components. Cawthon, (2002) further explains: 
appetitive [are] those whose lives are driven by passion rather than reason; the spirited those who would courageously protect us from our enemies; the rational those able to distinguish between shadow and light (p. 8)

Plato did not believe that leadership was hereditary, rather if was bestowed or a talent of an individual and their "souls must be examined" to identify that they are suitable for leadership (Cawthon, 2002, p.9). Position in society is predetermined and exposed when one is examined by those in the rational group. Plato emphasised that leaders must lead as it is their right and duty. Plato's idea of leadership is not exclusive in relation to status or class, yet it is exclusive to a small group of peoples, those who have been bestowed the spirit of leadership. Batmanglich (2015) believes that such philosophical beliefs about leadership are still engraved in peoples understanding.

\section{Aristotle}

Greek philosopher Aristotle who was Plato's successor. He went one step further with his definition of leadership. He believed that from birth leaders were made, and made to rule. Similarly, because there was a distinct differentiation at birth, only the rich, and primarily male would lead (Cawthon, 20020; Evans, 2010). Aristotle's definition is more precise than Plato's, defining those who should lead and those who should not. Division by social class had a very influential role in his way of thinking.

One of the distinct ideas of leadership from Aristotle, was birth right. For example, the circumstance and the social class a person was born into would determine where they would stay in the social hierarchy. If born to a slave one became a slave as would one's children, because "they lacked the time necessary for the leisurely contemplation of the "ultimate good" (Cawthon, 2002, p. 19). This type of leadership unlike Plato's produced more inequality because it is hereditary. This factor affected the relationship between the leaders and those being lead intergenerationally.

\section{Greek leadership in the modern world}

Raybum (2010) suggests that such definitions of leadership suggests that leadership consists of exploiting others and abusing the power given: that such beliefs must be resisted in modern times as they are not beneficial to the masses. Batmanglich (2015), however, suggests that such foundational beliefs about leadership are still held and unconsciously accepted by the masses in Western society. The differences between past and present times are mostly new titles that have a "modern spin" (Batmanglich, 2015, p.8). An example of this belief is when individuals 
think they are not good enough for a job or capable to pursue higher education because of previous educational assessments. Other beliefs which include male-led leadership, the right to lead because of heirs, and clans based leadership come from the same roots. These beliefs are visible in Western practice and may be an influencing component for young Pacific peoples and how they interpret and understand leadership in diasporic situations.

\section{Leadership and Pacific cultures}

Interestingly, the chief system that exists in many Pacific cultures has beliefs that are very similar to that of Plato's traditional leadership beliefs. An example of this from America Samoa is a well-known song with the lyrics "God selected Samoa to be ruled by chiefs" (Thompson, 2004, p.30). This indicates that only a select few should rule over Samoa because of their ties, and idea which directly links back to Plato's idea of leadership. Such thinking has been evidenced by other researchers who show that those who hail from chiefly families are believed to have inherited power directly from the divine (Sahlins, 1958; Goldman, 1970). In Polynesia, where the chiefly system is more commonly used, and Melanesia, where the big men system is used, practice often refers to masculine power and ideas of leadership (Taylor, 2008). These ideas are still relevant today with these communities, who reproduce these ideas and social norms. For instance, in the Pacific most of the nations' heads of state, Prime Ministers and royalty are men. This may be because such beliefs of leadership being the role of men are deeply ingrained in the cultures.

The chief position in Pacific society implies that certain individuals and families have higher value because of their associations or family name, as Goldman (1970) indicates:

The junior lines received only the weaker impulses, and therefore less honour, eventually distancing authentic the members of this junior line further away from more powerful lines of leadership and authority succession (p.418)

Hence, the closer family tie or association one had to the chief's family, the more power or influence one has. Even more important were the chiefs themselves. This system ensured that only a certain group of peoples were chiefs or leaders within these communities. Alongside the chiefly system, many Pacific cultures are strong in their beliefs concerning spiritual life and higher powers (Bodley, 2011; Donner, 2007). For example, the American Samoan Government Seal proclaims "Samoa Muamua Le Atua" meaning "God First" (Thompson, 2004, p.31). This encompasses the idea that God or gods and associated religions have a very important role in 
defining people's ties to the land and to one another. America Samoa is not the only Pacific nation to have an outspoken faith. Other countries also have popular sayings, songs, symbols and myths that often refer to gods in ways which shape ideas of leadership (Thompson, 2004; Bodley, 2011).

Tradition and culture are important. Thompson (2004) explains that there are no laws in the context of the Samoan culture. However, village peoples respect and abide by the decisions of the 'Village Council of Chiefs' (Thompson, 2004, p.32). That is, these councils lead them. This implies that religious and cultural beliefs are strongly integrated in the culture to the extent of reducing law to irrelevance. When discussing culture or religion, in either context the other cannot be ignored. The village chiefs must first approve a notion such as a matai/chief title before any other procedures are taken. These individuals are expected to be a member of a local church and have gifts on hand for the local reverend who has been praying for them during this process. This provides insight into how important religion is and the strong relationship it can have with leadership and local politics, for example the village chiefs. At the same time it indicates that there is a strongly hierarchical leadership system within societies that use the chiefly system, and emphasises that leadership is only for a certain group of people. Many Pacific cultures have processes or rituals that one must undergo to become a leader (Thompson, 2004; Bodley, 2011). One example is the Samoan culture's matai system where the individual and their family must provide gifts and monetary items, and the individual is also expected to participate in the ceremony. This role is both social and spiritual.

Having examined two different models of leaders and leadership, early philosophies and Pacific cultural traditions, it is important to see how these operate in different contexts, either together, or in tension. Various styles and understandings of leadership overlapping in various contexts will now be investigated.

\section{Different forms of leadership}

\section{Servant Leadership}

Servant leadership was bought to the forefront of academia by Robert Greenleaf in 1970s. Greenleaf who has worked in the corporate world realised the leadership style that was in place was not producing the best results for the company to grow (Mertel \& Brill, 2015). He then went on to research what is now known as servant leadership. Servant leadership is focused on the fostering the people under one's care, thus a leader being a servant first. Individuals do not 
set out to become a leader, but because of the nature of wanting to provide and take care of people, they become a servant leader. Servant leadership is putting others' needs first (Sanga and Walker, 2005). One is first the servant and then becomes a leader. Servant leadership emphasises being a good steward of the people in one's care. Importance is place on this because people are the most vital resource within any business, school or church, and the role for the leader is to nurture these relationships and build up the community (Gotsis, \& Grimani, 2016; Panaccio, Henderson, Liden, Wayne, \& Cao, 2015; Sanga \& Walker, 2005). Servant leadership is different from the models discussed above because it develops and is not given. It can lead to the assumption of leadership by those who have no position, and those who are not nominated by others.

\section{Transpersonal leadership}

This style of leadership is a personal perspective of what happens to the individual's internal values and beliefs (Bynum, 2010). Transpersonal leadership was derived from transpersonal psychology and is about going beyond oneself, extending past the ego and personality (PlaisterTen, p.3). Transpersonal leaders are always growing and learning to better themselves. Their characteristics include "(a) authentic, ethical, and emotionally intelligent behaviours into the DNA of the organisation; (b) build[ing] strong, collaborative relationships; (c) creat[ing] performance enhancing culture that is ethical, caring and sustainable" (Plaister-Ten, p. 1). Transpersonal leaders desire to not only improve their life and situation but also their environment and those around them. The result of this when done successfully, such as in an organisational setting, can show in employees' productivity in the workplace where they feel an increased sense of belonging. This kind of leadership focusses on the self, but can have social consequences.

\section{Transactional leadership}

Another style of leadership is transactional. Bennis and Nanus (1985) describe transactional leadership as an exchange between the leader and the followers based on the idea that they need each other to survive. The style can often be found in organisations, where the leaders set a goal and require their team to reach it (Tavanti, 2008). For example, leaders can often use incentives such as promotions and bonuses to appeal to a team (Jones, 2008). Although followers may comply and achieve the set goals, a lack of enthusiasm and commitment to set tasks can exist (Zagorsek, et al., 2009). Transactional leadership is hierarchical, like the Greek and some Polynesian forms, focused on instruction coming from the top down although in some cases it may work to achieve social results. However, for Pacific peoples this style of 
leadership is less appealing because it is concentrates on one person giving instruction to achieve their set goal and is less interested in the people who are doing the work than other forms., For this reason, it is not an ideal leadership style for Pacific peoples.

\section{Transformational leadership}

Transformational leadership takes a holistic approach to form leaders. It sees that is not only the desires and plans that transform peoples and society, but action and behaviours. Covey (2007) states that a transformational leader's desire is to influence and help as many peoples as they can through honest and good works. They are aware of their life being an example for others.

Young Pacific peoples have spoken about their views of leadership and what it looks-like. For example, Raybum (2010) stated that transformational leadership manifests itself through:

Vision, embracing the values and concerns of diversity, and promoting social justice goals. With a growing emphasise on multiculturalism, global citizenry, diversity, and multiple perspectives, effective leadership is increasingly viewed as inclusive, empowering, collaborative, and authentic. (Raybum, 2010, p. 253)

This description a of leadership can be operationalised anywhere at any time, and individuals do not have to be from a certain family lineage nor in a position of power to lead, rather they must have the desire to empower others to achieve and reach their full potential (Raybum, 2010).

Howell and Costley (2006) state that "leadership is a process" where an individual can influence a group of peoples to achieve a common goal for the benefit of all (Howell \& Costley, 2006, p.4). Sparrow (2012) discusses "a senior leader who directly manages senior peoples [...] has a role to inspire them and ascertain what they also stand for as leaders" (Sparrow, 2012, p.157). This suggests that leaders are influencers who have an important part in how teams work together to achieve a common goal, and emphasises that a person or peoples must pave the way for others to follow. Likewise, Raivoka (2012) explains that leadership is about the ordinary person choosing to make a difference in by producing "inspirational moments experienced with and shared by ordinary peoples" (p.70). An example is a coach motivating and sports team or a teacher supporting their students.

Transformational leaders have four distinct behaviours: idealised influence (behaviours and attributes), inspirational motivation, intellectual stimulation, and individualised consideration 
as shown in a study by Bass, Avolio, Jung, Berson and Zedeck (2003). This reveals that the leaders themselves find motivation and inspiration in helping other because they can identify and empathise with the individual or group of peoples they are working with.

Transformational leadership emphasise that one needs a support network that can motivate and encourage the individual when faced with challenges and difficulties. This support network can also provide advice, inspiration, and vision (Sparrow, 2012).

From a Pacific point of view, these styles of leadership will look different when compared to a Western point of view. For example, how the leadership styles are interpreted will be different. A transpersonal leader is more self-focused and this can be viewed as an independent style. However, transformational leadership aligns itself much more closely with Pacific values and beliefs. It is focused on improving relationships between individuals. Similarly, transactional leadership is also relationship focused and works as a reciprocal leadership style, traits valued in the Pacific more than in some Western thinking.

\section{Leadership development}

For models where leadership is not a given but is developed, it is important to examine the spaces and circumstances involved. Leadership development takes place in many different contexts depending on what the need is within a community, or business (Wheeler \& Edlebeck, 2006). Different approaches can be seen through varying leadership development strategies that include retreats and seminars to develop leaders (Klau, 2006).

The importance of definitions emerges from a case study of three different youth leadership development programs by Klau (2006) who explores the concept and understanding of leadership across contexts in the United States of America. The first case study was National Leadership Conference (NLC). This leadership training expands over the course of four days. To attend the conference, youth were selected from their state by submitting an essay or being referred by an adult. This selection progress limits youth leadership development, as Klau (2006) highlights. NCL development and pedagogy has a strong emphasis on authority and adult leadership by providing lectures and panel question-and-answers. Similarly, the second case study, Jewish Leadership Organisation (JLO), was of a four day course. This annual youth leadership conference is open to all Jewish people who apply and pay registration. It focuses on lectures from well-renowned Jewish leaders with the afternoons spent volunteering in the community, such as at homeless shelters. After the intense four-day training, students are 
expected to return home and execute the skills learned in their own community project. The third case study was of the Institute for Justice and Leadership, open to all interested youth. This training is focused on group discussion and scenarios, evaluating how people would react to certain situation and encounters.

Klau (2006) suggested improvements that could be made in the programs to release the full potential of enrolled young people. The key concern was that all three programs did not have a clearly defined idea of leadership, and when staff was asked they would recite the mission statement as an inaccurate proxy. Klau (2006) found this to be an instrumental omission during the programs, a cause of frustration and confusion amongst the team.

Wheeler and Edlebeck (2006) suggest that youth leadership programs that achieve significant outcomes instil four strategies for success: they "build young people's connections to their own identity, culture, and community; recognise that young people are assets to and experts about their own communities; engage young people as community leaders on issues that matter to them; [and] create development opportunities that are sustained and supported over time" (p. 89). Each of Klau's (2006) programs instilled at least one of these four qualities. All three programs were doing good work in developing young people, but to excel further these four strategies could be taken into consideration as in addition to a sharper definition of leadership. From a Pacific point of view these leadership development programs have strengths and weaknesses. A clear definition of leadership as a starting point for negotiation was a good idea given the variation in understandings of leadership demonstrated across cultures. Similarly, opportunities for contribution and voice are helpful in dialogic societies which has positional leadership, as these strategies create new spaces for those, such as Pacific young peoples who would normally be excluded on age grounds, gender and social class or status. This opens the space for mentoring across a broad spectrum.

\section{Mentoring}

For the purposes of my study, I have also included mentoring as a component of leadership as mentoring is a natural process of developing people. The term mentor can be traced back to Greek philosophy. When Telemachus, son of King Odysseus, came of age, he went in search for his father who had been missing for 10 years after a war. On his journey to find his father, the Goddess of war, Athena, becomes Telemachus' mentor on his search (Shea, \& Ebrary, 2002). It is believed from this, the term 'mentor' developed. It means to relate to someone who 
is trustworthy, older, wiser, who will provide guidance (Shea \& Ebrary, 2002). A mentor's lived experience is the main point of reference for their mentee, who more than often than not will be paving a similar path in their own life (Shea \& Ebrary, 2002; Lakind, Atkins, \& Eddy, 2015). This explanation indicates that mentors are those who have knowledge in certain areas because they have experienced this, making them qualified to mentor in the eyes of the mentee. Mentoring can take place in varied contexts, such as a sports coach who is trusted by their team because they are knowledgeable or have sporting expertise or a teacher with a special responsibility for a student.

Mentoring can be versatile. Alongside the one-on-one sessions, it can also be used for a small or large group of people. Results can be very different in groups because the process may be less personal than one-on-one mentoring as the mentor tries to appeal to all the individuals in the group together (Lakind, Atkins, \& Eddy, 2015). It can take place in any situation from formal and informal settings, from childhood to adulthood. " $[\mathrm{M}]$ entoring is a fundamental form of human development where one person invests time, energy, and personal know-how assisting the growth and ability of another person" (Viator, Dalton, \& Harp, 2012, p. 3). This suggests that mentors can have an impactful influence on individuals. In the case of students from minority groups, mentoring can involve a senior student assisting a junior student. In this case these senior student mentors are leaders. In educational contexts mentors nurture the intellectual development of their mentee (Darwin and Palmer, 2009). Mila-Schaaf and Robinson's (2010) research on Pacific students in tertiary education showed how following the footsteps of other Pacific students who have achieved high academic success can help newer students navigate their academic journey. This influence proved to be effective because junior students transitioned into senior students' roles and continued the process.

\section{Mentoring minority groups}

Kensington-Miller and Ratima's (2015) study proposed a mentoring model for tertiary indigenous staff in New Zealand, with results which are relevant for other minority groups in tertiary education. When individuals' cultural frameworks were valued within the tertiary institution, they were more likely to stay enrolled. Thomas (2001) states that mentoring minority groups should be different from employing "white protégés". This suggests that the approaches of mentoring must cater to the needs to each group; there is no standard system that will work for all. In all work, but especially in cross-cultural contexts, mentors must be aware of any biases they may have that may prevent the mentee from succeeding. When selfreflection is done and biased views, conscience or sub-conscience are brought to the surface, 
the mentor and mentee relationship can move forward in positive light (Kensington-Miller and Ratima, 2015; Thomas, 2001). Bringing together mentees from minority groups to create a community that supports one another can help with academic achievement (Viator, Dalton, \& Harp, 2012).

Lande's (2010) research focused on developing tips for mentoring students from diverse backgrounds going into professional work. They suggested mentoring covering at least one of the three following criteria: "(1) a wise and trusted counsellor or teacher, (2) an influential senior sponsor or supporter, (3) to act as a mentor" (Lande, 2010, p. 11). The implications the two definitions give are that there is a mentor and mentee relationship, one that is different to a role model. For example, the mentor and mentee are known to one another and build a rapport. Jayne's (2003) study of coaching and mentoring agrees with Lande (2010) about the importance of trust between mentor and mentee. When these relationships have a strong sense of trust the mentor can provide honest feedback and act as an objective sounding board for ideas (Jayne, 2003). Therefore, the mentor provides feedback and advice in the area their mentee needs, and this is a differentiating factor between a role model and mentor. Closeness between those involved is likely to be important in Pacific leadership development because of cultural expectations and because of the demands of diasporic contexts.

Research (Lande, 2010; Jayne, 2003; Greenleaf \& Spears, 1998) has emphasised that mentors are an essential part of life, especially in education. A mentor provides a support system that individuals may not receive at home, particularly relevant in inter-cultural contexts. Individuals grow in social settings and attitudes as mentioned earlier and young peoples need positive influences present in their lives at a young age. The challenge within minority groups is the lack of mentors, specifically mentors who are from similar background.

The benefits of mentoring improve various aspects of individual's lives. The effects can interweave into more than one area of life. For instance, academic mentoring can improve achievement measured as levels and grades but can also show improved self-esteem and communication skills (Boyle, Kwon, Ross \& Simpson, 2010). The relationship between a mentor and mentee is intimate because of the nature of the position of mentor. One cannot be mentored if there is no mentor and vice versa; the relationship is inter-dependant. For these reasons, mentoring is likely to be a significant strategy for developing leadership in Pacific peoples. 


\section{Role Models}

Role modelling is a further way of demonstrating and potentially developing leadership. Role models differ from mentors in that the relationship between the model and their audience is less intimate than in mentoring. To understand the role and influence of a role model understanding the characteristics and functions is important. One study that looked at entrepreneurship and role modelling (Bosma, Hessels, Schutjens, Praag, \& Verheul, 2011) found that there were two theoretical constructs to role models:

(1) The concept of role and tendency of individuals to identify with other people

(2) The concept of modelling, the psychological matching of cognitive skills and patterns of behaviour between a person and an observing individual (p. 10)

These two constructs suggest that individuals are attracted to peoples who they can relate to by means such as their characteristics, background, ethnicity or behaviour. Essentially individuals view that person as something to aspire to, the role, and attributes they will imitate or learn from, the model. Therefore, the role model should be successful in the area that their target person aspires to, such that their life provides motivation and evidence that set goals are attainable, eventually enhancing the desire to try to achieve (Bosma, et al, 2011).

In extreme cases, there may not be a personal relationship between an individual and their role model at all, for example if athletes or celebrities are involved. Where there is no personal relationship a model's life can be something the individual aspires to. This implies that the influence of a role model can only go to a certain point because there is no contact or feedback provided to the individual. Thus, a key difference between role models and mentors is revealed. Discussions with Pacific student about their fellows' success in academia can have positive impact in the context of role modelling. Often negative statistics are mentioned and discussed as if they predict the future, yet the many individuals who have successfully navigated their way through the education system can be forgotten (Berggen \& Wray, 2002). Berggen and Wray (2002) found that individuals from a minority groups who have done well indicate that solutions are already within the communities. The challenge is identifying key attitudes and behaviours which lead to a role model's success and reproducing them in various contexts and in other people as a result of example. 


\section{Questions of identity - a challenge for leaders}

One area where Pacific leaders can help younger generations of Pacific peoples is in navigating the complexities of identity. As discussed above, identity for New Zealand-born Pacific peoples can be a challenge. Grappling between sense of home as the motherland where their family ties originate from and their place in the country they are born in, New Zealand, can be difficult. The identity challenges that Pacific peoples face will continue to be echo across generations as the Pacific population continues to increase. This section of the literature focuses on identity and explains how this complex topic affects New Zealand-born Pacific peoples.

\section{New Zealand-born Pacific/Pacific youth and Identity}

New Zealand-born is a common term used to describe peoples from ethnic backgrounds born away from their parent's home country (Macpherson, 2001). The term New Zealand-born aims to encompass many different experiences that such people encounter, such as interactions on the playground, in the classroom or at the workplace. Chapter 1 discussed the issue that New Zealand-born Pacific peoples may not find their parents Pacific heritage and cultural practices as being of the greatest important in their lives. The most significant reference point may be the culture they are born and raised in (Teaiwa \& Mallon, 2005). An example could be parents only allowing their mother tongue to be spoken in the home, but their child not valuing this because the language is not used outside of the family group. Environment can influence values and beliefs; the importance of identifying with peers can be more important than one's parents' culture. New Zealand-born Pacific peoples will also be different from an individual raised in a Pacific nation. Pacific peoples' identities are not static and continue to be constructed and reconstructed depending on their surrounding context (Anae et al, 2001).

As discussed in Chapter 2, the expansion of numbers of Pacific peoples living in New Zealand from the early 1960's has resulted in Pacific people being more visible in New Zealand society. At the time of writing, the number of New Zealand-born young Pacific people has increased, and the Pacific population average has fallen to twenty-five years old or younger. The Ministry of Pacific People (MPP, 2013) found that number of Pacific young peoples under the age of twenty-five outweighs other ethnics groups including the New Zealand-European adult population (MPP, 2013). This suggests that Pacific peoples will be significant contributors and influencers in the wider New Zealand communities in years to come. Therefore, understanding New Zealand-born Pacific peoples and the challenges they face from childhood into adulthood is a significant aspect of planning for the future of New Zealand society (MPP, 
2013). Given the importance of education, it is worth reviewing the literature about Pacific young people's identity in this context.

\section{Identity in school}

As has been discussed, identity can be constructed and reconstructed continually and there are many influences to how this can happen. Santrock's (2011) research has focused specifically on social identity or social identification such as how society helps to shape one's identity. In the education setting, students try to navigate who they are within society and within school. Mullen, Robertson and Ebrary (2014) in a study about 'Black' and 'White' identity in school discussed the way children form identity in school and how this can reflect society's culture. They show that many can have a role in this, including schools' principals, stakeholders, and students. Researchers (Santrock, 2011; Berry \& Candis; Robertson \& Ebrary, 2014) have also shown that the academic achievement and behaviour of children who come from minority groups, whether they be socio-economic or ethnicity, can improve when they can identify with the information provided in the classroom. An example of this is teachers using concepts that the children are familiar with. This acknowledgement of identity reveals to the students their value and importance in the classroom. Similarly, negative connotations and associations can have the opposite effect on students. This in turn can see them steer towards negative cultural aspects: teachers must be aware of their biases.

Inputs from society such as media and friends can strongly influence who a young person believes themselves to be, and also the way they negotiate assimilation to the way they are portrayed (Mullen, Robertson and Ebrary, 2014). These influences can be both positive and negative. How individual handle and react to such pressures can vary. For example, a student could aim to prove incorrect negative influences such as stereotypes, or fall into the stereotype placed upon their ethnic group (Molix and Bettencourt, 2010; Syed, Azmitia and Cooper, 2011).

Despite every young person's experience being unique, there is a common theme amongst New Zealand-born Pacific peoples who describe themselves as living in two worlds or edgewalking. New Zealand-born Pacific peoples have been described navigating their way through the metaphor of edgewalking. An edge walker is "resilient to cultural shifts and able to maintain continuity wherever he or she goes, walking the edge between... cultures in the same persona" (Krebs, 1999, p. 9). The literature is not extensive on this topic. However, research about other ethnic minorities who also face the challenge of identity in school is useful. African American 
peoples who work with in dominantly American European environments, use a similar strategy to help them understand their experiences. Mullen et al., (2014) described this as switching codes or code-switching, and state that such students "switch codes among multiple identities ranging from White and Black to corporate and learner-centred" (Mullen et, al., 2014, p. 2). This reveals that these individuals can adapt to different environmental settings which can be difficult for them to interpret at times, sometimes behaving as two different people. For example, language se changes when they switch codes, similar to balancing during edgewalking. Edgewalking can be viewed as a negative because the concept of edgewalking or code switching often discusses how individuals feel like they are living in two worlds, potentially torn. However, fluency in switching or balancing is a strength (Mila-Schaaf, 2011).

\section{Coping Mechanisms}

Individuals handle challenges and difficulties differently depending on their environment, and past experience. In relations to edgewalking or switching codes, Molix and Bettencourt (2010) identified coping mechanisms that peoples from ethnic minority groups used to help manage negative stigmas with the following three findings: “(a) identifying with a different social group, (b) developing group pride (this will vary from group to group), (c) focusing on the distinctiveness of one's group membership" (Molix and Bettencourt, 2010, p. 516). This indicates that individuals who experience edgewalking or code switching can either choose to strengthen their cultural identity and association, or chose to affiliate with another social or ethnic group. Furthermore, two of the three findings emphasised the importance of ethnic identity and its strengthening, such as by providing opportunities where individuals can easily express their ethnic identity as well as their wider national identity. However, the environment must actively work to construct positive associations with and for minority groups, actively cultivating and incorporating identity for especially in educational settings.

Thus, research suggests that identity is important to New Zealand-born Pacific peoples, is shaped strongly by their peers' influence in schools and can also contribute to achievement in the classroom. Identity is not simply something that is to be achieved or inherited. It can also be a way that one chooses to be recognised and associated.

\section{Summary}

There are many factors that can influence one's understanding of leadership. This literature review has focused on various leadership philosophies and has suggested how these can 
strongly influence beliefs about leadership. The examination of leadership styles has shown that Pacific and Western understandings and approaches are different. Leadership styles are not bad in themselves. However, in a Pacific context some may not lead to the desired results, especially in education. The literature shown that identity is a challenge for young Pacific peoples born in New Zealand, which can influence other aspects of young Pacific peoples' lives. The relationship between identity and leadership can be a contributing factor to Pacific peoples' success in education where the style, people involved and context all work in ways which Pacific young people understand. 


\section{CHAPTER 4 METHODOLOGY}

This chapter is structured into three sections. The first section discusses the importance of theory. The second discusses methodology, and the third, methods. For this study, a Pacific method of knowledge seeking used to frame the data gathering process is Talanoa. This chapter explains why the chosen methodology and method is appropriate for this research. My position as researcher and how this influenced the data collection process is also explained. The procedures towards ethical approval are also explained.

\section{Theory in educational research}

Robert Slack (1996) suggests that "successful theorising is not measured by exact theoretical fit but by the ability to work with our always inadequate theories to help us move understanding 'a little further on down the road" (Robert Slack, 1996, p.113). Theory is something that is always evolving, and is not static (Neuman, 2006). As an explanation of theory Neuman (2006) states:

At their core, we use theories to organise and systemise our thinking and to deepen and extend understanding [...] because theories also become a way to communicate effectively with one another (p. 57)

Neuman suggests that theorising is always taking place whether no matter what the context and environment. He also implies that various types of theories act as a filter on how we are understanding information. When it comes to discussing theory, many studies (Wright, 2007; Sikes, 2006; Rimoni 2016) refer to Suppes (1974), 'The place of theory in Education Research'. Suppes identifies five key factors: argument by analogy, reorganisation of experience, complexity of issues, transformation of a situation and trivial empiricism.

Suppes (1974) explains through the first factor, argument by analogy, that ideas are easier to understand when analogies and universal generalisations are used. Rimoni (2016) says that "this is the classical and standard notion of theory" (p.56). The value of this kind of thought in research is to make analogous connections between the lives of individuals as described, for instance, in interviews, and more general areas of life. 
Suppes' (1974) second factor, reorganisation of experience, and fourth factor, transformation of a situation, are similar because they both challenge preconceived assumptions or ideas. Reorganisation of experience suggests how theory possesses the power to change one's perception, and differentiate what is important from what is not. This implies that the way people interpret what happens to them is from past understandings, and new experience can change their thinking. This links to Suppes' forth factor, transformation of a situation, because one can turn a negative experience to a positive experience by reconstructing ideas. Suppes (1974) emphasised that theory can be used as a tool for problem solving and "offers a continually developing perspective on life" (Rimoni, 2016, p. 57). This is important for research because theory is not fixed and continually evolving. New discoveries are always being made through researchers' enquiries.

Suppes' third key factor is that theory takes us past the surface and helps us identify the complexity of issues (Rimoni, 2016). This factor shows that what appears to be a problem can be a result of a much deeper issue. Theory helps deep issues come to the surface for solutions to be produced. Ultimately, Suppes' factors combine to suggest the importance of theory in educational research. They protect against trivial empiricism. Rimoni (2016) summarised: "if the data collected has no theoretical framework it leads nowhere" (p. 57). Theory helps to develop ideas and explains the data collected by researchers. It continues to construct and reconstruct preconceived ideas throughout the research process.

The importance of theory in research is acknowledged by other researchers. Jan Wright's (2007) study on the necessity of theory in research supports Suppes' (1974) ideas, and agrees that theory provides guidance for policy and practice. Additionally, other scholars cited by Wright show similar beliefs about the importance of theory: "we need theories - in order words to plausible explanations for what's going on - to live by... Theory is essential and inescapable" (Sikes, 2006 as cited in Wright, 2007, p. 8). This again suggests that theory exists in all circumstances. Therefore, it is evident that whether or not we chose to acknowledge theory in our everyday thoughts and research, it is always present. In educational research and following Neuman's statement, the question is less what is the importance of theory in research, but rather how it is used and what type it is (Neuman, 2006).

Suppes' factors concerning why and how theory is important are very clear ways of understanding the foundational functions of theory in educational research. For my specific study, Suppes' second and fourth factors are valuable for this research in trying to discover 
young Pacific people and their understandings of leadership. This is because they involve reorganising ideas, useful for qualitative research, and transforming a situation, helpful where progress is desired.

\section{Paradigm}

An appropriate way to investigate an interpretive social world is qualitative research. An interpretive paradigm seeks to understand the lived experiences of people. It sees reality as "mind-dependant and socially constructed" (Chilisa, 2012, p. 32). In this study, a qualitative approach is used to discover how young Pacific people understand leadership. A qualitative approach is viable for this study because it seeks to understand individuals lived experiences through their stories (Lyn Richards \& Janice M. Morse, 2013, p. 126). Qualitative research is a form of inquiry that tries to examine the world from the perspective of the people under study, not primarily from the perspective of the researcher (Connelly, 2007). Thus, a qualitative approach is the best fit when exploring individual's thoughts, feelings and behaviours in their own words.

\section{Phenomenological approach}

People interpret the world as phenomena. Thompson and Walker (1998) discuss understanding a phenomenon by asking questions such as "what is going on here? How can I explain it? or to describe how people live or cope with particular experience?" (Thompson \& Walker, 1998, p. 66). Using phenomenology to investigate leadership is a suitable way to gather data for this research, as individuals' testimonies allow for positional understanding. Moreover, phenomenology provides a platform for individuals and collectives to share their ideas and beliefs. Marriam (2002) adds that qualitative research, which includes phenomenology, allows individuals to construct their own world based on their interactions with others. This allows researchers to produce description of the phenomenon through interaction in research.

Patton (1985) explains that qualitative research should interpret information provided by the participants in an honest form, understanding it through the uniqueness of the context and interactions that take place there. The approach does not attempt to predict what will take place in the future, rather, it is focussed on the present situation, searching for depth of understanding of phenomena and factors that influence them such as, "what their lives are like, what is going on for them, what their meanings are, what the world looks like in that particular setting" 
(Patton, 1985, p. 1). This approach is important because it is a holistic view of the participant experiences.

A phenomenological approach to ideas about leadership is relevant when trying to answer the question "what are young Pacific peoples' understandings of leadership?". This is because it is focused on understanding peoples' experiences, such as young Pacific peoples, and looks at how these experiences influences their view on leadership.

\section{Methodology}

Methodology is "the overall approach to research linked to the paradigm or theoretical framework" (Mackenzie \& Knipe, 2006, p. 198) being employed. A methodology stands between theory and methods, providing a framework for theorised action. Methodology embeds the research purpose in a philosophical position, ensuring appropriateness and relevance of methods, used for developing and understanding data. Before methods are considered, the methodology should be established. This can be achieved by reconsidering the research paradigm; interpretative, qualitative, and Pacific.

Making the distinction between methodology and method is important for research. Linda Smith's (1999) study about indigenous methodologies in New Zealand assists in making this distinction stating:

A research methodology is a theory and analysis of how research does or should proceed...Methodology is important because it frames the questions being asked, determines the set of instruments and methods to be employed and shapes the analyses (1999:143)

This shows that methodology builds from theory. Choosing a methodology shapes the information that will be gathered, such as what data should be included or excluded. This is highlights the role that methodology has and how it moulds the data. Talanoa was used as the methodology for this research because Talanoa produces data about phenomena which can be interpreted from a Pacific perspective. This allows that information to be analysed differently from a Western methodology, relationally, the phenomena at the core of the Talanoa methodology is the concept of Pacific leadership.

\section{Talanoa Methodology}

Talanoa methodology is based on Pacific values and is "... an activity used for creating and transferring knowledge" (Vaioleti, 2014, p. 192). It is an oral tradition with roots as deep as 
classical Greek civilisation (Vaioleti, 2014). Talanoa is a combination of two words, firstly 'tala' means to command, tell, relate, inform, and announce, while 'noa' is of no value, without thought or without exertion (Churchward, 1959, p. 379). The word Talanoa is used in more than one Pacific language and this meaning derives specifically from Tonga (Otunuku \& Apos, 2011). This methodology is suitable for this research because it functions from Pacific values and beliefs that empowers Pacific people's voices as a participants and contributors to the research, valuing their inter-relatedness.

Talanoa is suited to Pacific participants because the conversation can build a relationship or connections where participants feel safe to share their stories (Otunuku \& Apo, 2011). The use of Talanoa to establish connections is a way of showing and building trust. Forming trust and confidence between the researcher and participant is vital because the information that participants are willing to share may not be shared with others in non-supportive circles (Otunuku \& Apo, 2011; Farrelly \& Nabobo-Baba, 2014). This implies that the researcher must be confident and understand how to enact Talanoa methodology, to understand how their participants can bring out underlying themes.

Talanoa is an integral part of data collection in research with Pacific peoples. Rimoni's (2016) study on Tama Samoa stories used Talanoa method to gather data. Rimoni (2016) explained that this methodology was appropriate for a Pacific researcher to obtain the data desired because Talanoa provides flexibility and understanding between the researcher and participant through a mutual understanding built on cultural beliefs and values. Manueli's (2015) study of Pasifika tertiary students' use of information and communication technologies used Talanoa becauss the protocols and understandings the Pacific researcher had were helpful when working with Pacific peoples. Wilson's (2010) study on the perceptions of Samoan students, teachers, and parents on the place of the Samoan language in New Zealand found similar benefits of Talanoa. Wilson (2010) expressed that Talanoa enabled the accustomed fa'aaloalo (respect) to be shown to the participants, and for it to be reciprocated. This is essential in the Samoan culture. Manueli (2012) agreed and added that Talanoa is collaborative in nature, the researcher and participant are equally important.

In summary, Talanoa as a methodology for researching Pacific matters uses Pacific values and beliefs to gather data. Talanoa is a methodology for involving Pacific peoples, where the "coconstruction of authentic, rich, contextual and inter-related knowledge" can take place (Vaioleti, 2006, p. 23) between researcher and participants. Talanoa creates a respectful place 
for the participant to share their ideas in the knowledge that they will be respected, thus building rapport. Talanoa has been increasingly used in research in New Zealand, and this study offers an opportunity to further the development and application of Talanoa in research supporting young Pacific people.

$\mathrm{V} \bar{a}$

Talanoa is also a reciprocal exchange between the two parties, and the sharing that takes place between the two is based on that deep interpersonal and emotional relationship (Farrelly \& Nabobo-Baba, 2014; Morrison et al, 2002). In Talanoa, the quality of the space between the two individuals is of great significance because it can direct how the individuals interact with one another and affect the depth of the conversation (Vaioleti, 2006). This space is often referred to as vaha'a (Tongan) or vā (Samoan) and translated as relationship, such as the vā between the researcher and participant.

Wendt (1999) describes vā as as "the space between, the between-ness, not the empty space, not space that separates but the space that relates, that holds separate entities and things together in the Unity-that-is-All, the space that is context, giving meaning" (Wendt, 1999, p. 402). This suggests that researchers who use Talanoa and with Pacific people should be aware of the value and influence of vā because it is part of who they are as individuals. Acknowledging and displaying respect for this value can make the participants feel more inclined to share information.

\section{Teu le Vā}

$V \bar{a}$ is emphasises the space between people that connects them through relatedness and commonality rather than separating them. Anae (2016) explains it as “...the social and sacred space that separates and yet unites in the context vā tapuia experienced in research relationship." (Anae, 2016, page, 121). This shows that vā allows for knowledge exchange to help construct and reconstruct meanings about information as the space or relatedness between the people evolves. This evolution of this space or relatedness is referred to as teu le vā.

Although relationship is often used as the English translation for the Tongan tauhi vaha'a/ vā, Poltorak (2007) suggests that it be viewed as relatedness, from one subject to another. Poltorak's (2007) study on raising awareness of mental illness in Tonga acknowledges that such topics must be approached with respect for the people's values and beliefs. Poltorak 
(2007) learned how to approach this topic by exploring tauhi vaha'a. This is a value that operates in any context, formal settings such as weddings, birthdays, funerals, and informal settings with friends and family members. It maintains healthy relations.

Teu le vā continues to add depth with the interactions between research and participant. It does this by acknowledging the space between two people, and explains that this must be looked after. The Samoan expression "teu le vā can be translated as cherish, nurse, care for the vā, the relationships" (Wendt, 1999, as cited in Polterak, 2007, p. 13). This emphasises that caring for the vā is a critical part of understanding and using Talanoa for data collection. The methodology goes beyond the surface of building rapport by producing and nurturing reciprocal relationships.

Similarly, the Tongan concept of vaha'a is linked to caring. There are ways that researchers can teu le vā /tauh vaha'a between themselves and participants, such as dialogue (Anae, 2010). This includes the dialogue of the Talanoa. It shows that the researcher values the participant speaking freely about their experience and opinion without interruptions or showing bias towards certain opinions.

\section{Features of Talanoa}

Talanoa does not follow the strict protocols of other forms of data collection (Perrot, 2015). This can have an impact on duration: there is no set time. Talanoa has flexibility for the conversation to be free flowing which is a strength, although this can also be a downfall, and the research should be aware of this (Manueli, 2012). Perrot (2015) states that the researcher should keep in mind the time it will take for transcribing Talanoa if they are hours long.

Talanoa allows participants to take the lead. They may interpret the information differently to what it was intended, and steer into another topic away from the research question (Manueli, 2012). The researcher must be skilled enough to bring the conversation back on topic (Perrot, 2015). Western methods often have a set agenda (Perrot, 2015) but Manueli (2012) showed that ensured that Talanoa can be used to full potential by providing the participants with briefing documents and questions to reflect on beforehand. This allows the participants to focus without restricting their contributions. 


\section{Appropriateness of Talanoa for this research}

As a Pacific young person myself, the relational aspect of Talanoa has advantages because I understand that the relationships are built on trust. Therefore, as the researcher I must facilitate this carefully because the participants are sharing some very personal stories.

Talanoa is used for two main reasons. The topic of the research is trying to understand young Pacific people and their understanding of leadership. Using a qualitative approach and Talanoa methodology promotes storytelling and keeps autonomy in the hands of the participants, allowing for accurate, honest perceptions to come out. Furthermore, because this research is working with Pacific peoples, Talanoa is appropriate because it incorporates appropriate values and beliefs into the methodology. Additionally, as a Pacific researcher, vā is a familiar concept that has been observed and absorbed by me from a young age. This background knowledge is an advantage in Talanoa research to produce quality information.

\section{Methods}

Methods are the tools used when conducting research, for example how data is gathered and understood (Mackenzie \& Knipe, 2006). The chosen method for research often aligns with the methodology framework. The methodology and method should fit for purpose, in this case to understand young Pacific peoples' development and understandings of leadership. When researching with Pacific peoples, a methods needs to be chosen that will fit with the customs, values and beliefs held by this group. This can be done by using cultural protocols, such as language which are recognisable to participants.

\section{Sampling Method}

This section explains the sampling method used in this research for recruiting participants. When sampling for participants in qualitative research it is important to be mindful of sampling method as this influence the data. In qualitative research, sampling is used to provide and reveal aspects of social settings or deeper understanding of complex situations, events, or relationship (Neuman, 2011).

The sampling method I used was purposeful sampling. Purposeful sampling for this study helped determine suitable participants. For the purposes of my study, participants needed to be of Pacific ethnicity and have finished a tertiary qualification or be near completion. They would also be serving in an influential role in the Pacific community, whether it be a teacher or gym 
instructor and so forth. Four of the seven participants were known to me. Connections in Pacific research circles are often facilitated through the established relationships in the community and through these existing relationships I knew that these people had met the participant criteria. The other three participants were selected through snowball sampling (Neuman, 2011; Creswell, 2013).

Having established a sample, I confirmed the suitability of participants. I had met them through education networks that encompassed leadership, education, and Pacific peoples. These included Pacific leadership seminars where I was introduced to mutual friends. To ensure the individuals were suitable for the study, I had conversations about the study and their line of work and/or service. From these conversations, I determined if they were suitable to have talanoa discussions with. I wanted to locate participants aged between 20 to 36 years from a Pacific heritage, who were raised in New Zealand and in a leadership position for Pacific youth. I had this age range in mind because such people were young (or old) enough to have connections and be in touch with young Pacific peoples. These ensured that participants' insight on the research topic was specific and sufficient.

At the end of this process my group of participants were made up of three male and four females, from the Pacific nations of Samoa, Tonga, Tokelau and Fiji. Their tertiary qualifications ranged from Bachelor's degrees, Honours, Graduate diplomas and Master's degrees. Additionally, they all were New Zealand-born and raised and, for convenience, living within the Wellington region during the time of the research.

Creating a relationship with the participants was important because it could help in with the Talanoa as the participants would be familiar with me. The participants and I had already crossed paths. However, the use of referrals and cultural networks was influential in reconnecting and building upon the relationship.

Both sampling methods align with the values of Talanoa because they are both built upon rapport with the participants. For instance, the participants who were chosen by snowball sampling were identified because of the relationship both the participant and I shared with another individual. Building a fast rapport between the participant and myself occurred because we both respected and trusted the person was the connection. The relationships became founded on trust. Talanoa places emphasis on trust because it can determine how in-depth the participant is willing to share with the researcher. Purposive and snowball sampling enabled a 
group to be assembled so that themes could be revealed such as the participants values and beliefs as they affected their views about leadership.

Table 1. Participant Profiles

\begin{tabular}{|l|l|l|l|l|}
\hline $\begin{array}{l}\text { Name } \\
\text { (Pseudonym } \\
\text { provided by } \\
\text { participant) }\end{array}$ & Age range & Ethnicity & $\begin{array}{l}\text { Qualification(s) } \\
\text { completed }\end{array}$ & $\begin{array}{l}\text { Degree } \\
\text { currently } \\
\text { completing }\end{array}$ \\
\hline Hana & $25-35$ & Samoan & BA, Hons, GDip & Not applicable \\
\hline Lisi & $25-35$ & Fijian & BA, Hons & Not applicable \\
\hline Luka & $25-35$ & Samoan & PgDip & Not applicable \\
\hline Maene & $20-25$ & Tongan & Not applicable & BA \\
\hline Manu & $25-35$ & Tokelauan & BCA & Not applicable \\
\hline Eseta & $25-35$ & Tongan & BA, Hons, GDip & MA \\
\hline Maria & $25-35$ & Tongan & BA & Not applicable \\
\hline
\end{tabular}

Table 2. Abbreviations of Degrees

\begin{tabular}{|l|l|}
\hline BA & Bachelor of Arts \\
\hline BCA & Bachelor of Commerce \\
\hline Hons & Honours degree \\
\hline GDip & Graduate Diploma \\
\hline PgDip & Postgraduate Diploma \\
\hline MA & Masters of Arts \\
\hline
\end{tabular}

\section{Data Collection}

Prior to the Talanoa process, participants were sent background information about the study. The information included the purpose and the aim of the study along with the consent form (see APPENDIX C) approved by the Victoria University Research Human Ethics Committee. Additionally, participants were asked to recollect their experiences and memories for this 
research. The participants were provided questions to think about prior to the Talanoa. This was done to help them feel comfortable when the Talanoa took place, helping to create a relaxed process of dialogue for detailed and in-depth responses.

In my first email message to the respondents I expressed: the reason and desire for the study; their contribution they could make; and my commitment as the researcher to them and the research. I asked if they had received all the information about the research, and if there were any questions. A second email to participants was effective in increasing the number of positive responses. Participants were then asked to indicate when they would be available for Talanoa. Of thirteen respondents who were contacted for this research, seven indicated their availability. I sent seven participants three forms about the research process: an information letter about the study; the questions that would be asked; and an informed consent form. Participants were asked to complete and return the consent form by email before the Talanoa proceeded. Following this, the time and location was made to suit the participant. They were asked whether they would like to meet them at their chosen location or have the researcher to set the location. All the participants chose the location for their Talanoa. This allowed the participants to feel comfortable in the environment, such as a community conference lounge that was reserved for a Talanoa. Thus, sharing stories was done in a familiar place and allowed for their stories to follow as if in a day-to-day conversation.

The Talanoa ranged from 30 minutes to an hour and half. I used a list of prompts (see Appendix A) to help guide the Talanoa and keep the Talanoa aligned with the research question. The Talanoa were recorded with participants' permission, and I transcribed to allow for the perspectives of the participants to be examined in depth at a later date (Creswell, 2013). The Talanoa methodology allowed for flexible exchanges of knowledge between the participant and me, enabling clarity and understanding of questions (see Appendix A) and responses.

Prompts were open-ended so participants could freely express, and thoroughly explain their thoughts and experiences about the research topic. In some cases, the participants' replies were rich in content that went broader than the topics of the research question. This indicated to me that they were comfortable with the Talanoa and trusted the conversational process taking place. When this occurred, participants were free to finish talking and then I posed a prompt which refocused participants' trains, of thought.

The questions were well-suited to the research topic was evident because participants were able to respond to them easily. In addition to this I took detailed notes of the Talanoa. With regards 
to the recording of the Talanoa it was important to avoid any chances that background noises being heard. This was helpful when transcribing the Talanoa's: everything was clear which made transcribing easier.

In the transcription process I was able to reflect on the way relationships were at the heart of the Talanoa. For instance, before sharing about their ideas of leadership it was important to find common ground and being able to relate to one another. One way this was done was by talking about recent events related to family or the Pacific, and then relating it to the research topic. This was important to do because leadership is holistic, and being able to make connections between leadership and everyday life is a characteristic that leaders possessed from the literature.

\section{Data Analysis}

In general, data analysis means a search for patterns in data: recurrent behaviours, objects, phases, or ideas. Once a pattern is identified, the researcher needs to interpret it in terms of social theory and/or the setting in which it occurred (Neuman, 2011). This section looks at the coding process that took place in the research. This process revealed the common threads between tall the participants. Creswell, 2013 (2013) explains coding role as:

"to develop a more general picture of data - descriptions and themes; representing the findings through narrative and visuals; making interpretation of the meaning of the results by reflecting personally on the impact of the findings and on the literature, that might inform the findings; and finally, conducting strategies to validate the accuracy of the findings"

A grounded theory approach was used to analysis the collected data. This theory was useful because the focus question is asking about the process of constructing and understanding leadership ideas. By asking the participants such questions it provide insight on how they interpret their understanding of leadership. Grounded theory provides a systematic way to collect, code and analyse the data (Creswell, 2013). Moreover, with the theory being ground in the data, it provides a viable explanation in understanding the findings (Creswell, 2013).

There were three phases of coding. The initial analysis of the Talanoa identified ten common themes. This was followed by open coding. This phase of the coding consisted of transcribing and reading each Talanoa line by line and identifying key words and phrased used to assist in summarising an idea (Creswell, 2013). Additionally, sentences and words with similar 
meanings were grouped together. Words were either underlined, highlighted or circled, such as "that is how I define leadership". This example was categorised as self-reflection.

Axial coding was achieved by arranging the common words and phrases into definitive categories in order to show the process of the narratives (Johnson \& Christensen, 2015). This process enables differentiation between the researcher's bias in analysing information and the message the participant is portraying. This potential gap explains the need to read over the text and analyse multiple times, recognising the relationship between categories and how they contribute to understanding the question (Johnson \& Christen, 2015).

The third phase that took place was selective coding. This involved redefining the categories further and honing down on the essences of each Talanoa in relation to the question. Once four main categories were developed to best represent the main themes in answering the question, these were arranged in an orderly way to portray a storyline that showed how phenomena link to specific results (Creswell, 2013).

\section{Validity}

This section describes validity and the measure taken to ensure the research is as authentic as possible for the participants' voices to be heard. One form of validity is descriptive validity, this refers to accuracy in reporting descriptive information (Johnson \& Christensen, 2012). In qualitative research, because description plays a major role (Johnson \& Christensen, 2012) and the researcher is the key to the data collection process, how research is conducted is central when looking at credibility. To assist validity, transcripts were sent back to participants for checking. The participants then provided feedback which helped to correct the researcher's interpretation. Participants, in effect, offered advice where interpretation could be improved (Johnson \& Christensen, 2012; Richards \& Morse, 2013).

\section{Ethical Considerations}

There were two sets of ethical considerations. The first was the university's ethics. This research involving human subjects required informed consents such as, but not limited to, the voluntary involvement of the subjects and voice recording. During the research this process was managed through completing the required ethical consent processes. The research gained approval from Victoria University of Wellington Human Ethics Committee on the $19^{\text {th }}$ August 2016 (see APPENDIX D). I gained informed consent from all participants and gave them 
enough time to reflect on the research topic through a briefing document so they could make informed choices and ask the researcher for any clarification if necessary.

The second set of ethics was relational. As Pacific research, my conduct as researcher was bound to the relationships between myself and the participants. As a result, I remain committed to them and to the cause of improving understanding and provision of leadership development for Pacific young people. In this ethic, research does not end when the thesis is submitted.

\section{Summary}

This chapter was presented in two parts. The first part described the methodology and theoretical frame works that were used to collect and shape the data that was gathered. This section also described my positions as the researcher and how this contributed to the method and theory that was used. The second part described how participants were selected and the method that was taken for data collection and data analysis. Additionally, the validity of the study was described and ethical considerations presented. The next chapter of this thesis presents the findings from the Talanoa and discusses the key themes. 


\section{CHAPTER 5}

\section{FINDINGS}

\section{Themes}

This chapter discusses the findings to answer the question 'What are young Pacific peoples' understandings of leadership'. This is achieved through a discussion of the data following the three phases of coding described in Chapter Four. Each Talanoa provided a glimpse into participants' lives as well as a small insight into a bigger picture. Common themes in the participants' stories were identified and then then categorised. Four main themes emerged: constructing leadership ideas; challenges for young Pacific leaders; values and beliefs; and mentorship.

In the direct quotes from the participants, names of institutions have been redacted and peoples' names changed to retain confidentiality.

Theme 1: Where do young Pacific people's ideas of leadership come from and what forms do they take?

\section{Pacific socialisation}

Participants identified that their understandings of leadership were constructed by their surroundings as a child, such as through parents and peers or other influences. This understanding of leadership was drawn particularly from how their parents defined leadership. For example, if a parent believed leaders should be loud and stern, their children would believe this as well.

Hana: When I think of myself, you know. I mean, when I was growing up living at home and, you know, I never thought leadership. I never thought that I could be a leader. Leaders are those that are in charge of things they are the boss of a company, you know (p.1)

Here, the idea of them being a leader was foreign to the participant because their surroundings did not nurture leadership potential. As a result, they believed that leadership was for other people, particularly those with authority and power positions. 
Another participant had a similar experience growing up, but with ideas coming from outside the family. They thought that to be a leader they must be in a position of power.

Eseta: I guess tv or um more like the media I guess, thinking of those being names of what a leader means. Usually those people who were in politics or um... Someone who led the country or um... Someone big or known well enough by some people. I never really thought of everyday people making a change or anything (p. 1)

In this instance, the idea of leadership was drawn from the media they consumed. As a result, leaders seemed people in prestigious roles, recognised by society. Therefore, leadership was not for everyone; there appeared to be only one clear path to leadership. In this thinking, some individuals stand out, and this makes them a leader. In this instance, this idea of leadership is exclusive to those who carry positions or titles.

Luka shared a similar experience constructing his leadership beliefs.

Luka: Leadership that I knew was controversial, but for all the wrong reasons... [the] sort of the leadership I grew up with was what I referred to before was the loudest, the scariest. Those who could scare people, those who had authority, that's what I thought was normal (p.2).

If a person was vocal and came to be noticed, it seemed to classify them as a leader because people would listen. This was because listeners were scared, rather than from a desire to listen and learn. This style of leadership is confrontational without good intent. It is focused on striking fear in the hearts of others to gain power perhaps for their own good. However, on reflection this style of leadership was unsettling.

\section{Luka: I never liked it (p.2).}

Although the wider community may accept this style of leadership, it does not represent everyone's thoughts on leadership.

The common denominator amongst the participants' understanding of leadership was that people with authority and power that society recognised were leaders. This emphasised social conditioning and its influence on individuals' ideas about leadership. This type of leadership suggested that they could only be a leader if they shared the same attitudes and behaviours as those they had observed. 


\section{Reconstructing beliefs about leadership}

Although the participants were familiar with the styles of leadership they were given, their personal idea of leadership could change. Change came about because they found the leadership beliefs they had held did not align with who they wanted to become as leaders. However, in the absence of another reference point for leadership, many followed their parents understanding. As the participants matured, they were introduced to different styles of leadership. This encouraged them to reflect and re-evaluate their foundational beliefs of leadership.

Luka: Before I met really good leaders I used to think leaders were like someone who like a manager or someone who had authority (p.2).

The above example illustrates that once the participants were shown a new type of leadership and definition, this made them reflect on what they believed leadership was and reconstructed their idea of leadership. Moreover, they begin to define leadership as related to themselves.

Eseta: I used to think it meant that you had to be someone who did a lot of change and was respected by a lot of people because you had a title that let you become that leader and you are recognisable for it (p.2).

Here, reflection and evaluation had an important role in constructing new leadership ideas and beliefs. The process of critiquing what one has been given to believe against what they chose to believe is evident. When individuals are exposed to new ideas of knowing, this provides space for ideas to be reconstructed.

Eseta: But now, after working with mentors that have taken on this [group] I can kind of. I can see that it means that every day people who want, have a goal, see an issue, and try to change it in a positive way. So that others will follow and on go that same kind of vision as well, so, yeah. My understanding I guess now is that its someone that makes change better (p.2).

Similarly, in this instance, new leadership beliefs could be constructed because the participant encountered different forms of leadership. These encounters led them to think critically. As a result, they concluded that leadership is available to those who desire to be a positive agent of change. Leaders can provide a platform that others can follow. 
Hana: If you...I believe that um... That's what I see as being a leader. When somebody takes a mantel to be of influence, and passionate about doing things about people for their community, for their families (p.1)

This participant's new-found definition of leadership was very self-reflective. They did not see themselves having the ability to be a leader as their character or attitude did not align with their past beliefs. In this case, it was not until Luka met a good leader in his eyes that his mind changed on what a good leader is:

Luka: Before I met really good leaders I used to think leaders were like someone who like a manager or someone who had authority (p. 1).

Also, Eseta's shift in mind demonstrates this, moving from understanding leadership as people with titles and positions, to seeing everyday people being leaders where they are. Developed ideas about leadership styles also included having a desire to serve others as an important leadership trait: a leadership that is not self-centred.

Confronting their own personal ideas of leadership meant that participants had to also evaluate their foundational beliefs of leadership. These ideas moved between what they had been taught and what they had constructed themselves.

\section{Conflicts between ideas of leadership from different sources}

Here the participants share how the leadership that they were nurtured with while growing up had changed.

Eseta: I think the older generation, this is just me assuming. I think they have this. Theirs is more black and white, and it's more obvious to them who leaders are. And to me they're quiet formal, like um, church ministers and stuff, um or like their elders. I think like modern day leaders, we still see them as leaders, but I think we're more opened minded. When we think of what is included as well so probably added onto that (p. 6)

The elders were the ones who passed down cultural beliefs. These beliefs included how they selected leaders because they had a concrete belief about what a leader should look like. Those who were recognised as leaders were usually in position where one would uphold standards of being and knowing. However, with the changing of generations leadership has evolved. Old and new leadership styles can be used together to create leadership that works in different contexts. 
Hana: I see leadership is totally different from probably a lot of older generation like for example my dad, I mean like you know aunties and uncles and in the Samoan background they would still see leadership as hierarchy, the chiefs (p. 3)

Here there is a contrast between the older and younger generations' views on leadership. This emphasises that those who come from more traditional leadership beliefs have a hierarchicalbased approach to leadership. Varying approaches can be seen through demonstrations, such as customs.

Maria: Um, I think, I think the differences would be um, obviously, customs and tradition. Um that there's always a lot of protocol in the way they think and feel and lead things, um our older generation. And there's no ways around it [...]. And it is what it is. Whereas the younger ones have a bit more flexibility to kinda, um I don't know, just be able to be free in the mind (p. 5).

Leadership models they were given, and their reconstructed understanding of leadership were incompatible for participants. It was easier for them to differentiate the barriers they encountered, negotiating between leadership styles by experience. Some of the reasons mentioned were keeping traditions and having a title, such as minister. Yet, their new leadership was more open minded, such as: if you desire to achieve a goal then you should go and pursue it.

The conflicts between the ideas of leadership from different sources, Western and Pacific, can lead to the need for a performative edgewalk (Tupuola, 2006), a contextual cultural negotiation.

\section{Theme 2: What challenges are experienced by young Pacific leaders?}

Reconstructing ideas of leadership can be a challenge young Pacific people face. The challenge includes understanding cultural and traditional beliefs as young Pacific peoples in New Zealand. The common difficulties faced by the participants include living in two worlds, selfdoubt, and having their abilities underestimated. 


\section{What are cultural beliefs and traditions which are challenges to young Pacific leaders?}

Culture was a reoccurring theme with the participants. It led to challenges in their lives. The participants shared in their talanoa that their own Pacific cultural tradition had barriers that held them back from growing as leaders. Some challenges were cultural traditions. These traditions stemmed from the past ways of being which had worked for peoples in the Pacific. However, for the diaspora, these traditions become a challenge because as mentioned the young must learn how to edgewalk successfully.

Challenges are experienced in a dual life. The duality produces judgement from people operating from both Pacific and Western perspectives. Difficulties include trying to uphold cultural traditions place on them by besides their parents.

Hana: Obstacles where I think where young people... I think also, yeah, if you are also in a kinda very traditional up brining, as well. For me as Samoans, you know that saying 'you're always seen, but never heard', you don't have um. You know, not parents. I don't want to bring in parents, but you know our own cultural values. It'll be so hard because you know that you have to um, you know...everybody's up here and you just have to be in the kitchen. (p.12)

The participant viewed traditions as challenges in their leadership journey. These traditions were reinforced mainly by people outside of their immediate family.

Manu: I feel like the biggest challenges are culture. Um especially being in New Zealand. Um, to use him [Tana Umaga] as an example. There was this thing in his book where um, he was saying something, [...] he worked for like four months to save up and um, and all the money went back to his family in Samoa, and then it just sort of kept happening (p. 5).

Stories from well-known New Zealand-born Pacific peoples resonate strongly with the participants because they have shared similar life experiences. Maria's experience is also very similar to Manu's. 
Maria: I think those are the challenges is that people like it's just status and titles that make people feel worthy, sometimes and that--Seems to kinda like, that's a culture that no one's created, but the people themselves you know and I, I sometimes feel guilty of that (p. 7).

Often, it is the position and status that can make people feel worthy to be a leader, rather than going through the necessary process to obtain such influence. This is a belief that people may not be aware they hold. However, it affects young Pacific people and their growth in becoming leaders. As a result, young Pacific people can get caught in this type of thinking. Here, they are navigating two types of cultures, as described by Tupuola (2004). Young Pacific peoples can feel like they are living in two worlds.

\section{Edgewalking}

Tupuola's (2004) study suggests that Pacific peoples' edgewalking can be seen in various ways, such as music. Young Pacific peoples use these forms to create their own identity. This duality produces judgement. This judgment comes from the Pacific and Western world. The Pacific judgement is from those steeped in cultural beliefs. The judgement that comes from the West is from those who judge the dual life. Perhaps as a result of double-criticism, edge walkers can underestimate their ability to be a leader. As a result, they internalise their experience that can result in self-doubt.

\section{Living in two worlds}

New Zealand-born and raised Pacific people can be exposed to different ways of socialising. They can access the Western world and their Pacific world, but participant expressed that at times this duality can be difficult to navigate in terms of knowing what thought or knowledge to use at what time.

Luka: Pacific leaders who have said this is the way we've always done it, so you know...then also mainstream leaders who say, "this is the way it's always been done" (p. 2)

There can be obstacles from both the Pacific world and the Western world. A common theme is the stubbornness to avoid change held by peolpe on both side of the 'edge'. This makes it difficult for the young Pacific person who is trying to navigate between the two worlds successfully. 
Luka: I can't speak on behalf of Pacific islands but I think definitely the challenges we face in New Zealand and I referred to it before we're in between two worlds (p. 8)

The young Pacific people in New Zealand acknowledge that their experience of being a Pacific person is different in comparison to those living in the Pacific homeland. Those living in Western societies experience and have difficulties edgewalking between the Pacific and Western worlds.

Manu: They're not gonna speak out when they want to, um they're not probably gonna be the first ones to put their hands up to do stuff. Cause I'm, I'm at the point where I question everything and why, why we do things a certain way (p. 6).

Here the conflicts between the customs of the West and Pacific can be something difficult to navigate and in the Western world young Pacific people actions can be passive. As Manu expressed, this was something that he also had to overcome.

Manu: Especially being in a country like this, um talking about the fa'alavelave system. Its's that way it just doesn't work anymore in terms of the place we're in now. And I think that's, that's probably where I sort of like things to go. I guess do not necessarily change the culture, but adapt it or adjust it to suit our current environment (p. 5).

The customs and traditions that worked in the Pacific do not always have the same outcome when in New Zealand. Manu suggested that the Pacific culture should be maintained, but this requires its willingness to adapt to new environments and ways of being to help diasporic people live a purposeful life.

\section{Underestimating individual's abilities}

External factors can strongly influence young Pacific peoples. External factors were often referred to as close family, friends and people within the community. Important people were known to the individual, and therefore their opinion was influential. Luka shared in his talanoa this experience:

Luka: I think leadership is always going to be challenging because it can be a bit lonely, even when those who are closest to you, even 
family throw off your ideas [...]. Ideas that possibly others aren't thinking about yet, when they share them with your closest people they might, “mmm that's not going to happen or there's no need for it" (p. 2)

As the individual is transitioning into leadership, they may experience times of loneliness. Emotions may arise because those around them cannot relate to their experiences. This can be very discouraging for the young Pacific person, especially when it is those closest to them who dismiss their ideas.

Eseta: You know how some people are quite resistant to change because they don't get it. Um I think one of the biggest challenges is creating that awareness for people that are so caught in what they've always believed. Like the biggest, you know, the majority way of thinking, or the Western way of thinking is so engrained in so many people, it even, even Pacific, even Maori, their minds kind of tell like, this is just how it is (p. 4-5).

Here, the participant acknowledges that usually others may not change with you. This suggests that because others do not understand, they can be reluctant to change. Therefore, it can make it difficult for Pacific young person to make positive progress when others continue to abide by old traditions, sometimes subconsciously.

Maria: Like sometimes you just underestimate people and think oh yeah they don't say much, but you can actually give them a task and like, have faith in them. Then it will, they will deliver because they feel privileged, "oh cool, this is my responsibility and I'm gonna embrace it". Yeah, sometimes we don't really give them that opportunity to do that and we hold that, but it's up to [them] (p. 7).

Maria's example shows how she underestimated others' abilities to be leaders. She found herself guilty of comparing one persons's leadership abilities to another, agreeing that the leader needs to have faith in those they are leading.

The participants identified that external factors were barriers, such as opinions from people and communities they were familiar with. Examples included Luka's family, and people in Maria 
and Eseta's communities. The participants expressed that these people were "resistant change" or saw "no use for it", as Luka and Eseta expressed. These external influences can impact an individual's thoughts about their capability to lead, planting self-doubt.

\section{Self-doubt}

Internal beliefs were identified as a challenge for young Pacific leaders to overcome. The internal belief identified was self-doubt. Participants thought they were not good enough, that they had to accomplish something great or have a noteworthy success to consider themselves as a leader.

Maene: Yeah, they did, eh. And self-doubt was for sure the main obstacle for me and I think it's common for everyone if you're Pacific or not but for our people it's something that can like really hold us back. So, like for me to have those friends who support me and believe in me, it kind of took my worries away. Yeah, so having a good network around you is important! (p. 4)

Here, self-doubt is seen as a widespread and universal problem. However, the solution is a strong social group for support. This group can be a peer group which provides emotional support. In this instance, that support has been experienced as belief. An effect of self-doubt is that people automatically disqualify themselves for leadership roles, as Luka mentioned in his talanoa.

Luka: I think we're always disqualifying ourselves. Whether it's leadership or even just going for a promotion at work [...] because we don't think we're good enough (p.11)

A shared experience is self-disqualification. Since individuals experience self-doubt, they do not think they are worthy for leadership positions, and they can continually disqualify themselves. A reason for this may be constant comparison to others, and to their standards. Therefore, young Pacific people sometimes do not see themselves as worthy. This can crossover to other areas of life, such as work. Eseta's example demonstrates this type of thinking.

Eseta: Like people are already pressured with time as it is and we have to juggle a lot. So, I guess taking on leadership roles, requires a lot of commitment and time but if you're pushed for time, 
resources and money. I think maybe idea of leadership can put people off or scare them [...]. Yeah, when it doesn't have to be, but guess that idea or that stigma is already out there (p. 5-6)

Self-doubt is a significant barrier making participants reluctant to put themselves forward for leadership roles. Internal factors can strongly influence the mind-set as Maene said "self-doubt was for sure the main obstacle for me and I think it's common for everyone if you're Pacific" (p. p. 5-6).

Eseta claimed that one reason for reluctance to lead was the stigma and responsibility that individuals associate with leadership, and the effects of comparing themselves to this. Even positional leadership can be affected by self-doubt.

Hana: Like I was leading Sunday school or youth group stuff or you they're working or even things like that where they. You know, some mature students supervise. They supervise their work places sometimes they don't realise that they have these leadership qualities (p. 12)

Here, Hana emphasises that she was in a leadership role in the community where people were looking to her. Yet what held her and others back was self-doubt. They did not view their position as significant, "sometimes they don't realise that they have these leadership qualities". This relates back to Luka and Eseta's experiences; self-doubt was a barrier for them in becoming a leader. By knowing the leadership, they did not want, the participants were able to identify values a good leader had.

\section{Theme 3: What forms of leadership are valued by young Pacific leaders?}

Life experience had an important part to play in how the participants identified desirable leadership. The participants imitated certain traits because they wanted to reproduce good leadership. Here, the participants share how there were people in their lives who demonstrated holistic leadership. They could pick out the characteristics that made a person a good leader. Following this, the participants shared their understanding of the uniqueness of Pacific leadership. 


\section{Holistic demonstrations}

\section{Parents as leaders}

Among the participants there was a common theme in relation to leadership aspirations. Many of the participants explained that their first role model or representation of a leader was a family member, such as their mum or dad. Their parents had the leadership qualities to lead them as a child.

Hana: When I think of Pacific leaders in the community or people in my family, I think, I would say my Dad because you know everything was all about education. Our family, we had a pretty rough upbringing, but um at the same time seeing my father and how he would lead in his family, in our gatherings. [...]. When you think, you want to be like somebody you know, I would always say I want to be like my Dad. Um, and his traits of honestly and his work ethic (p.2)

Hana describes how the set of values and beliefs her father held for their family was something she admired. Although there was a lack of resources growing up, this did not disqualify the participants from becoming leaders, nor did it make them think less of themselves. These demonstrations of leadership were aspired to by Hana in private and public settings. It was more than her father as a person she aspired to be like. Her aspiration included gaining the traits of a good leader. Maria also drew her holistic demonstration as a leader from her family.

Lisi: If I look back on my own journey, it'd be my grandad. It's people actually in my family [...]. Um, my grandad since I was brought up by my grandparents. From a village with my pa, my mum was the oldest of nine so I was brought up with them and so my grandad was the leader of the family there, and then when I came to New Zealand to join my mum, it was my mum (p. 1-2).

Additionally, when the participants reflect who were leaders in their eyes, it was everyday people, like their parents and grandparents. As in Hana's experience, the demonstration of leadership in their day-to-day lives influenced the participants' understandings of leadership.

As the participants witnessed good leadership first-hand, they hoped they would be similar. Manu's example shares a similar experience of his mother: 
Manu: I think the biggest one right from the start would obviously had to be my mum. Um just guess she sort of just defied everything, sort of, a woman, well not only a woman but a Pacific Island woman. That she defied all those odds, you know [...]. She was the breadwinner you know you want something you'd expect the male to be the breadwinner. You know she was the breadwinner, the cleaner, the cook. She was the mum, and the dad, so, I guess she showed us. Oh she showed me the work ethic, what you need to do. (p. 2)

The participants witnessed first-hand the sacrifices that their family members made for them to live a good life. Parents and other family members had a significant role in participants' lives and in how they viewed leadership. It was very interesting to see participants relay the reasons why they remembered the specific moments that made them appreciate a particular person. Generally it was because that individual had a direct influential impact on their life.

Marie suggested that leadership begins at home with the family.

Maria: Yeah, there's been a number of um different people in my life that are really great leaders. Um, obviously it would start from homle, like my, my parents' um have been awesome [...]. People may not know but I do rely a lot of, on my parents to take the lead for me (p.1).

Moreover, the reason why the participants chose certain leaders as roles models is because they demonstrated what good leadership is to them. The participants expressed this by isolating specific traits that these leaders had.

\section{Characteristics of leaders}

Once participants said who they viewed as good leaders, they explained why. Participants identified the characteristics they believe a good leader should have, and which were demonstrated by leaders they admired.

Hana: Somebody that has those characteristics, work-ethic, integrity um honestly, servant heart, you know? No one that's sort of like um thinks that they've above everybody else. Um I think also yeah that's number one. Being able to be of influence and being able 
to do those that are influenced that you know seeing the mindset change and it's like a cycle (p.4)

Hana identified servant leadership as an important characteristic for a good leader to have because such leaders do not think they are better than their peers. This was also an important characteristic for the other participants.

Manu: I guess push them to work or be the best that they can be and obviously, everyone's working um. If you've got a leader who can get the best out of everyone then, I guess, and push everyone to achieve all the same goal, and the same purpose then that's sort of what a good leader does I guess (p. 1)

Another characteristic of a good leader is seeing the potential others have to become a leader. The leader recognises others' potential and helps them to reach it. Moreover, they can also inspire and motivate a team to reach their full potential to achieve their shared cooperative goal.

Luka: So, people that advocate for others and make things happen in terms of causes. Not about themselves, not in it for themselves, not about the pay check, not about the power but just really about doing the work (p.5)

Luka explains that a characteristic of a good leader is someone who cares strongly about others. This characteristic drives the leader to help those less fortunate than themselves by providing their service without incentives, because they are more focused on improving the circumstances of others. Eseta also highlighted that leaders work for the people to create the change they want to see. Hana agreed: good leaders work to positively influence others. The evidence suggests that young Pacific people think that good leaders believe in others and have a desire to produce change.

\section{The uniqueness of Pacific leadership}

Data from the talanoa with the participants shows that there were important attributes that Pacific leaders had. These were rooted in strong cultural values and beliefs that were demonstrated through their actions. A common value amongst the participants was respect.

Manu: And I, I guess a lot of Pacific islanders are very respectful. Respect all cultures, respect the people, I think [they are] natural leaders (p. 3). 
One way they demonstrate respect is by appreciating other peoples' cultural values. Pacific people understand themselves and are open to respecting new ways of knowing. This suggest that one of the positive traits of Pacific leaders is their willingness. Luka agreed with this and added:

Luka: I also think the other thing [strength] not everyone does it, but I think a value in our culture is humility. Our fa'amaualalo, you know, like and I think those are really good qualities, cause like I think if you don't have those people get angry at you... you just think you're amazing and you're not (p.4)

This illustrates how participants reflected on the leadership they saw and were able to distinguish what made these Pacific leaders different from others they had encountered. As participants stated, they could adapt to different contexts but still desired to remain strong in their identity as a Pacific person.

Maene: Strengths... I think culture. Like Pacific leaders are taught a lot of good cultural customs. For example, like being cautious of what others think and others around us. Pacific leaders are the ones who always look out for others, you know. And like you can see it with Pacific leaders in the community are always doing stuff to help our people (p. 2).

The protocols, values, and unspoken rules of Pacific cultures which are passed down are what make Pacific leaders unique in a Western context. This could be because of the nature of Pacific peoples to care for others, rather than being individualistic. This leadership can be seen in communities with large Pacific populations.

Hana: I think too, the strength that Pacific people have is um, communication the ability to be able to engage, the ability to be able to communicate at all levels. You know, like umm, but engage and communicate in an influential way, in a way that ... it encourages people's hearts (p.6)

As a result of being socialised in Pacific culture and learning how to teu le vā between different groups of people, young Pacific people can develop the ability to relate to others. Additionally, 
because they can relate to various people from different walks of life they can provide advice to others.

There are two main strengths claimed for Pacific leadership: respect and humility. Pacific leaders respect others and are cautious of their thoughts and feelings of those around them. The second strength that Pacific people have is humility. They are humble in their actions and this provides them with the ability to relate and communicate with others.

\section{Theme 4: How do young Pacific people become leaders?}

There are different ways that people can become leaders, and in the talanoa the participants identified four main features: being identified; being given leadership opportunities; enacting leadership; and mentoring for leadership.

\section{Being identified}

Others viewed the participant as a leader before they did through leadership potential. The people who recognised the participant as a leader included, friends, family and role models. The main point from this subtheme was the belief held by another helped the participant build self-belief as a leader.

Maene: Like on my team, I wasn't sure I could be the leader, but like my friends just kept encouraging me to go for it and that I could do it, so I did eh. And like now I am kind of willing to put myself out there first and believe in myself more (p. 4).

This suggests that others who could see his potential as a leader were an essential part in Maene's leadership journey. Although individuals may doubt themselves, an encouraging support group can make a difference. As a result of encouragement, Maene's self-confidence increased. He now willingly puts himself forward for leadership opportunities.

Hana: that ability to speak into somebody's life, umm, you know. Speak into their lives, which means for me speaking into their hearts, talking to that person, understanding that person. Coming down to that level and from there it's up to that other person (p. 9).

Here, words of encouragement also played a big part in participants deciding to become a leader. It is important for leaders to encourage others, but they must also understand the encouraged individual by being able to relate to them. Hana goes on to make an important point 
that it is the choice of the individual if they want to take the steps to becoming a leader. The ideal outcome would be that the individual would be encouraged and then try and do so.

Mentors were significant for the participant finding their leadership abilities and without them, the participants may have not accomplished what they did. As Maene's said in his experience, because his friends encouraged him to lead he became open and "willing to put myself out there first and believe in myself more". Hana added that these people were also vital in her journey and those she wants to be around.

\section{By being given opportunities}

The leadership opportunities for the participants came in various arenas because of their different life experiences. The participants spoke about roles they did not realise were preparing them for leadership. These roles included church opportunities, such as youth group leader.

Luka: And I think when I grew up, like when I, I'm really generalising but when I look at my palagi friends that I grew up with. I was really comfortable speaking from the front and stuff like that cause I actually had to at church. We always had a platform to actually share our opinions and you know, even little things. Being in a play at church. Singing even though my voice was really stink, and talking because there was a safe environment $(p .1-3)$

Generally speaking, growing up in church encouraged young Pacific people to take the lead, such as public speaking. As Luka reflected on his experience, he was able to see that what he thought was normal for other people was not actually common, such as public speaking. The difference between Luka and his friends was the chance to develop these skills. Additionally, a stable church environment helped encourage and nurture these skills.

Hana: I wanted to get involved with young adults and I started helping out in Sunday school, so those were the things that were like my small little steps to umm when I think about leadership, to um when I started leading (p.6).

Similarly, Hana found safety in the church environment a good place to practice her leadership skills. In her view, having a safe space to practice and grow one's leadership skills means leadership can cross over into other areas. 
Maria: Uh I've always been asked to take the lead or um you know speak on behalf of my mates when we go to gatherings and that sort of thing. And even just coming up through, you know, got leadership roles from church um, through school and obviously here at the university, um ...in the student community (p. 15)

Maria reiterates Luka and Hana's experiences. Her confidence as a public speaker and leader was made possible because she had opportunities.

Leadership opportunities for young Pacific people were available through community groups such as church youth groups and Sunday school. Participants stated that people would put them forward to represent their group and speak, and from there they felt they were naturally taking up leadership role.

\section{By enacting leadership}

As a result of being nominated for leadership roles the participant's mind-set about leadership began to shift. This shift was the realisation that leaders led by example. Lisi talks about her experience of realising that being a leader to others you must first lead yourself well.

Lisi: Lead yourself to whatever you are wanting to achieve first. So, it's yourself first that you need to lead before you become, um anything above and--- of everyone else. So, three truths about leadership is: yeah be true to yourself and lead yourself out and to whatever you want to achieve first [...]; and two is you don't really have to look far as to who is a good leader; and three would be to find for yourself your definition of leadership (p. 21).

Leading yourself and achieving your goals can qualify you to lead others because you have led by example. Having a personal definition of leadership is important to working towards that goal.

Maria: Everyone is, everyone's got leadership in them, it doesn't mean to say that, ok I'm president of this um, this organisation and all. I am the secretary for this particular group, I'm that, like everyone seems to think about that a lot. But it's like mate, if you like just doing assignments, turning up to classes, you may not be involved in all these different extra-curricular activities on 
campus or off campus, but if you're rocking up to your classes, contributing to classroom discussions, being a good student, you know obeying your parents, honouring that, that is like, that's gold you know. If they could do more, cool, but that's like, it's basics aye (p. 9).

When Maria was a tertiary student she realised that turning up to every class is a sign of personal leadership. She understands that it is the simple and basic things that makes one a leader, not a title or position. Again, leading oneself and then using what has been learned to mentor others can produce positive results.

\section{Mentoring for leadership}

Once the participants realised that they must first lead themselves well before they can lead others they began to actively mentor others for leadership. The participants understood that mentoring others was a form of giving back, especially if they had others who had invested in them.

Hana: You know, are we needing to reposition ourselves and how are we going to instil, you like we were saying encourage the heart of this young generation from now. Um, to think different about leadership, to be able to become um agents of change, world changers. Like um influential, um in what they do and in the lives of people that come their way so that it's like that um... what is it... domino effect (p. 24)

Eseta: Yeah. It's like this pay it forward kind of thing. They'll mentor me and then they'll make me see, I mean, they don't make me see it but [like] I'll want to pay it forward to my students. Then it's like building this bigger leadership (p. 4)

Mentoring others for leadership implies realising that anyone can be a leader. This involves caring for people and helping in their area of need so they become the leader they could be. 


\section{Summary}

This chapter revealed the lived experiences of the participants, and showed how their understanding of leadership was informed, influenced, and reconstructed. The chapter that follows is an analysis and discussion of the research findings. 


\section{CHAPTER 6}

\section{DISCUSSION}

The aim of my research was to answer the question 'What are young Pacific peoples' understandings of leadership'. In order to understand how the participants gained understanding of leadership I used phenomenology approach and talanoa methodology. These were appropriate because appreciative inquiry has a future orientation and talanoa can be seen as a methodological approach which matches Pacific concerns for relationships.

As explained in the last chapter, I established four main themes from the data: where young Pacific peoples' ideas of leadership come from; what challenges face young Pacific peoples; forms of leadership valued by young Pacific peoples; and how young Pacific leaders become leaders. These themes will now be unpacked to present an answer to the question at the core of this study. This answer deals with: the historical roots of young Pacific peoples' ideas about leadership; the environment in which these ideas are developed; the qualities which young Pacific peoples see as the leadership; and the negotiated nature of leadership to young Pacific peoples.

After a presentation of an analysis of the findings from the talanoa, the discussion will then turn to how elements underlying these findings operate in tension in the diasporic setting of New Zealand. Various styles and understandings of leadership from different contexts will be investigated to produce recommendations on how to empower young Pacific people in leadership. The value of this is to influence educational growth for Pacific people through leadership opportunities and training.

\section{Cultural influence}

Pacific young peoples' ideas about leadership are informed by two traditions of leadership from different historical roots: the Pacific and the West. Each will be discussed in turn.

Views of leadership which have their roots in the Pacific and have been passed down in the diaspora are understood by Pacific young people particularly through the Pacific role models. In effect, this means that young Pacific people learn by experience what leadership is. For example, some young people saw leadership to be hierarchical and authoritative because that 
is how members of their community operated. Learning to lead by experience was a vital part in participants' leadership development. They learned different skills for leadership in the Pacific context when compared to the Western context. This was because the leadership ideas present in each were informed by different sources.

\section{Pacific influence}

Learning to lead by experience in the Pacific context for the participants was informed by church and home life. The participants shared that from a young age they were expected to know how to perform certain duties, such as serving guests who came to visit their parents at home with cups of tea. They were taught to perform these duties by watching others in their families such as their older siblings. By observing from a young age they were slowly integrated into doing the tasks themselves. The participants explained that this was their training ground for leadership. It was the leadership responsibility of the older siblings to teach those younger than them the correct way of doing things.

However, the learning experiences were not always positive for the participants. The style of leadership that the participants expressed that they learned was also hierarchical and authoritative with a strong emphasis on status and position. These ideas of leadership also placed an emphasis on masculine ideas of leadership (Taylor, 2008). As a result of their place in the hierarchy as Pacific young people, the participants did not believe that they could become leaders because they did not possess the skills, titles or position that they thought a leader should possess. For example, Luka expressed "I grew up with was what I referred to before was the loudest, the scariest [leader]. Those who had authority, that's what I thought was normal". The general understanding shared by participants was that people with authority and power in society were recognised as leaders. This emphasises social conditioning and its influence on individuals' ideas about leadership. It suggested to participants that this style of leadership is socially acceptable, and something to aspire to if one were to pursue leadership. Through this kind of experience, Pacific young pole learned that leadership is only allocated to a certain few who are appointed. This belief aligns with the discussion about Pacific cultures being strongly rooted in hierarchical systems, such as the chiefly system, big men system or monarchy (see Chapter 2) It also shows some similarities to some forms of leadership in the Western context (Sahlins, 1958; Goldman, 1970; Taylor, 2008). 


\section{Western influence}

Leaning to lead by experience in the Western context for the participants took place in school. This was because the school foundations are Western and schools are hierarchical. The participants expressed how leadership in institutions such as school had to be earned. For example, a leader had to have been the best at a subject. Leadership was also presented as an exclusive opportunity where only those who could reach the expectations placed on them by others were considered leaders. These leadership ideas can be linked back to foundational beliefs from Greek philosophers, such as Plato and Aristotle as discussed in Chapter Two.The extremes of Plato's leadership thinking, that only a small group who were gifted to lead, or Aristotle's view that focused on class and birth right, are not prominent today (Cawthon, 2002; Evans, 2010). However, traces of these foundational beliefs can still be seen in Western societies (Batmanglich, 2015).From their experiences in Western contexts it seems that young Pacific peoples have developed a sense of these ideas. For example, participants understood that leadership in school was reward-based and with a strong sense of hierarchy justifying it..

Looking at these two contexts, it is clear that young Pacific people's ideas of leadership have historical roots in the Pacific and from the West, and that for people who live across these spaces, a negotiation between beliefs is required.

\section{Environmental contexts where young Pacific peoples' ideas about leadership develop}

From the birth of a child until the end of a human life cycle, external influences will always be present, positive, and negative (Eggen \& Kauchak, 2010). My research places emphasis on certain environments being significant places for learning about ideas of leadership from two historical roots. An environment in this context is about how leadership ideas are formed and understood. The environment that one is exposed to has a large impact on the way one thinks and acts, as suggested above. How individuals choose to accept, discard, and understand ideas from these external sources is to do with how they how have understood leadership in the past by seeing it happen in others' lives (Eggen \& Kauchak, 2010).

Pacific ideas are important to young Pacific people but in every diasporic setting, migrants' historical understandings are open to change because of new influences from the current setting. In terms of my research, this setting is New Zealand, a bi-cultural country where ideas of European origin predominate for reasons of power. The participants saw how different 
leadership styles were demonstrated depending on the contexts they were in. The main environments where the participants saw leadership demonstrated were the home, church, and school environments. The participants generally understood leadership at home and church to be Pacific, and school to be Western.

\section{Home life}

Home life, which consists of the family unit, has an important role in young peoples' lives (Tupuola, 2004). For example, values and beliefs will often be informed from home where young people are taught the difference between good and bad. However, how these ideas are passed down to people is important; it will differ with countries, cultures, and families. Generally, the data suggested that Pacific families in New Zealand share many common traits in how they pass on their knowledge and understandings to their children and grandchildren. For example, the home and church were places where Pacific young people observed and imitated beliefs and values, in comparison to the New Zealand Europeans who may learn in the family more than elsewhere.

One way that participants understood leadership was by adopting their parents' understandings of leadership. The findings show that family relationships strongly influence young Pacific peoples' beliefs about leadership. The family home is where key intergenerational relationships are enacted. The participants explained how they understood leadership from a young age. Parents' understandings of leadership were passed down from their own parents, and were informed by their cultural values and beliefs (Pene, 2009). Beliefs passed down by parents and extended family involved demonstrating or approving other's demonstrations of cultural values and beliefs. Hana shared that learning these values was not always easy, "you know our own cultural values. It'll be so hard because you know that you have to um, you know...everybody's up here and you just have to be in the kitchen". Although there were some difficulties, as she began to grow into a leader herself Hana understood that there are processes to transfer knowledge and understanding to the next generation.

The choice making processes the participants' parents demonstrated in relationships as leaders affected young Pacific people in significant ways. Manu's mother was a positive example of this. Manu saw his mother work hard as a single mother, moving to a foreign land while not knowing the language so her children could have more opportunities. Seeing this instilled a good work ethic and courage for Manu, to the extent that he believed he could achieve the goals he put his mind to. This is evidence that a parent is a child's first leader (Morton, et al., 
2012). How the parents ran their household, and treated others demonstrated to their child how their behaviour should be (Santrock, 2011). The way parents ran their relationships also had an instrumental role in their child's life, which influenced their child's view of leadership.

Among the participants there was a common theme in relation to leadership aspirations: Within various environments, relationships are a source of ideas about leadership. Leadership starting from home was a major theme with the participants. Upon reflection many of the participants said the first example and source of leadership they could recall was a close relative who was not a parent, such as an aunt or parent. Additionally, participants expressed that leaders in their eyes were everyday people they were related to, extending intergenerationaly to grandparents. This thinking aligns with Raivoka (2012) who expressed that part of leadership is, "inspirational moments experienced with and shared by ordinary peoples" (Raivoka, 2012, p.70). This suggests that leadership does not require titles or recognition of positions, rather, it is individuals choosing to make a change in each other's lives. It makes sense that this happens in close relationships. The influence of the relationship between parent and children has been discussed elsewhere. Maria's parents also played an important role in her life, being her roles models and she stated her first example of leadership came from the household, "it would start from home, like my parents" (p. 6). For instance, the importance of leadership being understood through the family models can be seen in Morton, Wilson, Perlmutter, and Beauchamp (2012), where parental roles influence their children's attitudes. If parents display dissatisfaction towards a situation, the children will imitate their parent's attitude.

Influential relationships need not be limited to parents-child contexts. As shown in Pene's (2009) study, young Tokelauan people learn values and beliefs not only from their parents but their extended family. For example, grandparents can have a big influence where they believe it is their responsibility to do so. In Pene's study they did this by having evening prayers or attending church with the young (Pene, 2009, p. 12). Wells (2011) says that leadership that inspires others come from influential leaders - those who are consistent with their actions in private and public. This is what the parents of Pacific young people in this study displayed to their children, and this was one aspect that the young Pacific peoples hoped to replicate. The home is private, but the young Pacific peoples also see their parents in public such as in church.

\section{Church}

For Pacific people, the church was another environment where Pacific origin values and beliefs were passed on. The church plays the role of a community hub, cultural revitalisation centre, 
religious nourishment, and a site of general social interactions (Hunkin, 2012). Moreover, going to church for Pacific families in New Zealand involves everyone, parents, and their children (Suaalii-Sauni, Samu, Dunbar, Pulford, \& Wheeler, 2012).

What makes this uniquely Pacific is that the church (the congregation and minister) and strongly integrated Pacific culture. The church can be very influential on families in that sense that opinions and decisions about families are taken very personally. In fact, religion acts as a space of intersection of family and church. Parents set high expectations for children to do well (Okagaki, 2001). This expectation weighs heavily on the shoulders of the children, particularly if one's parents have leadership roles within the church (Muaiava, 2015). This type of expectation can either work for or against the individual. Studies have shown culture and religion are closely linked together (Bodley, 2011; Donner, 2007), and it is important to note that many of the participants who spoke about church attended homogenous cultural churches, for example an all Cook Island congregation.

The church instils values in Pacific young people, which the community hope they will abide by. This was evident in Suaalii-Sauni, Samu, Dunbar, Pulford, and Wheeler (2012)'s research about young Pacific peoples' consumptions of alcohol. Participants in that study explained that their community environments, including the church, had a large influence on their alcohol consumption. For example, the young were conscious of how much alcohol they would drink because it was not acceptable to the church to be drunk. Some of the participants chose not to drink at all because of the church values they had learned. This suggests that the church influence is very powerful, especially for the young peoples who are still constructing their understandings of the world, and provides a Pacific framework for behaviour and Pacific ideas of leadership behaviour despite western influences.

Hana's first role model of good Pacific leadership was her father. She shared that her father, a church minister, could lead his church congregation and his family well. This was because she observed that her father demonstrated that his leadership in public was consistent with his leadership at home; he was the same person no matter the context. Her father displayed leadership attributes that Hana admired.

The church acted as a positive influence for Luka, and Eseta but when it came to leadership, the church was a site of a hierarchical and award based system which restricted the kinds of leadership ideas available. For Eseta, the church environment which was strongly Pacific peoples focused had a certain view on leadership, "theirs is more black and white, and it's 
more obvious to them who leaders are. And to me they're quiet formal, like um, church ministers and stuff, um or like their elders". This style of leadership expects individual leaders to have a title and status whether it be a chiefly title or as a deacon within the church. Behaviour in church made clear that this was the way to be recognised as a leader. This was a barrier for the participants because they could not view themselves as leader at their stage of life. The idea of being a leader appeared too large, and in the eyes of the participants they did not possess the traits of a leader.

The home and church were where demonstrations of leadership from a Pacific view took place. Outside of these environments, leadership beliefs differed.

\section{School}

The school environment was a place where leadership understanding was formed in the western tradition. The leadership style that was shown at school to the participants was managerial and authoritative. The participants gave examples from their schooling experiences and discussed how it influenced their leadership beliefs. Eseta understood that school students were rewarded for participating in out of class activities with leadership opportunities and titles which implied that they were special, different from others. She understood that only a handful of students are chosen to be leaders. This was not helpful in terms of Esta's leadership development because it subconsciously repeated the idea that leadership is only reserved for a few, and unless one can obtain such a reward one must keep trying. This style of leadership is transactional: you have to do something in order to earn the right to lead (Zagorsek, et al., 2009).

\section{Environment as a factor in Young Pacific Peoples development}

As a result of living in a variety of environments, external factors, that is socially-generated influences, were used by young Pacific peoples to grasp an understanding of leadership. If they chose to adjust the beliefs about leadership gained from one source or another, social factors also influenced this. Analysing the participant's personal experience produced the following factors of influence: tradition, life experience, leadership, and leadership development.

The environments that young people are exposed to provide different models of leadership which can have positive and negative effects on how young Pacific people view leadership. However, an individual's perception of leadership can change over time as they grow and experience less restrictive environments. The first environment participants experienced is 
their childhood influences. Here, external influence was out of their control. They could not pick or choose relationships or places to live at a young age. Many of the participants spoke about their experience growing up, and expressed that there were good and bad aspects to these environments. As they began to explore and develop their own personal leadership they became more decisive about the leader they wanted to become. As a child, one's mind is being moulded subconsciously by the environment one is exposed too. This involves both positive and negative experiences (Ormond, 2008). Participants found this to be true about their leadership beliefs: where they were raised and how they were raised moulded their ideas about leadership.

The participants felt they were not prepared to be a leader at a young age because of the leadership beliefs they held. These beliefs were strongly influenced by traditional cultural ideas of leadership. However, later in their lives, other external factors can have a strong impact on young people. Peers and community start to become more important (Spano, 2003). That is, as one grows, wider environments and more individuals can have a significant influence. This was true for young Pacific people's development in terms of thinking and philosophies (Santrock, 2011; Ormond, 2008; Anae, et al., 2001).

However, whatever the influence, many of the participants maintained for an extended period the belief that they could not be a leader because they did not have a title, status or position. Rethinking this was one of the toughest barriers for participants to overcome, and one that they all faced. Hana shared how the environment at home did not offer leadership development opportunities. The only forms of leadership at home that was understood as valid leadership was that of individuals in positions of power. Although young Pacific people understood leadership to be like this, it did not encourage or nurture skills to become a leader. In contrast, some empowering environments were encountered not only giving a change to demonstrate aspiring leadership characteristics, but also helping develop young Pacific peoples' leadership potential.

\section{Additional environments}

In addition to school and the home, individual young Pacific people also receive positive input from other individuals. For example, Maene emphasised that having caring people around to support and encourage is important, "like on my [work] team, I wasn't sure I could be the leader, but like my friends just kept encouraging me to go for it and that I could do it, so I did eh". Support networks can be mentors, peers and family. Hana added that having others who can "encourage the heart", especially when self-doubt continues to creep in, was crucial in her 
journey. Therefore, being around others and having a support network for young people can make the difference between going forth and enacting leadership or not. The participants shared that their leadership ideas changed as a result of others believing in them.

Others who believe in their abilities can strongly influence the actions of young Pacific people. This was evident where the participants chose to listen to the positive affirmations from peers to be a leader, rather than negative ideas from other sources (Mullen, Robertson and Ebrary, 2014; Azmitia and Cooper, 2011; Molix and Bettencourt, 2010). The participants who were exposed to positive environments that allowed them to grow their leadership qualities sought for more environments like this. Moreover, they began to differentiate between environments. The difference for the participants was that one kind of environment struck fear and into the hearts of followers with ideas about title, position and status. The other type was about cultivating any individual and empowering them to become a leader in the area they in which wish to succeed. Therefore, being surrounded by others who can speak positive words can have a big impact on the way leadership is perceived.

As Morton, et al., (2012) found, young people who have a strong, positive support system in their lives can have positive outcomes compared to those who do not. Additionally, the more positive input given, the more young people want to give to others (Austine, 2003). The environment as an external factor has a vital role for shaping leadership beliefs and behaviours which illustrates that ideas of leadership are alterable.

\section{Leadership qualities}

The findings show that participants clearly identified the leadership qualities and characteristics they believed a good leader possessed. There were two main qualities: vision and service.

\section{Vision}

One trait of a good leader is a vision for the people. Luka explained that visions bring a different perspective and helps people to see things from another angle. Sanga (2005) says that "leadership vision is about the future and what they aspire for and how they might make it happen" (p.5). This suggests that the vision leaders possess should inspire people to go further than they could have imagined for themselves, provide overall improvement for people. Vision and good leadership come together when individuals see a situation or challenge in the present moment and have a vision to improve these circumstances for the betterment of the people involved. A visionary individual, who often becomes the leader of the movement, has no 
ulterior motives (such as self-promotion) when pursing their vision. This kind of leadership motivates the group to reach a shared vision, by bringing out the best traits in everyone. This is why the participants identified vision as a necessary characteristic for good leadership.

Participants also spoke about vision being imparted in them by others. A vision is an ongoing process and everyone has a role in completing the group vision and their own life vision. Luka expressed that good leaders have a vision that will bring about life changing results. Sometimes others will not see the vision but a visionary must have faith that following it is the right thing to do, and continue on. Maene's view about leaders and vision is very similar to Luka's. Maene said that now that when he recognised what good leadership is, he understood that vision has a significant role in it.

A vision is like a goal: it is shared amongst the group of people and they all work together towards it to achieve it. An example that Lisi gave was her mother moving to New Zealand because she envisioned a better life for her family. This kind or leadership has influenced the generations in New Zealand, providing them the possibilities to experience a new way of living and new opportunities they may not have had otherwise. Vision can be closely related to service, a second desirable leadership quality.

\section{Service}

In the findings, the participants expressed that service to others was a quality they cherished in the leaders they looked up to. The participants shared that service is one of the greatest forms of leadership because it is selfless. Samala (2009), who wrote about the leader as a servant or providing a service, explains it as follows:

Their actions reflect leaders who are servants. Genuine leadership is providing true service to others. It is leading without expecting anything in return; being motivated to show concern, to demonstrate care and to strive for excellence (Samala, 2009, p.

Serving others to the best of ones' ability not only shows care but also that life is about living beyond us. The participants saw how unique service is in relation to Pacific peoples and culture. The participants explained how they had seen those in their life who serve others, and that their leadership was so inspiring that it caused people to follow in the individual's footsteps. Barnes' (2015) study about servant leadership in higher education explained that the main principle in this kind of leadership is to "first serve others" (Barnes, 2015, p. 246). Barnes continues by 
suggesting that one does not need to be self-promoting because other will see your work and as a result will see you as a leader.

The findings from the participants resonated strongly with this style of leadership. Although the participants did not explicitly use the term 'servant leadership', they described the types of characteristics and behaviours they saw in others that they desired to identify with in their leadership roles. For example, some of the participants mentioned that these types of leaders were not in it for themselves. Luka said leadership was "not about themselves, not in it for themselves, not about the pay check, not about the power but just really about doing the work". Hana added, "somebody that has those characteristics, work-ethic, integrity um honestly, servant heart, you know? No one that's sort of like um thinks that they've above everybody else". Lisi's mother sacrificed the life that she was familiar with and worked with family so her children and grandchildren could have a better life in a new country. This shows that being of service to others was important to Pacific young people because they wanted to be a part of something that was bigger than them. Additionally, the skills that are learned from leadership through service can be transferable in different settings and last throughout a life time (Barnes, 2015).

In return, the leaders also found great joy in seeing their mentees progress because they helped contribute to their success. The leaders who supported and encouraged the participants through their service demonstrated a form of leadership that the participants wanted to replicate in their lives. Russell (2016) adds that this style of leadership through service can benefit everyone involved because it has a full circle effect.

\section{Negotiation of leadership ideas}

Through the participants life experiences from childhood to adulthood, as a result of living in a number of environment and in multiple relationships, young Pacific peoples had a developing picture in their head what a good leader was, how they would act, and what they would stand for. However, the participants also showed how they had to negotiate or shift their leadership beliefs so they could believe they could be leaders themselves and mentor others. The negotiation process was internal for the participants; they reconstructed ideas of leadership, choosing what beliefs would remain and which needed to be compromised. This involved negotiating between the two historical traditions of leadership in a number of environments, as well as with personal values. 


\section{Leadership development}

On the journey to leadership, the participants mentioned that there was a turning point for them that made a difference in their lives. These moments were often when they were encouraged to keep do what they were doing. At these moments they showed great leadership potential which others could recognise. For one of the participants, the realisation that they were a leader came when others were looking to them for advice and knowledge. As a result of others believing in them, they could begin to believe in themselves. Maene expressed, "I wasn't sure I could be the leader, but like my friends just kept encouraging me to go for it and that I could do it, so I did eh. And like now I am kind of willing to put myself out there first and believe in myself more." This shows that self-doubt about leadership which could perhaps stem from hierarchical models could be overcome with a strong support system and encouragement. As a result of overcoming self-doubt in becoming a leader, the participants could also help and mentor others to fulfil their leadership potential.

Mentorship and leadership growth is about connecting with the right people such as connecting a mentee with a mentor who has already travelled the road desired to go down. On the leadership journey, mentors are by your side and guide you along the path already familiar to them. Eseta shared: "yeah... It's like this pay it forward kind of thing. They'll mentor me and then they'll make me see. I mean, they don't make me see it but [like] I'll want to pay it forward to my students. Then it's like building this bigger leadership". Here, the importance of mentors is that they help you stay on the path to your goals. In this context, mentorship is a form of service to others exercised by choosing to mentor young people. Hana described the responsibility for each generation to mentor the next: "we were saying encourage the heart of this young generation from now...to think different about leadership, to be able to become um agents of change, world changers. Like um influential, um in what they do and in the lives of people that come their way so that it's like that um... what is it... domino effect". This shows that the mentoring relationship goes beyond the mentor and mentee. The hope is that one by one people will be influenced to bring about positive change and will create a domino effect that could change the future lives of many people. Through the mentoring processes ideas of leadership were modified to become personal by young Pacific peoples. This contrasts with static position-driven ideas such as those from school and church which limit alternative styles of leadership growth.

In summary, the first section of this chapter has given a multi-layered picture of the development of young Pacific People's ideas of leadership. This has involved cultural 
influences, environments, and leadership qualities. Understanding the topic in this way gives rise to a number of implications which in term lead to recommendations. These areas are the subject of the following section.

\section{Implications}

From the above analysis and discussion there are three main implications which can be drawn. The first implication is that problems can be caused for Pacific young people in their understanding of leadership by over focus on one cultural leadership belief from one space. Over focus is not helpful for young pacific peoples' leadership development where they are living in an edgewalking space and must negotiate between Western and Pacific leadership ideas. This means encouraging young Pacific peoples to move freely between traditions without feeling they are permanently choosing one way over the other.

The second implication is that change over time results in differences between the beliefs of older and younger generations of Pacific people. Leadership beliefs that older Pacific people value may not be recognised as useful by the younger generation of Pacific people. This is because the change in society over time calls for Pacific young people to adjust their leadership beliefs to reflect their experiences. This draws attention to how culture continues to evolve, and highlights the need for young Pacific peoples to be equipped as leaders with cultural roots but in the here-and-now.

The third implication is that it is helpful for young Pacific peoples if others recognise and value their strengths their and abilities to negotiate leadership ideas of Western and Pacific worlds. Creating their own definitions of leadership is an act of identity formation which is responsive to their changing context. It is therefore important to pay attention to where young Pacific peoples are drawing their identity from, and how it defines them as young Pacific peoples in their particular context.

These implications can be operationalised to the betterment of Pacific young people by considering and acting on a number of recommendations. These apply to the various environments in which Pacific young people's lives are lived and to programmes designed to support their leadership. 


\section{Recommendations for young Pacific peoples' leadership development}

\section{Environments}

As discussed above, the two environments where young Pacific peoples learned their Pacific ideas of leadership were home and church. As the participants shared, they learned many good things from home and church. However, the ideas of leadership were exclusive and only cultivated some for their leadership. These environments did not help them grow fully in their leadership abilities.

\section{Rethinking leadership for Young Pacific peoples in a New Zealand-Pacific context}

A suggestion Pacific Island families and churches might consider is the value of less positional leadership styles in the context of New Zealand. These traditions that were upheld in the Pacific homeland might be reconstructed for those who are born and raised in other countries outside of the Pacific. It is possible to maintain Pacific value and beliefs without taking the cultural essence from it. There needs to be a partnership between the different generations working on how reconstruction can take place, and what it will look like. For example, the young generations can inform the older generations on the new context and ways leadership and culture and be incorporated while the older generations can provide the knowledge of culture for the young generation who will know how to relay it to their generation. Ideally, there should be a safe space the young Pacific people to express their ideas on leadership without feeling like they are intruding or being disrespectful.

\section{Rethinking for Young Pacific peoples in a Western context}

Western ideas of leadership were learned by participants from school. These environments had set views on leadership, and the participants shared that the focus on transactional leadership, was a barriers for them in this context. For example, they were forced to consider what they could offer in exchange for the recognition as a leader. The young Pacific people began to view leadership in a transitional way in Western contexts because they were influenced to thinks this is what leadership is. As a result, young Pacific peoples may feel they lack the abilities to exchange for leadership in some circumstances. This can contribute to low self-esteem and a lack of Pacific leaders in this area. 
My recommendation for schools would be to pay attention to the leadership models favoured by Pacific young people. Models of leadership that empower and speak life into their leadership potential are important were emphasised by the participants. If the school does not know where to start, the servant leadership model that closely aligns with Pacific values can be adopted. If schools, which are places of learning about leadership ideas, shift their exclusive beliefs and attitudes about leaders, it will also help change the beliefs and values of young Pacific peoples who believe they cannot be a leader in this context. As possible result of the schools serving the students by adopting a servant leadership model, students could do better in school. A sense of belonging and stepping up can be the result of exercising leadership.

\section{Leadership development programs}

Ways that young Pacific people can be moulded into leaders include the availability of programs that addresses their values and beliefs as a Pacific young person in New Zealand. Ideally, leadership programs will create a community of strong Pacific young people who will encourage one another, and become mentors in the future for other Pacific young people. Effective programs will be those that provide a positive environment that can cultivate young Pacific peoples. A recommendation for those develop leadership programs for Pacific young people's such as the Ministry of Pacific Island affairs is that partners need to provide spaces for a discussion of Pacific and Western styles of leadership before embarking on new programs. Such discussions would consider where Pacific Young Peoples might be starting from in their leadership journeys. As a result of these discussions stronger Pacific leaders can be raised up because development can start in the context which Pacific young people recognise.

\section{Recommendations for research}

Researchers should investigate sites of powerful new models of leadership so that more can be learned about these ideas to direct ways forward. Research going forward for Pacific people to consider includes: research to look further at the processes of Pacific young people's leadership development; research to investigate leadership development in New Zealand for young people from individual Pacific nations; research to investigate how a Pan-Pacific identity may fit into the development of Pan-Pacific leadership among Pacific young people; relevant research which takes account of gender. 
Based on this research the following model maps young peoples' leadership development in a way which can guide future research and thinking. 
Figure 1.

Model

The Tupulaga Fou (Next Generation) model

6. Relationships

1. Environmental
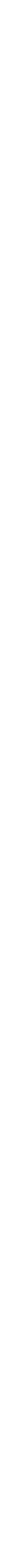
Tupulaga fou comes from the Samoan language and loosely means 'next generation'. The idea of this framework came about through this research when discussing the responsibility to mentor the next generation. This idea was reoccurring with the participant and in discussions with people in my communities, such as church and university. All emphasised the older generations' importance to lead the tupulaga fou on their journey. This term captures the essence of this research by emphasising that in leadership there is always going to be the next generation that needs to be mentored, cultivated, and made room for. It is the responsibility of the older generation to make opportunities accessible and available.

As the researcher I wanted to find young Pacific leaders who were mentored by others who believed in them as the next generation of leaders. These leaders are now mentoring the next generation as a result. This model is dedicated to those who have committed their time to raising young Pacific leaders who will bring about positive change in the lives of Pacific peoples around the world. The model is based on the stories from the participants and literature that highlights external and internal factors that make up leadership beliefs for young Pacific people. The visual representation may help with understanding and implementation of the model.

The Tupulaga fou model is intended to help future research for young Pacific peoples to evaluate and further develop leadership models to help Pacific peoples. As an emerging researcher I developed this model to inspire a change for young Pacific peoples in education through leadership. Circles were chosen to represent each aspect as a complete idea. Each circle represents one of the six aspects that young Pacific leaders value. A successful leader is one who has learned how to use 'what skills when'. For example, working within a Pacific community they understand how to address elders. Each aspect is important. A good leader understands this by knowing what circle of knowledge to pull from, depending on the context. This is a skill that young Pacific peoples have learned to do living in New Zealand by moving between church, school and home life.

Circles were also used to represent a holistic approach to leadership for young Pacific peoples. In the 'leader' circle, the young Pacific person has the ability to move freely between each circle space. This shows that there are many aspects that make a leader. These are not limited to the six in the model: historical; alterable; personal qualities; components; relationships; and environmental. 
The development of this model was tested on my leadership journey through writing this thesis. As I became more aware of my abilities to switch between contexts and pull knowledge from the appropriate circle, I become more accountable as a leader to my beliefs and values.

\section{Lou Malaga: Reflecting on my journey}

My leadership belief was formed as a result of wanting to help others. The only way this seemed possible was by obtaining a leadership position. I decided to ignore the need to have a tittle or position and began to pursue my desire to help others and try my best to live to the highest standard of my being. To my surprise, others began to recognise me as a leader, and I started to question "what does it mean to be a leader, and what does it mean to be in leadership?".

Before conducting this research my ideas about leadership were fairly similar to how they are now. I believed then and I still do now, that everyone has leadership potential. What I believe is important about everyone's leadership potential is that it does not need to look the same because different contexts calls for different skills. This was one lesson that I learned from the participants, and something I remind myself and others. I found it important because we can compare our leadership journey to others and think that we are not progressing, but remembering that everyone's journey and skills are different can help relieve some of the selfcritical stress. When working on the thesis, being in an environment surrounded by people who would support me and help me move towards my goals was something I intentionally began to look for in all aspects of my life. As a result I had to move away from environments that were not helping me grow. This made a difference in my leadership and the completion towards this thesis.

One of the most confronting ideas when conducting this research was accountability. This research made me become more accountable for my actions as a mentee and mentor. It challenged me to live up to the standards of others who believed I could reach my full potential. Moreover, for those I was mentoring it meant that they could see that I was "walking the talk", and "if I can, they can too." Similarly, how the participants explained leadership is a full circle, I have seen this happen in my leadership journey.

The two categories of implications emphasise in the research as being firstly environmental and secondly relevant to leadership development programs. The environment for the participants and those described in literature have shown that being surrounded by some supportive groups of peoples (or even one individual) to help to cultivate leadership 
development is vital. This is because a lack of leadership belief and encouragement can make an individual believe they do not have the leadership capabilities. A positive leadership environment that cultivates individuals, especially young Pacific people, can be viewed as necessary for a positive leadership outcome.

\section{Conclusion}

By seeking to answer, 'what are young Pacific peoples' understandings of leadership?' this thesis revealed that was no simple answer. Instead, there were many pieces that contribute to complete the picture. Without being fully aware, I was activating my leadership abilities by pursuing this thesis. As a young Pacific person, writing this thesis took me through many experiences. My experiences mirrored some of those of the other contributors to the research. For instance, the church and home were places where I also learned Pacific values and beliefs. Particularly, learning to negotiate between the Pacific and Western ways of knowing and doing also resonated with me. These findings highlighted that this is a challenge that many Pacific peoples encounter. To overcome this challenge the participants and I shared the same solution; edgewalking.

I also changed my view of leadership to include a much more defined understanding of servant leadership. Prior to researching what had been written about servant leadership I thought it was about meeting everyone else's needs. Instead, servant leadership is about providing a service that helps others. This service will range from person but person, because the service that one chooses to provide is personal, something that one happily does for others. For example, a university student who has a passion for playing rugby will coach a high school rugby team, or one who loves a subject may help other students with assignments. These are examples of servant leadership, which emphasises that acts do not have to be recognised by mass groups of people. It is about helping people one by one, and everyone learning and choosing to do a good deed for others.

In the end, this research is a contribution to young Pacific people around the world. I hope that this research inspires, encourages and motivates each individual who reads this, especially young Pacific people. I hope it inspires you to take a leap of faith and pursue education to your highest and best ability possible, because when you succeed we all succeed. I challenge you to give it your all and see what happens. I hope that the stories of the participants encourages you. 
They show that no matter where you start, no matter your circumstances or environments you have everything you need to lead. These challenges that you overcome become what makes you standout. I hope this learning motivates you to do your best and give your all in every area of education, church and home life. You can do it.

I thank Almighty God for all the challenges that have come my way and doors that He kept closed. Had I not encountered difficult situations and overcome them I would not be where I am, or who I am today. 


\section{REFERENCES}

Anae, M. (1997). Towards a NZ-born Samoan identity: Some reflections on "labels”. Pacific Health Dialog, 4(2), 128-137.

Anae, M. (2001). The New Vikings of the Sunrise: New Zealand-borns in the Information Age. In P. Spoonley, C. Macpherson, \& M. Anae (Eds.), Tangata o te Moana Nui: The Evolving Identities of Pacific peoples in Aotearoa, New Zealand (pp. 101-121). Palmerston North, NZ: Dunmore Press

Anae, M., (2009). Auckland University services, \& New Zealand. Ministry of Education. Pacific peoples and tertiary education: issues of participation. Finale report. Wellington: Ministry of Education.

Anae, M., Mila-Schaaf, K., Auckland University Services. \& New Zealand Ministry of Education. (2010). Teu Le Va--relationships across Research and Policy in Pasifika Education a Collective Approach to Knowledge Generation \& Policy Development for Action towards Pasifika Education Success. Retrieved from: http://ndhadeliver.natlib.govt.nz/delivery/DeliveryManagerServlet?dps_pid=IE2196155

Anae, M. (2010). Research for better Pacific schooling in New Zealand: Teu le va-a Samoan perspective. MAI review, 1. Retrieved from http://www.review.mai.ac.nz.

Anae, M. (2012). All power to the people: Over stayers, Dawn Raids and the Polynesian Panthers. In S. Mallon, K. Mahina-Tuai, \& D. Salesa (Eds.), Tangata o Le Moana: New Zealand and the People of the Pacific. Wellington, New Zealand: Te Papa Press.

Anae, M. (2016). Teu Le Va: Samoan relational ethics. 4(3), 117.

Austin, J. E. (1998), Business Leaders and Non-profits. Non-profit Management and Leadership, 9: 39-52. doi: 10.1002/nml.9103

Banks, J.A., \& Banks, C. A. M. (2006). Multicultural education: Issues and perspectives (6 ${ }^{\text {th }}$ ed.). Hoboken, N.J: Wiley.

Barnes, A. (2015). Servant Leadership for Higher Education: Journal of College and Character, 16(2), 131-133. Retrieved from: http://www.jstor.org/stable/j.ctt1f2qqz2

Barclay, J., \& Edith Cowan University. (2010). Peer Mentoring in Higher Education: Mentees' Perceptions and Experiences. Retrieved from: http://ro.ecu.edu.au/cgi/viewcontent.cgi?article=2335\&context=theses_hons

Bass, B., Avolio, B., Jung, D., Berson, Y., \& Zedeck, S. (2003). Predicting Unit Performance by Assessing Transformational and Transactional Leadership. Journal of Applied Psychology, 88(2), 207-218. Retrieved from:

http://web.a.ebscohost.com/ehost/pdfviewer/pdfviewer?vid=0\&sid=4dd2f3d6-08d0-4cfc887a-81c59312f198\%40sessionmgr4010

Batmanghlich, C., \& Springer Link. (2015). Why Leaders Fail Ethically A Paradigmatic Evaluation of Leadership. Springer eBooks. doi: 10.1007/978-3-319-12733-0 
Beck, A., Corak, M., \& Tenda.M. (2012). Migrant youths and Children of Migrants in a Globalized World: family, fertility, and the lifecycle timing of migration: Age at Immigration and the Adult Attainments of Child Migrants to the United States. Annals of the American Academy of Political and Social Science, 643, 134-239. Retrieved from: http://www.jstor.org/stable/23316163

Bean, L., \& Martinez, B. (2015). Sunday School Teacher, Culture Warrior: The Politics of Lay Leaders in Three Religious Traditions. Social Science Quarterly, 96 (1), 133-147. doi: 10.1111/ssqu. 12080

Benson, J., Ansari, D., (2015). Advances in Child Development and Behaviour. Volume 48 / Edited by Janette B. Benson; Contributors, Daniel Ansari [and Twenty-two Others]. Retrieved from https://ebookcentral.proquest.com/lib/vuw/detail.action?docID=1974042.

Biggs, J. (1976). Educology: The theory of educational practice. Contemporary Educational Psychology, 1(3), 274-284. Retrieved from http://www.sciencedirect.com/science/article/pii/0361476X76900345?via\%3Dihub

Bodley, J., \& Ebooks Corporation. (2011). Cultural Anthropology Tribes, States, and the Global System ( $5^{\text {th }}$ ed.). California: AltaMira Press.

Boyle, F., Kwon, J., Ross, C., \& Simpson, O. (2010). Student-Student Mentoring for Retention and Engagement in Distance Education. Open Learning, 25(2), 115-130. doi: 10.1080/02680511003787370

Cawthon, D. (2002). Philosophical foundations of leadership / David Cawthon; with an introduction by Blue Clark. New Brunswick, N.J.: Transaction.

Chilisa, B. (2012). Indigenous research methodologies. Thousand Oaks, Califonia.: SAGE Publications.

Chu, C. (2009). Mentoring for Leadership in Pacific Education: A Thesis Submitted to the Victoria University of Wellington in Fulfilment of the Requirements for the Degree of Doctor of Philosophy in Education. Wellington: New Zealand

Chu, C., Abella, I., \& Paurini, S. (2013). Educational Practices That Benefit Pacific Learners in Tertiary Education: Research Report. Wellington: New Zealand

Chu, C., Glasgow, A., Fuapepe R., Hodis M., \& Meyer, H, L. (2013). An analysis of recent Pasifika education research literature to inform and improve outcomes for Pasifika learners.

Wellington: Ministry of Education. Retrieved from http://www.educationcounts.govt.nz/publications/pasifika_education/an-analysis-of-recentpasifika-education-research-literature-to-inform-and-improve-outcomes-for-pasifika-learners

Chughtai, A. (2016). Servant Leadership and Follower Outcomes: Mediating Effects of Organizational Identification and Psychological Safety. The Journal of Psychology, 1-15. doi: 10.1080/00223980.2016.1170657

Coperrider, D. L. (1986). Appreciative inquiry: Toward a methodology for understanding and enhancing organisational innovation (Theory, Social, Participation). Retrieved from http://search.proquest.com/docview/303467138? accountid=14782

Corbin, J., \& Strauss, A. (2008). Basics of qualitative research: Techniques and procedures for developing grounded theory. (3rd ed.). Los Angeles: SAGE Publications. 
Cotterell, G., Randow, M., McTaggart, S., Sua'ali'i-Sauni, T., Patrick, D., \& Davis, P. (2009). Pacific families now and in the future. Changing Pacific households (Pasifika report no. 1/09.). Wellington [N.Z.]: Families Commission.

Cram, F., Brunton, F., \& Brunton, M. (2014). Maori and Pasifika Higher Education Horizons: Diversity in higher education, volume (15). Bingley, UK: Emerald Group Pub

Crane, N. (2011). Young People, Place and Identity. Journal of Cultural Geography, 28(2), 370-371. doi: 10.1080/08873631.2011.585901

Crawford, M., \& Rossiter, G. (2006). Reasons for Living Education and Young People's Search for Meaning, Identity and Spirituality: A Handbook/Marisa Crawford and Graham Rossiter.

Creswell, J.W. (2012). Research design: qualitative, quantitative, and mixed methods approaches. Thousand Oaks, CA: Sage.

Davidson-Toumu'a, R., \& Dunbar, K. (2009). Understanding the experiences of Pacific students and facilitating socio-cultural adjustment into higher education in Aotearoa, New Zealand. JANZSSA, (33), 69-88. Retrieved from http://search.informit.com.au/fullText;res=AEIPT;dn=175093http://search.informit.com.au/fu llText;res=AEIPT; $\mathrm{dn}=175093$

Dominelli, L., \& Hackett, S. (2013). Social work research: Highlighting diversity in theory, practice and education. International Social Work, 56(2), 131-133. doi: 10.1177/0020872812474398

Donner, S. (2007). Domain of the Gods: An editorial essay. Climatic Change, 85(3-4), 231-236. doi: 10.1007/s10584-007-9307-7

Earle, T. (1997). How Chiefs Come to Power. The Political Economy in Prehistory. California: Stanford University Press.

Ebener, D. (2011). On becoming a servant leader. Sojourners Magazine, 40(2), 32-34.

Eckermann, A. (1994). The interdependence of culture and education. One classroom, many cultures: teaching strategies for culturally different children. Sydney: Allen and Unwin

Eggen, P. D., \& Kauchak, D. P. (2010). Educational psychology: Windows on classrooms. Upper Saddle River, NJ: Pearson/Merrill/Prentice Hall

Evans, J. (2010). 'Our leaders are all Aristotelians now'. Public Policy Research, 17(4), 214-221. doi: 10.1111/j.1744-540X.2011.00632.x

Freebody., (2003). Qualitative Research in Education: Interaction and Practice (Introducing Qualitative Methods Series). Sage Publications

Goldman, I. (1970). Ancient Polynesian society. Chicago: University of Chicago Press.

Gotsis, G., \& Grimani, K. (2016). The role of servant leadership in fostering inclusive organizations. The Journal of Management Development, 35(8), 985-1010. doi: 10.1108/JMD07-2015-0095

Greenleaf, R., \& Spears, L. (1998). The power of servant-leadership: Essays. San Francisco, Califonia: Berrett-Koehler.

Howell, J., \& Costley, D. (2006). Understanding behaviours for effective leadership / Jon P. Howell, Dan L. Costley. (2nd ed.). Upper Saddle River, N.J.: Pearson Prentice Hall. 
Hunkin, G. (2012). “To Let Die”. AlterNative: An International Journal of Indigenous Peoples, 8(2), 203-214. doi: $10.1177 / 117718011200800208$

Ioane, Lambie, \& Percival. (2013). A review of the literature on Pacific Island youth offending in New Zealand. Aggression and Violent Behavior, 18(4), 426-433. doi: 10.1016/j.avb.2013.05.002

Jayne, V. (2003). Coaches, mentors and you. New Zealand Management, 50(1), 34-39. Retrieved from https://search.proquest.com/docview/201645832?accountid=14782

Johnson, B., \& Christensen, L. (2012). Educational research: Quantitative, qualitative, and mixed approaches. Sage, Los Angeles

Kavaliku, S., \& Massey University. Office of the Directorate Pasifika@Massey. (2007). Pasifika leadership: An issue of quality and relevance / Senipisi Langi Kavaliku. (Pasifika occasional paper series, v. 1, no. 1). North Shore City, N.Z.: Directorate Pasifika@ Massey, Massey University.

Kensington-Miller, B., \& Ratima, M. (2015). Maori in Partnership: A Peer Mentoring Model for Tertiary Indigenous Staff in New Zealand. Race, Ethnicity and Education, 18(6), 813-833. doi: 10.1080/13613324.2013.831824

Macpherson, C. (1996). Constructing moral communities: Pacific Islands identity and community. Pacific studies (pp. 124-143). Palmerston North, NZ: Dunmore Press. Retrieved from http://lir.byuh.edu/handle/123456789/1461

Manuela, S., \& Sibley, C, G. (2013). The Pacific Identity and Wellbeing Scale (PIWBS): A Culturally-Appropriate Self-Report Measure for Pacific Peoples in New Zealand. Social Indicators Research, 112(1), 83-103. doi: 10.1007/s11205-012-0041-9

Manuela, S., \& Sibley, C. (2014). Exploring the Hierarchical Structure of Pacific Identity and Wellbeing. Social Indicators Research, 118(3), 969-985. doi: 10.1007/S11205-013-0472-Y

Manuela, S., \& Sibley, C. (2014). Why Do Pacific People with Multiple Ethnic Affiliations Have Poorer Subjective Wellbeing? Negative Ingroup Affect Mediates the Identity Tension Effect. Social Indicators Research, 115(1), 319-336. doi: 10.1007/s11205-012-0220-8

Manueli, K. (2012). Pasifika Tertiary Students' Use of Information and Communication Technologies : A Thesis Submitted to the Victoria University of Wellington in Fulfilment of the Requirements for the Degree of Doctor of Philosophy in Education

Marshall, C., \& Rossman, G. B. (2006). Designing Qualitative Research (Fourth Edition). Los Angeles: Sage Publications

Maxwell, J. (2008) Mentoring 101. Nashville, Tennessee: Thomas Nelson Publishing.

Mila-Schaaf, K. (2011). Polycultural Capital and the Pasifika Second Generation Negotiating Identities. Retrieved from http://ndhadeliver.natlib.govt.nz/delivery/DeliveryManagerServlet?dps_pid=IE13263457

Ministry of Education. (2005). Pasifika Achievement Engagement and Choice. Wellington: New Zealand. Retrieved from https://www.educationcounts.govt.nz/publications/p

Ministry of Education. (2008). Pasifika Peoples in Tertiary Education in New Zealand. 
Molix, L., \& Bettencourt, B, A., (2010). Predicting Well-Being Among Ethnic Minorities: Psychological Empowerment and Group Identity. (Report). Journal of Applied Social Psychology,40(3), 513.

Morton, K, L., Wilson, A, H., Perlmutter, L, S., \& Beauchamp, M, R. (2012). Family leadership styles and adolescent dietary and physical activity behaviours: A cross-sectional study (Research). The International Journal of Behavioural Nutrition and Physical Activity, 9, 48.

Morse, J., \& Richards, L. (2002). Readme first for a user's guide to qualitative methods / Janice M. Morse, Lyn Richards. Thousand Oaks, Calif.: Sage.

Muaiava, A., \& Victoria University of Wellington. School of Education. (2015). Imprisonment: Young Pacific Women's' Experiences of Living with Depression: A Thesis Submitted to the Victoria University of Wellington in Fulfilment of the Requirements for the Degree of Master of Education / by Aotearoa Muaiava.

Mullen, C., Robertson, K., \& Ebrary, Inc. (2014). Shifting to Fit : The Politics of Black and White Identity in School Leadership / by Carol A. Mullen, Virginia Tech, and Kim Robertson, Vandalia Elementary School.

Nakhid, C., Collins, E., Tanielu, T., \& New Zealand. Families Commission. (2009). Pacific Families Now and in the Future. Pasifika Youth in South Auckland Family, Gangs, Community, Culture, Leadership and the.

Nakhid, C., (2011). Equity for Maori and Pasifika students: The objectives and characteristic of equity committees in a New Zealand university. Equity \& Excellence in Education. 44(4), 532-550. Retrieved from http://search.proquest.com/docview/964179151?accountid=14782

Neuman, W. (2011). Social research methods: Qualitative and quantitative approaches / W. Lawrence Neuman. (7th ed.). Boston: Allyn \& Bacon

New Zealand. Education Review Office. (2006). The achievement of Pacific students. Wellington, N.Z.: Education Review Office.

New Zealand Qualifications Authority. (2014). Annual Report on NCEA and New Zealand Scholarship Data and Statistics : for the year ended 30 May. Wellington : New Zealand. Retrieved from : http://www.nzqa.govt.nz/assets/About-us/Publications/stats-reports/nceaannualreport-2014.pdf

Norwawi, S., \& Sanga, K., (2011). Leadership Styles: A Comparative Analysis of PTD Officers and DG Officers in the Ministry of Education Malaysia.

Okagaki, L. (2001). Triarchic model of minority children's school achievement. Educational Psychologist, 36(1), 9-20.

Onwuegbuzie, A. J., Leech, N. L., Slate, J. R., Stark, M., Sharma, B., Frels, R., Combs, J. P. (2012). An exemplar for teaching and learning qualitative research. The Qualitative Report, 17(1),

Oxford online dictionary. (2010). DOI: 10.1093/acref/9780199571123.001.0001

Paea, Mele Katea, Proctor-Thomson, Sarah, \& Jones, Deborah. (2009). The Leadership Processes of Pacific Public Servants in Aotearoa, New Zealand.

Panaccio, A., Henderson, D., Liden, J., Wayne, R., \& Cao, C. (2015). Toward an Understanding of When and Why Servant Leadership Accounts for Employee Extra-Role Behaviors. Journal of Business and Psychology, 30(4), 657-675. 
Patton, M. Q. (1990). Qualitative evaluation methods. Newbury Park, CA:Sage.

Pene, G., \& New Zealand. Families Commission. (2009). Pacific Families Now and in the Future. Living the Tokelauan Way in New Zealand Teenagers' Perspectives on Extended-famliy.

Perrot, A,. (2015). Overcoming Challenge : Pacific Students' Experiences of Being Resilient through Tertiary Education: A Thesis Submitted to the Victoria University of Wellington in Partial Fulfilment of the Requirements for the Degree of Master of Education / by Arden Raymond Dujon Perrot.

Phuntsog, Nawang B. (2012). The Role of Ethnic Identity in School Engagement: Perceptions of Immigrant Tibetan Adolescents in Select US Public Schools. Intercultural Education, 23(3), 237-247.

Prastacos, G., Soderquist, K., Wang, F., \& Springer Link. (2012). Leadership through the Classics Learning Management and Leadership from Ancient East and West Philosophy / Edited by Gregory P. Prastacos, Fuming Wang, Klas Eric Soderquist.,Springer eBooks.

Raivoka, M. (2009). Creating Opportunities: The Village at the University: Living and Leaving a Legacy of Hope: Stories by New Generation Pacific Leaders. Institute for research and Development in Maori and Pacific education Victoria University of Wellington: Wellington.

Reed, J. (2007). Appreciative inquiry: Research for change / Jan Reed. Thousand Oaks: Sage Publications.

Reynolds, M. (2016). Relating to Va: Re-viewing the concept of relationships in Pasifika education in Aotearoa New Zealand. AlterNative: An International Journal of Indigenous Peoples, 12(2), 190-202.

Riley, K. (2013). Pacific islanders: A misclassified people. The Chronicle of Higher Education, Retrieved from: http://search.proquest.com/docview/1370714419?accountid=14782

Rimoni, F. (2009). Leadership as 'Tautua': Service to the church: Living and Leaving a Legacy of Hope: Stories by New Generation Pacific Leaders. Institute for research and Development in Maori and Pacific education Victoria University of Wellington: Wellington.

Rimoni, F. (2009). Identify and its relationship to place: Exploring what it is and how it is achieved. Harvesting Ideas: Niu Generation Perspectives. USP Press: Suva, Fiji Islands

Rimoni, F., Sanga, K., \& Hynds, A., (2016). Tama Samoa Stories: Experiences and Perceptions of Identity, Belonging and Future Aspirations at Secondary School.

Robertson, A., Robertson, P., Robertson, L, T, T., \& Robertson, J. (2009). "'In Order to Teach You, I Must Know You." The Pasifika Initiative: A Professional Development Project for Teachers. (Report)." New Zealand Journal of Educational Studies 44.2: 47-62.

Rosenthal, M. (2016). Qualitative research methods: Why, when, and how to conduct interviews and focus groups in pharmacy research. Currents in Pharmacy Teaching and Learning, 8(4), 509516.

Richards, L. (2002). Readme first for a user's guide to qualitative methods. Thousand Oaks, Califonia.: Sage.

Russell, E., (2016). In Command of Guardians, Springer eBooks. 
Sadala, M. L. A., \& Adorno, R. D. C. F. (2002). Phenomenology as a method to investigate the experience lived: a perspective from Husserl and Merlau Ponty's thought. Journal of Advanced Nursing, 37(3), 282-293

Sahlins, M. (2000b). Poor Man, Rich Man, Big-Man, Chief: Political Types in Melanesia and Polynesia (1963). In M. Sahlins (Ed.), Culture in Practice: Selected Essays (pp. 71- 94). New York: Zone Books.

Sanga, K., \& Walker, K. (2005). Apem moa : Solomon Islands leadership. Wellington, N.Z.: He Pārekereke, Victoria University.

Sanga, E. (2009). Pacific student success at university: Exploring what it is and how it is achieved. Harvesting Ideas: Niu Generation Perspectives. USP Press: Suva, Fiji Islands

Seidler, K., (2010). "Crime, Culture \& Violence : Understanding How Masculinity and Identity Shapes Offending.

Selladurai, R., \& Carraher, S (2014). Servant Leadership: Research and Practice / [edited By] Raj Selladurai, Shawn Carraher.

Shea, G. (2002). Mentoring How to Develop Successful Mentor Behaviours.

Shilliam, R. (2013). The Polynesian Panthers and The Black Power Gang: Surviving Racism and Colonialism in Aotearoa New Zealand. In N. Slate, \& J. Trotter, Black Power Beyond Borders (pp. 2-16). Wellington: Victora University of Wellington.

Shore, B. (1989). Mana and Tapu. In A. Howard \& R. Borofsky (Eds.), Developments in Polynesian Ethnology (pp. 137-174). Honolulu: University of Hawaii Press.

Sikes, P. (2006). Towards Useful and Dangerous Theories. Discourse: Studies in the Cultural Politics of Education, 27(1), 43-51

Simonr, V., Cheryl, J. (2012), Cultural Transitions in Higher Education: Individual Adaptation, Transformation and Engagement, in Stuart A. Karabenick, Timothy C.

Urdan (ed.) Transitions Across Schools and Cultures (Advances in Motivation and Achievement, Volume 17) Emerald Group Publishing Limited, pp.241 - 284. Doi: 10.1108/S0749-7423(2012)0000017012

Smith, L., T. (1999). Decolonising methodologies: research and indigenous people. London: Zed Books. Retrieved from: https://books.google.co.nz/books?hl=en\&lr=\&id=Nad7afStdr8C\&oi=fnd\&pg=PR9\&dq=Dec olonising+methodologies:+research+and+indigenous+people\&ots=lDkEi6nC7i\&sig=XF5Fj_ ThOi42QRNfDQuqqbPlvO0\#v=onepage $\& \mathrm{q}=$ methood $\& \mathrm{f}=$ false $=$ ?

Sopoga, F., Zaharic, T., Kokaua, J., Ekeroma, A, J., Murray, G., \& Van der Meer, J. (2013). Pacific students understanding the first year of health sciences at the University of Otago, and factors associated with academic performance. The New Zealand Medical Journal, 126(1384), 96108. Retrieved from http://search.proquest.com/docview/1443962596?pq-origsite=summon

Sousa, M., \& Dierendonck, D. (2017). Servant Leadership and the Effect of the Interaction Between Humility, Action, and Hierarchical Power on Follower Engagement. Journal of Business Ethics, 141(1), 13-25.

Sparrow, J. (2012). The Culture Builders Leadership Strategies for Employee Performance. Retrieved from https://ebookcentral.proquest.com/lib/vuw/detail.action?docID=1002987. 
Spoonley, P., (2009). Tangata Tangata: The Changing Ethnic Contours of New Zealand From Pacific Islanders to Pacific People and Beyond. Retrieved from: https://books.google.co.nz/books?hl=en\&lr=\&id=QSnoI0RWBD8C\&oi=fnd\&pg=PA135\&d $\mathrm{q}=$ who+are+pacific + people\&ots=B51Sc71BIo\&sig=9iJGSnCPdveOiCSDHupmfPYse5Y\#v= onepage \&q\&f=false

Spoonley, P. (2014). New diversity, old anxieties in New Zealand: The complex identity politics and engagement of a settler society. Ethnic and Racial Studies, 1-12.

Statistics New Zealand. (2013). Pacific peoples ethnic group. 2013 census quick stats about culture and identity. Retrieved from http://www.stats.govt.nz/Census/2013-census/profile-andsummary-reports/quickstats-culture-identity/pacific-peoples.aspx

Stewart-Withers, R. (2016). Edgewalking ethics. New Zealand Sociology, 31(4), 28-42. Retrieved from https://search.proquest.com/docview/1852699623? accountid=14782

Stowell, F. (2013). The Appreciative Inquiry Method—A Suitable Candidate for Action Research Systems Research and Behavioral Science, 30(1), 15-30.

Suaalii-Sauni, T., Samu, K., Dunbar, L., Pulford, J., \& Wheeler, A. (2012). A qualitative investigation into key cultural factors that support abstinence or responsible drinking amongst some Pacific youth living in New Zealand. Harm Reduction Journal, 9, 36.

Suppes, P. (1974). The Place of Theory in Educational Research. Educational Researcher, 3(6), 310.

Syed, M., Azmitia, M., \& Cooper, C. (2011). Identity and Academic Success among Underrepresented Ethnic Minorities: An Interdisciplinary Review and Integration. Journal of Social Issues, 67(3), 442-468.

Tahau-Hodges, P., Ako Aotearoa National Centre for Tertiary Teaching Excellence, \& New Zealand. Te Puni Kōkiri. (2010). Kaiako Pono Mentoring for Māori Learners in the Tertiary Sector / Pania Tahau-Hodges, Te Puni Kōkiri.

Tanielu, R., \& Johnson, A. (2013). More Than Churches, Rugby and Festivals. A Report on the State of Pasifika Peoples in New Zealand. The Salvation Army Social Policy and Parliamentary Unit.

Teaiwa, T., \& Mallon, S. (2005). Ambivalent kinships? Pacific people in New Zealand. New Zealand identities: Departures and destinations, 207-229. Retrieved from:

http://s3.amazonaws.com/academia.edu.documents/31301398/nzidteaiwamallon.pdf?AWSAc cessKeyId=AKIAJ56TQJRTWSMTNPEA\&Expires=1465304568\&Signature=I8\%2FMUUH 6hVqu0BReyd4yQSo3Y4M\%3D\&response-contentdisposition=inline\%3B\%20filename\%3DAmbivalent_Kinships_Pacific_People_in_Ne.pdf

Thomas, D, A. (2001). The Truth about Mentoring Minorities: Race Matters. Harvard Business Review, 79(4), 98-107.

Thompson, M., \& University of San Diego. (2004).Roles and Responsibilities of Chiefs in the Village Council of Chiefs within a Village in American Samoa., Dissertation Abstracts International 65-05A.

Thompson, \& Walker. (1998). Basics of research (Part 12): Qualitative research. Air Medical Journal, 17(2), 65-70.

Tiatia, J. (1998). Caught Between Cultures. Auckland: Christian Research Association 
Tongati'o, L. (1994). Challenging success: Developing Pacific Islands education in Aotearoa, New Zealand. Wellington, New Zealand: Pule Maata Pasefika, Ministry of Education.

Tuagalu, I., (2008). Heuristics of the va. AlterNative, 4(1), 107-126.

Tukuitonga, C. (2013). Pacific people in New Zealand. In I. St. George (Ed.), Cole's medical practice in New Zealand (Chapter 6, 12th ed., pp. 65-71). Wellington, New Zealand: Medical Council of New Zealand.

Tupuola, A. (2004). Pasifika edgewalkers: Complicating the achieved identity status in youth research. Journal of Intercultural Studies, 25(1), 87-100.

Turner, C. (2015). Mentoring as Transformative Practice: Supporting Student and Faculty Diversity / Caroline S. Turner, Editor.

Vaioleti, T. (2014). Talanoa: Differentiating the Talanoa Research Methodology from phenomenology, narrative, Kaupapa Maori and feminist methodologies. Te Reo, 56/57, 191212.

Van, d. B. (2014). An integrative approach to the understanding of transformational leaders: Connecting cognitive, social, and behavioural complexity. Available from ProQuest Dissertations \& Theses Global. (1561546830). Retrieved from https://search.proquest.com/docview/1561546830?accountid=14782

Viator, R., Dalton, D., \& Harp, N. (2012). How to Be a Successful Mentor. The CPA Journal, 82(5), 68-71.

Wells, N. (2011). The Leadership Umbrella: tok piksa of Leadership Pacific: As Seen Through Students Eyes. Institute for research and Development in Maori and Pacific education Victoria University of Wellington: New Zealand.

Wendt, A. (1999). Afterword: Tatauing the post-colonial body. Inside out: Literature, cultureal politics, and identity in the new Pacific (pp. 399-412). Lanham, MD: Rowman \& Littlerfield.

Wright, J. (2007). Reframing quality and impact: The place of theory in education research. The Australian Educational Researcher, 35(1), 1-16. doi: 10.1007/BF03216872 


\section{Appendix A: Information sheet}

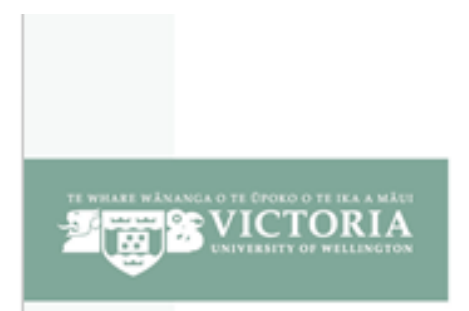

TE KURA MĀORI

MÄORI EDUCATION

VICTORIA UNIVERSITY OF WELLINGTON, PO BOX 17-310, Donald St, Karori, Welington 6147, New Zealand

Phone + 64-4-463 5633 Fax +64-4-4639548 Email tkmgvuw. ac.nz Web waw. victoria.ac.nzleducation

\section{INFORMATION SHEET}

\section{What are Young Pacific peoples' understandings of leadership?}

Researcher: Grace Faletutulu, Te Kura Maori, Victoria University of Wellington

Talofa lava,

I am a Masters of Arts student in School of Education at the Faculty of Education, Victoria University of Wellington. The purpose of this study is to understand how young Pacific Peoples understand leadership. I am interested in finding out about how young Pacific Peoples understand leadership and their leadership experiences.

I am also interested in identifying leadership development strategies that may be useful to Pacific peoples and educators who are also interested in this topic.

If you are willing to participate I will arrange a time to come and interview you. I will conduct the interviews. The interview will be one-on-one and take between $60-90$ minutes hours and these will be audio recorded. Following the interview you will be given an opportunity to check and amend transcripts before the results are analysed. Should you choose to withdraw from the project you can do so without question at any time within four weeks of the interview taking place. You can let me know.

Your responses will form the basis of my research but I will ensure that neither you nor any person you mention in the course of the interview will be personally identifiable. I shall also ensure that it is not possible to identify your comments. Withdrawal from the study is available until October $13^{\text {th }} 2016$. All material collected will be kept confidential and no one other than myself who will transcribe the interviews will have access to the taped interviews or the interview transcripts. Research materials will be destroyed at the conclusion of the research. It is intended that the research might be disseminated in academic journals and at conferences.

If you have any concerns or questions about any aspects of this study you can contact me directly through email faletugrac@myvuw.ac.nz. Additionally you can contact my primary supervisor Dr Cherie Chu cherie.chu@myvuw.ac.nz or phone (04) 4635316.

Thank you,

Grace Faletutulu 


\section{Appendix B: Talanoa and question(s) prompt sheet}

\section{Talanoa Prompt Sheet}

- Can you talk about your general understanding of leadership?

- Who are good Pacific leaders in your eyes? Why?

- What are some challenges for Pacific leadership?

- If you were to describe a Pacific leader, what words would you use? Why?

- What strengths do Pacific leaders have?

- How do you think Pacific leaders become leaders? Any stories?

- In what ways do you think Pacific leadership is important?

- Do you think Pacific people are enabled to become leaders? Why/Why

- What are some of the difference between the older generation of Pacific leaders and younger generation?

- Do you think that there are differences and/or challenges between leadership in the Pacific Islands and New Zealand? If so, why? Why not?

- What are the main obstacles that prevent young people from being involved in leadership?

- Can you tell me about your own personal leadership - that is if you consider yourself a leader? 
Appendix C: Participant consent form

\section{CONSENT TO PARTICIPATE IN RESEARCH}

\section{What are Young Pacific peoples' understandings of leadership?}

I have been given and have understood an explanation of this research project. I have had an opportunity to ask questions and have them answered to my satisfaction. I understand that I may withdraw myself (or any information I have provided) from this project within 4 weeks of completing the interview without having to give reasons.

I understand that any information I provide will be kept confidential to the researchers and the person who transcribes the tape recordings of our interview. I understand the published results will not use my name, and that no opinions will be attributed to me in any way that will identify me. I understand that I will be able to check the transcript of my interview before publication of the results.

I agree to take part in this research.

Signed:

Name of participant:

Date: 
Appendix D: Ethics approval

TE WHARE WRNANGA O TE OPOKO O TE IKA A MR̃UI

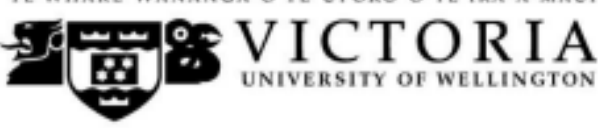

MEMORANDUM

Phone 0-4-4635480

Email susan.corbett六uw.ac.nz

\begin{tabular}{l|l}
\hline TO & Grace Faletutulu \\
\hline COPY TO & Dr Cherie Chu \\
\hline FROM & AProf Susan Corbett, Convener, Human Ethics Committee \\
\hline & \\
\hline DATE & 19 August 2016 \\
\hline PAGES & 1 \\
\hline
\end{tabular}

SUBJECT Ethics Approval: 23190

Young Pacific people and their understandings of leadership

Thank you for your application for ethical approval, which has now been considered by the Standing Committee of the Human Ethics Committee.

Your application has been approved from the above date and this approval continues until 10 March 2017. If your data collection is not completed by this date you should apply to the Human Ethics Committee for an extension to this approval.

Best wishes with the research.

Kind regards

\section{Susan Corbett}

Convener, Victoria University Human Ethics Committee 
